WALDEN

UNIVERSITY

Walden University

$A$ higher degree. A higher purpose.

ScholarWorks

Walden Dissertations and Doctoral Studies

Walden Dissertations and Doctoral Studies

Collection

2019

\title{
Leadership And Employee Engagement
}

Kevin O'Brien Grant

Walden University

Follow this and additional works at: https://scholarworks.waldenu.edu/dissertations

This Dissertation is brought to you for free and open access by the Walden Dissertations and Doctoral Studies Collection at ScholarWorks. It has been accepted for inclusion in Walden Dissertations and Doctoral Studies by an authorized administrator of ScholarWorks. For more information, please contact ScholarWorks@waldenu.edu. 


\title{
$\underline{\text { Walden University }}$
}

College of Management and Technology

This is to certify that the doctoral study by

\section{Kevin O’Brien Grant}

has been found to be complete and satisfactory in all respects, and that any and all revisions required by the review committee have been made.

\author{
Review Committee \\ Dr. Janet Booker, Committee Chairperson, Doctor of Business Administration Faculty \\ Dr. Cheryl Lentz, Committee Member, Doctor of Business Administration Faculty \\ Dr. Carol-Anne Faint, University Reviewer, Doctor of Business Administration Faculty
}

Chief Academic Officer and Provost

Sue Subocz, Ph.D.

Walden University

2019 


\author{
Abstract \\ Leadership Strategies and Employee Engagement \\ by \\ Kevin O’Brien Grant
}

MBA, University of Wales, 2010

BS, University of Phoenix, 2008

\author{
Doctoral Study Submitted in Partial Fulfillment \\ of the Requirements for the Degree of \\ Doctor of Business Administration
}

Walden University

December 2019 


\begin{abstract}
Business leaders often encounter difficulties in achieving sustainable employee engagement in the work environment, yet employee engagement is critical to an organization's financial success. The purpose of this qualitative single case study was to explore strategies business leaders use to overcome or mitigate the challenges of employee disengagement. A purposeful sample of 6 leaders employed at an insurance company participated in the study based on their knowledge and experience in implementing successful employee engagement strategies. The conceptual framework for the study was Kahn's personal engagement theory. Data were collected using semistructured interviews, company documents, and archival information. Data were analyzed using thematic analysis. Four themes emerged: leader-employee relationship; effective internal communication and feedback; compensation, awards, benefits, and incentives; and professional training and development to improve employee engagement. The implications for positive social change include the potential to provide leaders with strategies to increase employee engagement, which may create employment opportunities for community members, which could lead to the stability and general well-being of the community.
\end{abstract}


Leadership Strategies and Employee Engagement

by

Kevin O’Brien Grant

MBA, University of Wales, 2010

BS, University of Phoenix, 2008

Doctoral Study Submitted in Partial Fulfillment

of the Requirements for the Degree of

Doctor of Business Administration

Walden University

December 2019 


\section{Dedication}

To the leaders around the world: I dedicate this study to the leaders around the world. I hope that this study can assist in understanding and implementing better leadership practices. Employees are the most important asset of an organization, and the relationship between leaders and employees can be the deciding factor on the success or failure of an organization. 


\section{Acknowledgments}

The findings of this research study identify successful employee engagement strategies, which leaders can utilize to engage employees effectively. I want to first acknowledge my family for the support they gave to me during my DBA journey. To my mother and father, I thank you sincerely for your direction, wise counsel, and continuous commitment to ensuring that I succeed in all my pursuits.

Thanks to my wife and children for staying by my side as I journeyed through this doctoral program. It has been a long, fulfilling journey. I wish to thank Dr. Janet Booker for her faith, support, patience, and encouragement. Dr. Janet, this one is truly for you. I could not have done it without you. Dr. Lentz, many thanks for assisting me, having faith in me, guiding me, and ensuring that I got to this point of my doctoral study. I also want to thank Walden University for accepting me into this doctoral program. I thank all who contributed to the completion of this study and who had faith in me to succeed. 


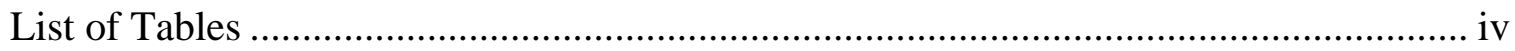

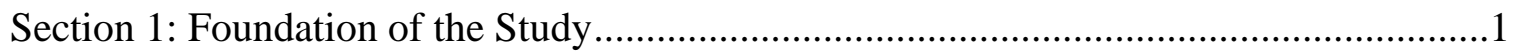

Background of the Problem ..................................................................................

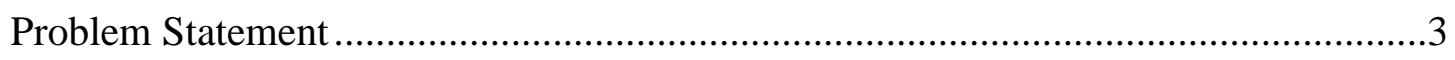

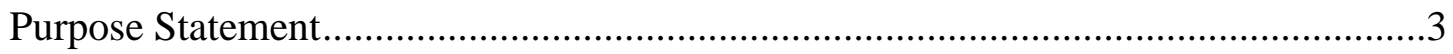

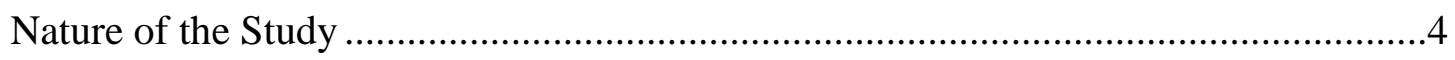

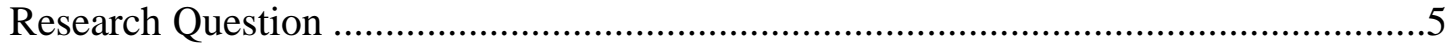

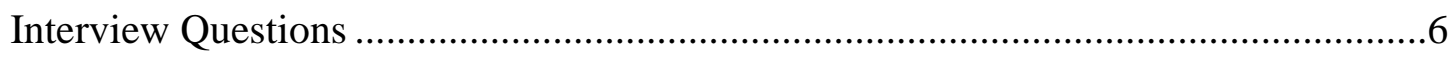

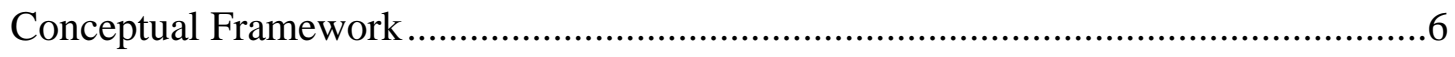

Operational Definitions ...............................................................................

Assumptions, Limitations, and Delimitations..............................................................

Significance of the Study ....................................................................................10

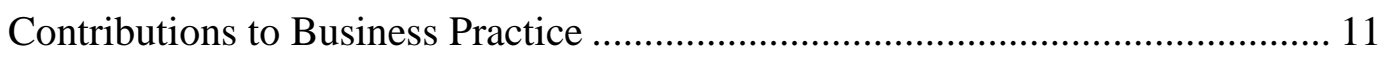

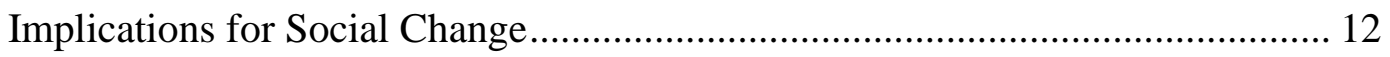

A Review of the Professional and Academic Literature.............................................12

Application to the Applied Business Problem ....................................................... 14

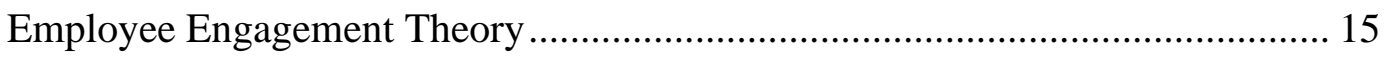

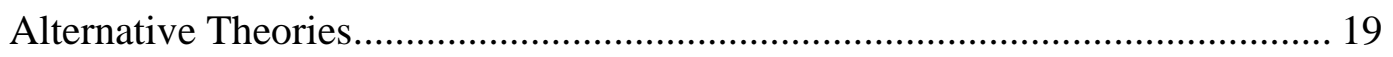

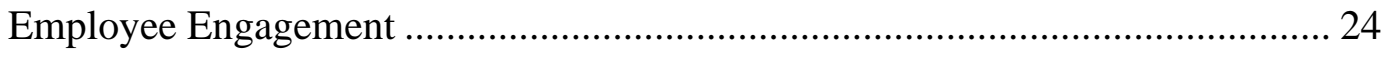

Antecedents to Employee Engagement ……………………………………... 26

Benefits and Outcomes of Employee Engagement .............................................. 27 
Measuring Employee Engagement .................................................................. 34

Categories of Employee Engagement ................................................................. 36

Leadership and Employee Engagement......................................................... 48

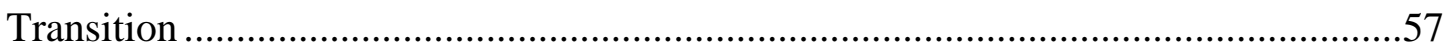

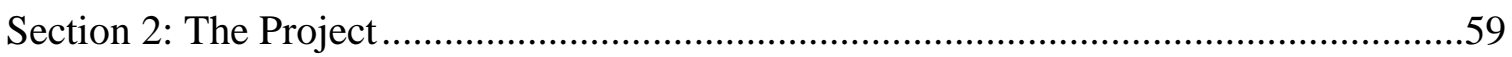

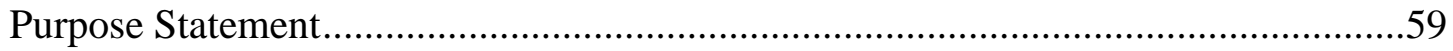

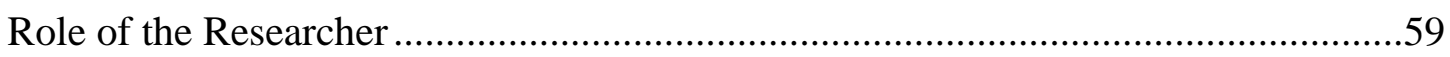

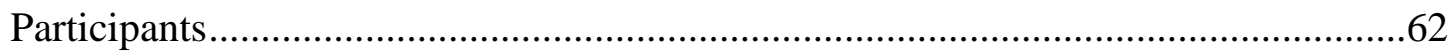

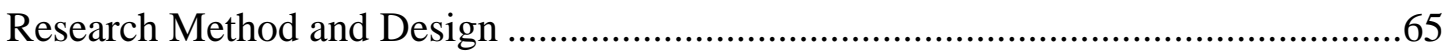

Population and Sampling .....................................................................................69

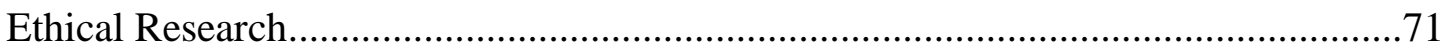

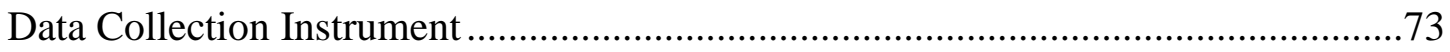

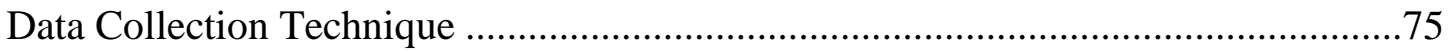

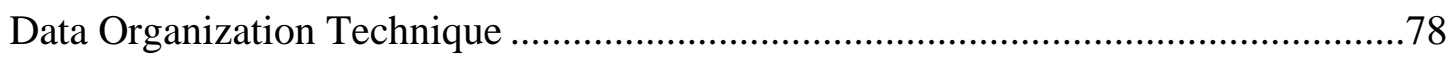

Data Analysis ...................................................................................................79

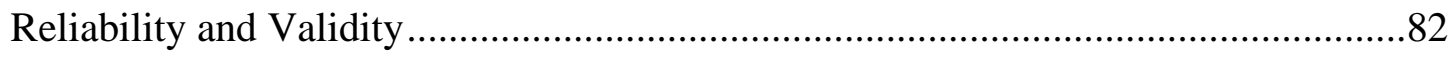

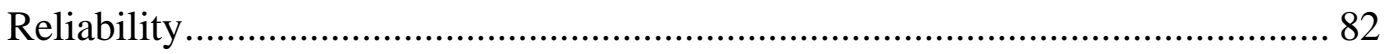

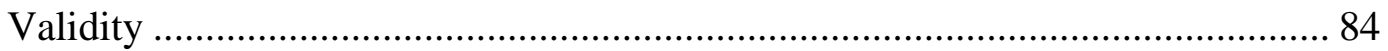

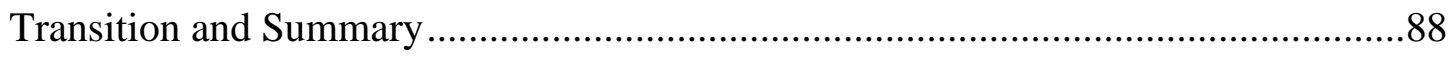

Section 3: Application to Professional Practice and Implications for Change ...................89

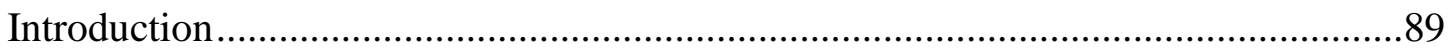

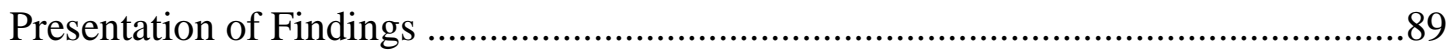


Theme 1: Leader-Employee Relationship ......................................................... 91

Theme 2: Effective Internal Communication and Feedback ................................ 96

Theme 3: Compensation, Awards, Benefits, and Incentives ................................ 99

Theme 4: Professional Training and Development ........................................... 103

Applications to Professional Practice …………………….......................................105

Implications for Social Change............................................................................107

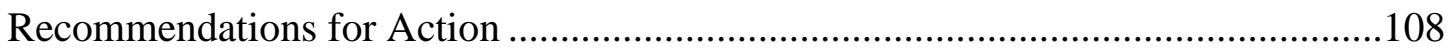

Recommendations for Further Research...............................................................109

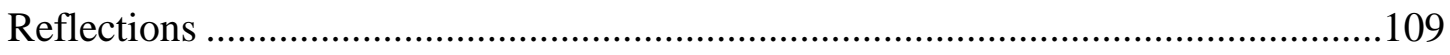

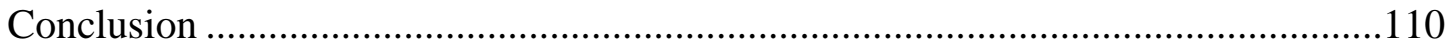

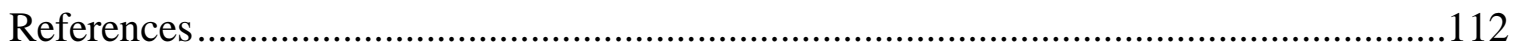

Appendix A: Interview Questions .......................................................................158

Appendix B: Interview Protocol ..........................................................................159 


\section{List of Tables}

Table 1. Literature Review Source Content............................................................... 13 
Section 1: Foundation of the Study

Organizational leaders increased the responsiveness and competitiveness of their organizations to succeed in the global economic conditions of the 21st century (Garg, 2014). Researchers suggested that the global decline in productivity caused by disengaged employees affects all types of organizations, thereby causing organizational leaders worldwide to pay close attention to productivity and engagement levels (Anitha, 2014; Shuck \& Reio, 2014). Ensuring employees commit fully to their work and that they engage and perform well in the workplace during challenging times can be difficult (Keating \& Heslin, 2015). Effective leadership motivates employees and promotes positive employee performance and growth in organizations (Nasomboon, 2014). Employees whose emotional well-being allows them to feel committed and dedicated to their workplace are engaged employees (Nasomboon, 2014). The most productive and functional organizations include those with employees who engage physically, cognitively, and emotionally in their work (Storm, Sears, \& Kelly, 2014).

The focus of this case study research was to explore the successful strategies that business leaders use at an insurance company in Florida, (ABC Corporation, a pseudonym), to overcome or mitigate the challenges of disengaged employees and to encourage employee engagement. I conducted a qualitative exploratory single case study. Researchers perform this type of research when seeking to view certain strategies in a real-life setting (Bettis, Gambardella, Helfat, \& Mitchell, 2014). This study may contribute to an appreciation of the successful strategies leaders should use to ensure employee engagement. 


\section{Background of the Problem}

Employee engagement refers to the personal relationship of an employee with the work environment and the employee's positive attitude toward employers, while having a high level of perceived empowerment in the workplace (Nieberding, 2014). The results of a 2014 Gallup study indicated that approximately $70 \%$ of the workforce, comprising 147,615 million employed persons in December 2014 (U.S. Bureau of Labor Statistics) in the United States experienced low occupational engagement, which led to a $\$ 300$ billion loss in productivity nationwide (Adkins, 2015). In 2015, of the 150,614 million employed persons in the United States (U.S. Bureau of Labor Statistics, 2016), 50.8\% (76,512 persons) did not feel engaged, 32.0\% (48,196 persons) felt engaged, and 17.2\% (25,906 persons) felt actively disengaged (Adkins, 2016). These averages were similar to those in 2014 (Adkins, 2016; Guaspari, 2015).

Many factors contribute to this lack of engagement, but leadership is a key driver that fosters employees' motivation toward engagement and productivity (Anand, 2017). Engagement refers to employees' positive work-related state of mind (Huertas-Valdivia, Llorens-Montes, \& Ruiz-Moreno, 2018). Disengagement causes high absenteeism, high employee turnover, and employee conflicts, which negatively affect organizational effectiveness (Popli \& Rizvi, 2015). In this study, I sought to explore the successful strategies business leaders have used to overcome or mitigate the challenges of disengaged employees and to encourage employee engagement. Understanding this issue could have a positive effect on a business, an industry, and an economy. 


\section{Problem Statement}

Disengaged employees can cause productivity to decline and negatively affect the financial performance of many U.S. corporations (U.S. Merit Systems Protection Board, 2015). In 2014, the findings of an employee engagement survey conducted by Gallup indicated that more than $50 \%$ of the 147.6 million employed U.S. workers felt disengaged from their work, which resulted in an annual loss in excess of $\$ 300$ billion from low productivity (Radda, Majidadi, \& Akanno, 2015). The general business problem is that disengaged employees contribute to low productivity and low organizational performance. The specific business problem is that some business leaders lack successful strategies to overcome or mitigate the challenges of disengaged employees and to encourage employee engagement.

\section{Purpose Statement}

The purpose of this qualitative single case study was to explore successful strategies that business leaders use to overcome or mitigate the challenges of disengaged employees and to encourage employee engagement. The population consisted of six leaders who worked in executive leadership at ABC Corporation in Florida, for a minimum of 5 years. These leaders successfully implemented strategies to engage employees. The findings might contribute to social change by providing business leaders with possible solutions for improving organizational performance and retention, providing job opportunities within the local community, and contributing to the stability of the local economy. 


\section{Nature of the Study}

The qualitative method was the most suitable research method for this study, as the study involved exploring the successful strategies that business leaders use to engage employees. Researchers use the qualitative research method to study participants in their work environment to understand what elements or strategies contribute to their situation (McCusker \& Gunaydin, 2015). Through qualitative research, researchers can understand and interpret individuals' thoughts, experiences, and feelings (Opsal et al., 2016). Through the qualitative method, researchers can explore a phenomenon in depth (Barnham, 2015).

The quantitative research method was inappropriate for this study. Hoare and Hoe (2013) noted that quantitative studies involve testing a theory or hypothesis and collecting quantitative data for statistical inferential testing. I did not test hypotheses, nor did I perform inferential testing to determine the strategies used to engage employees. The quantitative method was therefore not needed for this study. Mixed-methods research involves using both qualitative and quantitative methods (Annansingh \& Howell, 2016). To explore strategies for employee engagement, quantitative data was not necessary, and therefore, mixed methods research was not part of this study.

In this research study, I used a case study design. In case studies, researchers can use multiple data sources and identify themes to achieve a holistic understanding (Haddock-Millar, Sanyal, \& Muller-Camen, 2015; Yin, 2014). Tetnowski (2015) suggested that researchers use case studies because they allow researchers to discover 
how leaders influence employee engagement, rather than only determining whether an increase of employee engagement takes place.

Other research designs that I considered and found inappropriate included narrative, phenomenology, and ethnography. The narrative design requires understanding the lives of individuals by interpreting stories of their experiences (Petty, Thomson, \& Stew, 2012); however, interpreting stories of the lives of individuals may provide the reader with a sense of being part of the experience, but themes may not emerge from the stories. This design was inappropriate because interpreting stories was not the purpose of this study.

A phenomenological design involves exploring the lived experiences of several participants in multiple organizations using a single data source, usually only interviews, for each participant (Marshall \& Rossman, 2016). More than one data source, as is customary in case study design, provides for a more rigorous study (Marshall \& Rossman, 2016). The phenomenological design was, therefore, less suitable for this study than the case study design. Researchers use the ethnography design to explore the behavioral patterns and beliefs of a culture (Tetnowski, 2015). The primary emphasis of this study was not on organizational culture; therefore, an ethnographic design was not the best choice.

\section{Research Question}

The overarching research question for the study is: What strategies do business leaders use to overcome or mitigate the challenges of disengaged employees and to encourage employee engagement? 


\section{Interview Questions}

The interview questions used in this study included the following:

1. What does employee engagement mean to you?

2. What role do you play in engaging your employees?

3. What strategies do you use to engage the employees within your corporation?

4. What strategies work best to engage your employees? How did you determine that these strategies worked best?

5. How did your employees respond to these strategies?

6. What benefits did your organization derive from successful employee engagement strategies?

7. How do you gauge the success of employee engagement strategies in your organization?

8. What information can you share that was not already covered?

\section{Conceptual Framework}

The theory of employee engagement formed the basis of the conceptual framework for this study. I used the employee engagement theory developed by Kahn (1990) to understand the strategies that business leaders use to engage employees. Employee engagement can influence productivity levels in the workplace (Anitha, 2014). Engagement theory helps to explain the causes and barriers of employee engagement from a behavioral aspect of organizational commitment and performance. According to Kahn's theory, engaged employees express themselves emotionally, physically, and 
cognitively when involved in activities that are meaningful and safe and when they know resources are available to complete the activities (Kahn, 1990).

Emotionally engaged employees experience high levels of well-being (Kahn, 1990). Kumar and Pansari (2015) argued that cognitively engaged employees consider work to be meaningful, and physically engaged employees demonstrate high levels of productivity. Physical engagement requires emotional and cognitive engagement (Shuck \& Reio, 2014).

Engaged employees demonstrate commitment, put forward their best efforts, are innovative, and pay attention to quality, costs, customer service, and safety (Kahn, 1990). Disengagement occurs when employees withdraw physically, cognitively, and emotionally from their duties at work (Kahn, 1990). Employee engagement is important for achieving strategic goals in a business by creating the conditions, resources, and working environment for leadership to be successful and for employees to be productive (Anitha, 2014).

Researchers use the theory of employee engagement to underscore the strategies business leaders can use to engage their employees and for employees to be productive and effective for the business (Albrecht, Bakker, Gruman, Macey, \& Saks, 2015; Kahn, 1990). The theory of employee engagement is therefore appropriate. It aligns with this research study, as leaders can affect employee engagement (Popli \& Rizvi, 2016).

\section{Operational Definitions}

Employee disengagement: Employee disengagement occurs when employees emotionally withdraw from work. Disengaged employees do not operate at full capacity, 
nor do they permit their thoughts and feelings to manifest in their work (Keating \& Heslin, 2015).

Employee engagement: Employee engagement occurs when an employee emotionally commits to the success of an organization (Nasomboon, 2014).

Leadership: Leadership refers to the ability of an individual to affect the motivation or competence of other individuals in a group to achieve common goals (Carasco-Saul, Kim, \& Kim, 2015).

Servant leadership: Servant leadership puts followers' needs above their own, provide direction to followers, and empower and develop followers. Servant leaders focus on stewardship, humility, interpersonal acceptance, authenticity, emotional healing, creating value for the community, and behaving ethically (Liden, Wayne, Liao, \& Meuser, 2014).

Transactional leadership: Transactional leadership involves influencing followers to achieve organization goals by reward or punishment depending on employees' behavior (Sajjadi, 2014).

Transformational leader: A transformational leader refers to an individual who (a) inspires creativity, (b) through the leader's influence raises the level of consciousness about the value of achievement and the methods needed to meet those achievements, (c) encourages support, (d) articulates a vision, (e) sets clear goals, (f) has high expectations, (g) encourages followers to look past their self-interests, and (h) encourages role model behavior (Bass, 1985; McCleskey, 2014). Leaders and their followers raise each other to higher levels of morality and motivation (Burns, 1978). 


\section{Assumptions, Limitations, and Delimitations}

Assumptions refer to facts considered true, but not verified, that influence the results and findings of a study (Schoenung \& Dikova, 2016; Turner \& Endres, 2017). The first assumption was that six leaders with the required characteristics and who have experienced successful employee engagement programs would be available to participate in interviews. The second assumption was that participants would provide honest responses. The third assumption was that common themes would result from the interviews, which would lead to identification of effective strategies to increase employee engagement.

Limitations are weaknesses in a study, some of which may be out of a researcher's control (Marshall \& Rossman, 2016; Matza et al., 2015). In a previous job, association with certain staff members of ABC Corporation, both professionally and socially, included discussions on certain aspects of the corporation. A limitation of the study was that these discussions may influence the analysis of the data and challenge its credibility. To mitigate this bias, using the interview protocol was important and as Yin (2017) noted, researchers should not introduce their own opinions during the interviews. I followed this advice and did not introduce personal opinions during the interviews. A geographical limitation also existed within this study, as the sample selected for this qualitative single case study was restricted to Florida. A third limitation was that the findings of the study may not be generalizable to all businesses in all settings due to the small sample size. 
Delimitations refer to the scope or boundary of the study imposed by the researcher (Knafl, Leeman, Havill, Crandell, \& Sandelowski, 2015). The first delimitation was that the target population size was six leaders with 5 years of leadership experience or more. Guest, Namey, and Mitchell (2017) noted that case studies generally have small sample sizes. The small size, however, can present challenges with regard to diversification and generalization (Guest et al., 2017). The second delimitation identified was that the selection process for the target population in the single organization under study was purposeful sampling. Other individuals from the same corporation or other corporations may be better able to answer the questions, but a larger target population and or multiple organizations would involve more time and costs than currently available. The third delimitation was that the population was from one area and from one company. The geographical restrictions bounded the study, as the information gained may not necessarily apply to other types of businesses or locations. I may have learned more on the topic using more than one company within the same industry and in different geographical locations.

\section{Significance of the Study}

The significance of this study is that business leaders could identify successful employee engagement strategies from the findings. Researchers have noted that an engaged employee is more productive than a disengaged employee (Bedarkar \& Pandita, 2014), and a strong positive correlation exists between employee engagement and an organization producing good results (Guaspari, 2015). Researchers have also noted the gaps in the literature on employee engagement, especially relating to leadership and 
employee engagement, suggesting the need for additional qualitative research on employee engagement (Kaliannan \& Adjovu, 2015; Shuck \& Reio, 2014).

Leaders must understand the effect of employee engagement on the workplace if they wish to experience corporate success. Improving employee engagement strategies increases the level of engagement and productivity and leads to the achievement of the goals and objectives of the corporation (Alagaraja \& Shuck, 2015). Exploring strategies that may affect employee engagement could allow business leaders to receive information about policies that may improve productivity and profitability.

\section{Contributions to Business Practice}

This study may be valuable to business leaders because successful engagement strategies could increase morale, productivity, profitability, and competitiveness in an organization and could contribute positively to absenteeism and employee turnover (Alagaraja \& Shuck, 2015; Zhang, Avery., Bergsteiner \& More, 2014). Gupta and Sharma (2016) contended that improving levels of engagement in organizations helps to develop positive employee attitudes, which promotes organizational effectiveness and higher productivity levels. Disengaged employees react negatively in the workplace and can disrupt the work environment and prevent growth (Anitha, 2014). Business leaders must develop strategies to increase employee engagement if they wish their organizations to experience growth (Alagaraja \& Shuck, 2015; Jha \& Kumar, 2016). The findings from this study can provide business leaders with certain strategies to engage employees and increase productivity, while reducing costs related to hiring and retention in highly competitive talent markets. 


\section{Implications for Social Change}

Business leaders who use strategies that successfully engage employees and increase productivity could find a positive outcome on the financial performance of their organizations. Leaders of stronger businesses could reinvest in their local communities. Improved financial performance in organizations could also lead to a more stable workforce. Employee engagement could cause an improvement in a community's stability and quality of life (Shuck \& Reio, 2014). The findings from this case study could contribute to positive social change by providing potential strategies for improving local business relationships, providing job opportunities, and providing new products and services within the community. Identifying and using strategies that improve employee engagement could also lead to (a) more humane, open-minded, and culturally strong workplaces, (b) stronger local economies, and (c) greater social cohesion.

\section{A Review of the Professional and Academic Literature}

The purpose of a literature review is for a researcher to reveal information relevant to the research question and identify information published in journal articles, newspaper articles, books, historical records, government reports, and theses and dissertations (Adedayo, 2016). The purpose of this qualitative, exploratory single case study was to determine the strategies that business leaders use to overcome or mitigate the challenges of disengaged employees and to encourage employee engagement. Kahn's (1990) employee engagement theory served as the conceptual framework. In this section, I provide knowledge about published literature, identify gaps, compare viewpoints, and detect the strengths and weaknesses of past and current literature. The objective of the 
study was to review the existing peer-reviewed literature on employee engagement, to use past research to answer the overarching research question, and to provide information for future research on the applied business problem.

The databases I used to conduct research were Google Scholar, linked to Walden University's electronic library, ABI/INFORM, Emerald Management, Sage Premier, Academic Search Complete, ProQuest Central, and Business Source Complete. Keywords searched included leadership, leadership styles, leadership theories, leadership effectiveness, motivation theories, employee motivation, employee engagement, employee engagement theories, employee disengagement, job satisfaction, and productivity. The search for literature resulted in more than 200 journal articles, dissertations, and books, of which 180 appear in the literature review. Within this literature review are 175 peer-reviewed journal articles, three non peer-reviewed sources, and two seminal books. As shown in Table 1, the literature review included 132 references between 2015 and 2019 and 48 references published in 2014 or earlier. Of the 48 references in or before 2014, 40 were from the year 2014, and eight were prior to 2014.

Table 1

Literature Review Source Content

\begin{tabular}{lcc}
\hline Literature reviewed & $N$ & $\%$ \\
\hline Sources with publication dates between 2015 and 2019 & 132 & 73.3 \\
Sources with publication dates in 2014 or earlier & 48 & 26.7 \\
Peer-reviewed sources & 175 & 97.2 \\
Non peer-reviewed sources, including seminal books & 5 & 2.8 \\
\hline
\end{tabular}




\section{Application to the Applied Business Problem}

Disengaged employees can cause productivity to decline and negatively affect the financial performance of many U.S. corporations (U.S. Merit Systems Protection Board, 2015). The aim of the literature review and the study in general was to gain a comprehensive understanding of employee engagement strategies. The study findings might encourage the improvement of business practices by identifying strategies that lead to highly engaged employees in the workplace. Business leaders who increase employee engagement provide a strategy for organizational success (Popli \& Rizvi, 2016). Popli and Rizvi (2016) arrived at this conclusion from the results of an empirical study based on data collected from 340 front-line employees from five organizations across the service sector in the Delhi, India, National Capital Region. The results from this study revealed synergies between leadership styles and employee engagement, and organizational success.

\section{Employee Engagement Theory}

The different terms used interchangeably by researchers to describe engagement include personal engagement, work engagement, job engagement, and employee engagement (Anitha, 2014). I chose Kahn's (1990) engagement theory as the conceptual framework for this study. The foundation of Kahn's theory is the work of Goffman (1961) titled Encounters: Two studies in the sociology of interaction, who suggested that employees lack consistency in their attachment to their work roles and are sometimes attached and sometimes detached in their work role performances (Kahn, 1990). 
Additionally, Kahn's work reflects the work of Hackman and Oldham in the 1980s, who developed research around job design (Kahn, 1990).

Prior to determining any conclusions, Kahn (1990) investigated psychologist Freud's (1922) documented work, sociologist Goffman's (1961) work, and the work of sociologist Merton (1957). Kahn's engagement theory indicates that individuals invest affective, behavioral, and cognitive energies in the workplace, which allows them to have a holistic view of their investment of self toward their work connection and work role (Barrick, Thurgood, Smith, \& Courtright, 2015). Researchers have used Kahn’s (1990) theory of engagement to explain why employees become disengaged from their job or organization (Ford, Myrden, \& Jones, 2015).

George and Joseph (2014) expanded on Kahn's (1990) theory of engagement and noted that leaders need to work toward attaining engaged employees if they desire organizational success. Employee engagement assumes a fulfilling work-related state of mind that characterizes vigor, dedication, and absorption (Kim, Khan, Wood, \& Mahmood, 2016). Kahn's theory includes discussion on an individual's self-image. Researchers have linked organizational trust and psychological empowerment to employee engagement, which aligns with Kahn's (1990) theory (Barrick et al., 2015).

Three approaches to understanding the precursors of engagement have appeared in previous research. One approach is Kahn's (1990) psychological conditions of engagement, in which Kahn assumed that employees need to engage in meaningful work, have the resources available to complete the work successfully, and feel psychologically secure in immersing themselves in the work (Hazelton, 2014). In engagement, Kahn 
(1990) contended that employees express themselves cognitively, emotionally, and physically.

In the workplace, employees display various levels of personal engagement or disengagement based on three types of attributes: (a) cognitive, (b) emotional, or (c) physical (Handayani, Anggraeni, Andriyansah, Suharnomo, \& Rahardja, 2017). The cognitive aspect is about employees' beliefs about an organization. The emotional aspect shows how employees feel toward an organization and its leaders. The physical aspect of employee engagement represents the amount of efforts expended by individuals to achieve their goals (Kahn, 1990). Rothmann and Baumann (2014) summarized that displaying these three attributes meant fully engaged individuals were cognitively alert, emotionally attached, and physically involved.

In contrast, disengagement encouraged employees to disconnect themselves cognitively, physically, and emotionally from their work roles, resulting in a negative impact on the organization (Kahn, 1990). Kahn contended that organizational circumstances influence employee behavior and that an assessment of these circumstances is necessary. Employees who believe their organizations are providing necessary support and are willing to invest their personal resources at work achieve emotional engagement (Anitha, 2014; Filipova, 2015; Shuck \& Reio, 2014). High levels of engagement lead to positive outcomes for both individuals and organizations (Kahn,1990). Other researchers who have studied employee engagement have not examined the psychological and emotional aspects of employees (Kahn, 1990). Kahn's 
engagement concept indicates that people need both self-expression and self-employment in their work lives.

In the engagement theory, employees tend to be engaged when they perceive synergy with the organization's values and purpose, while feeling that their own purpose matters (Glavas, 2016). Kahn (1990) contended that meaningfulness, resource availability, and safety help to shape employee engagement. Jose and Mampilly (2014), in support of Kahn, summarized that meaningfulness, resource availability, and safety are reasons employees exceed expectations and help organizations attain their goals.

Kahn (1990) used two qualitative studies focused on the various degrees to which people chose to engage or disengage. In those studies, individuals engaged and disengaged consistently (Dagher, Chapa, \& Junaid, 2015) depending on whether individuals thought they required a defense, or they were in a position to express themselves. Defense reflects disengagement, whereas expressing oneself reflects engagement (Zhu, \& Akhtar, 2014). Expression is harnessing oneself into a work role (Jose \& Mampilly, 2014).

Full self-harnessing requires optimal working conditions (Kahn, 1990). Working conditions determine the extent to which individuals express themselves in job roles (Kahn, 1990). Workers exhibit personal energy or drive through emotional, cognitive, or physical engagement (Kahn, 1990). According to Kahn (1990), an individual is personally engaged when the individual acts and expresses his or her best self within a work role in an optimal work environment without emotional, physical, or cognitive sacrifice. Personal disengagement occurs when an individual is detached from his or her 
work role (Valentin, Valentin, \& Nafukho, 2015). Personal engagement or disengagement reflects the work environment, and need satisfaction (Valentin et al., 2015). When workers do not experience a positive state of mind and their needs are not met, the workers may disengage (Alagaraja \& Shuck, 2015).

Disengagement does not align with organizational strategy, nor does it allow for or promote knowledge sharing and teamwork (Huertas-Valdivia et al., 2018). Disengaged employees do not participate, and team members are silent and withdrawn. Knowledge sharing disengagement can be disruptive and cause concern for organizations (Ford et al., 2015). Ford et al. (2015) described failing to share knowledge as incompetent passivity. Employee engagement can improve organizational performance. Engagement requires leaders to implement engagement strategies to influence employees to increase work performance and productivity (Bakker \& Albrecht, 2018; Kahn, 1990). Albrecht et al. (2015) promoted engagement as a main tool to enhance competitive advantage and financial profitability. The concept continues to receive attention from practitioners. Scholars and practitioners tend to focus on engagement behaviors (Yalabik, Popaitoon, Chowne, \& Rayton, 2013). A contrary view proposed by Alagaraja, \& Shuck (2015) held that research should include how characteristics of the organization and leadership affect employee engagement practices. Lee, Kim, and Kim (2014) and Anitha (2014) studied employee engagement in a study involving 12 five-star and four-star South Korean hotels and concluded that employees working in the hotels, when fully engaged, embraced the brand and delivered the promise to the customers, demonstrating alignment with the organization's goals. 
Anitha conducted a study using middle managers and lower-level managers from small organizations in India. Anitha concluded that seven work-related processes supported successful employee engagement, including (a) workplace, (b) leadership, (c) interpersonal relationships, (d) learning opportunities and career growth, (e) pay, (f) company guidelines, and (g) well-being. Anitha's findings suggest that leaders need to understand the importance of these processes that support employee engagement and ensure that these processes are in place if they expect to achieve employee engagement.

\section{Alternative Theories}

In contrast to Kahn (1990) employee engagement theory, Vroom (1964)

suggested that based on the findings of his expectancy theory, motivation is the product of expectancy and expectancy is the effort that results in a desired level of performance. Van De Voorde, Van Veldhoven, and Veld (2016) applied the expectancy theory to study workplace motivation and found that when individuals understood and met expectations, higher levels of engagement existed. Employees who do not understand the organizational objectives or experience high demand that does not allow them to meet expectations may be less willing to expend efforts to perform a task, which may cause decreases in engagement (Van De Voorde et al., 2016).

Job involvement and trust are the main determinants of organizational effectiveness and trust creates employee motivation (Nasomboon, 2014). Organizations must be an environment in which leaders can express their expectations and identify clear objectives for employees (Karanges, Johnston, Beatson, \& Lings, 2015). Organizations that meet employee expectations influence employee motivation (Imran, Arif, Cheema, \& 
Azeem, 2014). Imran et al. (2014), like Van De Voorde, Van Veldhoven, and Veld (2016), pointed out that when individuals understand and meet expectations, organizations realize increased engagement and productivity. Leaders not able to establish clear goals for employees may negatively affect employee engagement, motivation, and productivity (Imran et al., 2014).

Vroom (1964) noted that, through the expectancy theory (a) a correlation existed between a person's effort and performance, (b) good performance resulted in a positive return, (c) the return satisfied a person's need, and (d) the longing to satisfy the person's need made the effort worthwhile. Expectancy, instrumentality, and valence form the base of the expectancy theory. Valence is the emotional responses people have to outcomes, instrumentality assumes that the reward correlates to the effort expended, and expectancy relates to a person's confidence and capabilities (Purvis, Zagenczyk, \& McCray, 2015; Vroom, 1964). Ferinia, Yuniarsi, and Disman (2016) found support for Vroom's theory and pointed out that a relationship between personal effort, performance, and awards that could lead to employee satisfaction and engagement.

Ernst (2014) noted the existence of four assumptions based on the expectancy theory. The first assumption is that individuals join organizations with expectations about their motivations, needs, and prior experiences. The second is that an individual's behavior is intentional (conscious choice). The third is that individuals want different things from their employer, such as advancement, a good salary, and job security. The fourth is that individuals will think about alternatives to enhance outcomes for themselves (Ernst, 2014). 
Individuals become motivated when they believe that the following three elements exist: (a) effort will lead to an acceptable performance, (b) awards will follow performance, and (c) the value of the awards will be positive (Nimri, Bdair, \& Bitar, 2015). These elements characterize expectancy, instrumentality, and valence. Managers must ensure that a combination of all three factors is present when they seek to develop and implement strategies to motivate and engage employees (Nimri et al., 2015). Expectancy theory aligns with this study in that positive valence and instrumentality and an increase in expectancy encourage employee engagement (Nimri et al., 2015).

The expectancy theory may be inadequate, as no reward is linked to performance in many organizations (Barron \& Hulleman, 2015). Other elements such as (a) position, (b) effort, (c) responsibility, and (d) education, among others may influence employee engagement. Therefore, consideration to other leadership styles and motivation skills and other theories for improving employee engagement within an organization is appropriate.

Another theory, relevant to employee engagement is the job demands-resources model, in which the availability of certain job resources leads to engagement (Xanthopoulou, Bakker, \& Fischbach, 2015). These resources include (a) job security, (b) supervisor support, and (c) role conflict and autonomy. Certain psychological concepts, such as (a) motivation, (b) job involvement, (c) job satisfaction, (d) organizational identification, (e) proactive behaviors, (f) organizational citizenship behaviors, and (g) organizational commitment tend to impact employee engagement positively (Xanthopoulou et al., 2015). Researchers use the job demands-resources model to understand employee health and well-being (Schaufeli, 2015). Bakker and Demerouti 
(2017) suggested that the job demands resources model allows researchers to understand employee job burnout, explain, and predict work engagement outcomes.

Empirical analysis demonstrates that job resources influence whether employees become engaged or disengaged (Bakker \& Demerouti, 2017) and leaders should be cognizant of the fact that the model is inclusive of all job resources, and that employees may seek to alter their work environment if the environment is unacceptable (Schaufeli, 2015). The job demands-resources theory assumes that the demand component is a stressor and the resources are motivators (Bakker \& Demerouti, 2017). The theory aligns with Kahn's (1990) employee engagement theory, that focused on the psychological conditions of engagement. Kahn assumed that employees need to engage in meaningful work, have the resources available to complete that work successfully, and feel psychologically secure in immersing themselves in that work (Kahn, 1990).

The third theory related to employee engagement is social exchange theory, which concerns the relationship between the organization and employee (Gilliam \& Rayburn, 2016). Similar to transactional leadership theory, the basis of social exchange theory is service from the employee in exchange for monetary and nonmonetary awards from the organization (Slack, Corlett, \& Morris, 2015), thereby engendering a feeling of obligation on the part of the employee. Albdour and Altarawneh (2014) pointed out that if employees appreciate the monetary and nonmonetary exchanges, and if they believe that the organization values them, employees will commit to the organization. With increased commitment, employee engagement and job satisfaction should be positively affected (Albdour \& Altarawneh, 2014). 
In contrast, Zhang et al. (2014) contended that no meaningful relationship exists between transactional leadership and employee engagement. Zhang et al. concluded that this was because of the characteristics of transactional leaders who rely on a reward in exchange for completing the task. Zhang et al. came to this conclusion after conducting a quantitative study using a sample of 439 retail sales assistants in Sydney, Australia, who responded to a mixed-mode questionnaire survey. The strengths to this study are that the study is replicable and resolves the question about the components of employee engagement (Zhang et al., 2014).

A similar philosophy underpins the social exchange theory. A research study carried out by Karanges et al. (2015) attempted to find out if communication as a form of social exchange encouraged employee engagement. This study involved 200 nonexecutive Australians, ages 18 to 25 years, working in organizations with 50 or more persons (Khuong \& Yen, 2014). Khuong and Yen (2014) discovered a positive relationship especially between the employee and management and this relationship formed the basis for the employee becoming engaged.

Another study conducted by Herda and Lavelle (2015) and related to the social exchange theory, examined the relationship between 102 auditors from a large private audit firm in the United States, and their clients. The conclusion was that clients preferred social exchanges rather than transactional exchanges (Herda \& Lavelle, 2015). The relationship between auditor and client, and the way the auditor viewed the social exchange relationship will determine the auditor's level of engagement (Herda \& Lavelle, 2015). Leaders who build strong relationships with subordinates or clients are more 
effective at increasing employee engagement because people are more willing to follow leaders with whom they have a relationship (Hamon \& Bull, 2016).

\section{Employee Engagement}

Scholars defined the term engagement in many ways (Harrell-Cook, Levitt, \& Grimm, 2017). Kahn (1990) considered personal engagement to exist when individuals employ and express themselves emotionally, cognitively, and physically when doing a task, and that personal engagement was the harnessing of organization members' selves to their work roles. Kahn therefore viewed engagement (or disengagement) as a response to work environments (Huertas-Valdivia et al., 2018). Cheema, Akram, and Javed (2015) considered employee engagement as harnessing employees in their work roles while allowing them to express themselves cognitively, emotionally, and physically.

Anitha (2014) described employee engagement as the level of involvement and commitment an employee displays toward an organization. Karumuri (2016) contended that the emotional and intellectual commitment an employee has toward the business, as well as the employee's willingness to do whatever is necessary to enhance organizational goals, drives employee engagement. Karumuri came to these conclusions based on a study conducted within the hotel sector in India.

Jha and Kumar (2016) noted many researchers agree that engagement can affect both nonfinancial performance and the financial performance of an organization. Each employee must contribute to the organization by (a) seeking to improve employee team building, (b) encouraging communication, and (c) assisting in creating an environment of cultural diversity, to improve the organization's engagement initiative (Nazir \& Islam, 
2017). Leaders, therefore, must work to motivate employees to develop attitudes and behaviors to enable them to engage (Eneh \& Awara, 2016; Maghraoui \& Zidai, 2016).

Employee engagement is a new business idea that is crucial to business success (Saks \& Gruman, 2014b). Gelderman, Semeijn, and Bruijn (2015) pointed out that employee engagement is important to achieving organizational goals, and researchers therefore took an interest in employee engagement to identify the elements that would encourage or discourage employee engagement. Bakker and Albrecht (2018) suggested that employee engagement maintained its popularity because it can predict organizational outcomes.

The lack of a single definition of employee engagement has created a fundamental challenge (Kassa \& Raju, 2015). Bettis et al. (2014) examined the many definitions and concluded that the definition of employee engagement changed over time. Lu and Anderson-Cook (2015) stated that engaged employees work to fit their job role and to reach their potential, reinforcing the importance of deploying employee engagement strategies. Although there are differences, the basic components of employee engagement are the same.

\section{Antecedents to Employee Engagement}

Leaders may find difficulty selecting and implementing employee engagement strategies that can lead to a competitive advantage (Bedarkar \& Pandita, 2014). Leaders must, however, combine any engagement program with organizational policy and alignment and define it according to need (Alagaraja \& Githens, 2016; Kaliannan \& Adjovu, 2015; Oswick, 2015). Although increased interest in employee engagement as a 
construct exists, the concept is still misunderstood. Academia is still in search of antecedents and strategies that might lead to higher employee engagement (Oswick, 2015). Oswick (2015) therefore implored human resource development practitioners to engage in research and discussion about the implications of employee engagement and hopefully practitioners could develop more useful strategies.

Understanding engagement drivers is key to implementing a successful engagement strategy and an overall organizational business strategy. (Singh, 2016). Singh (2016) proposed certain antecedents to employee engagement as follows: (a) creativity, (b) employee empowerment, (c) flexible welfare policies, (d) job satisfaction, (e) servant leadership, (f) career growth opportunity, and (g) procedural justice (Singh, 2016). These strategies are drivers or antecedents to employee engagement (Singh, 2016). Psychological conditions inspire engagement and commitment. Employing the right engagement strategies allows employers to create the right working conditions (Lee \& Ok, 2015). Society for Human Resource Management (SHRM), through one of its executives conducted a study on antecedents of job satisfaction and engagement. Results showed that some antecedents included (a) good relationships with coworkers and supervisors, (b) organizational financial stability, and (c) sufficient compensation.

A positive work culture is an antecedent to increased engagement (Alagaraja, \& Shuck, 2015). Positive work culture occurs when organizational and individual goals align for employees (Alagaraja \& Shuck, 2015). Work experience or organizational culture is therefore important in building employee engagement. Another antecedent to engagement is leadership (Huang et al., 2016). Leaders are responsible for engagement 
(Ibrahim \& Falasi, 2014). Part of this engagement responsibility is providing a conducive working environment that is safe, supportive, meaningful, and empowering (Huang et al., 2016).

Another antecedent linked to engagement is leader emotional intelligence. High emotional intelligence plays a significant role in mediating employee work engagement. De Clercq, Bouckenooghe, Raja, and Matsyborska (2014) conducted a study where 272 employees showed the role between supervisors and employees can have a negative affect when leaders have low emotional intelligence. The higher the emotional intelligence, the higher work engagement becomes (De Clercq et al., 2014).

\section{Benefits and Outcomes of Employee Engagement}

Researchers continue to highlight the outcomes for organizations, which focus on engagement strategies. Dagher et al. (2015) surveyed 426 service industry employees to confirm the historical notion of self- efficacy and employee engagement and found that belief in a person's own capabilities is an effective driver of employee engagement. Carter, Nesbit, Badham, Parker, and Sung (2016) also found a positive correlation between employee engagement and self-efficacy.

Chaudhary, Rangnekar, and Barua (2013) conducted a study with 126 business executives from the private and public sectors. Private sector participation was from the manufacturing and service industries. The intention was for the authors to examine whether an engaged workforce could be distinguished from a disengaged workforce based on occupational self-efficacy. The findings confirmed the hypothesis that an engaged workforce functioned more productively than a disengaged workforce, as 
engaged employees had self-efficacy. Organizational leaders should build the selfefficacy of their employees to improve employee engagement rates.

Bedarkar and Pandita (2014) posited that an employee engagement program may be a cost-effective way to increase organizational performance. Bedarkar and Pandita (2014) stated further that a highly engaged workforce effects the organization they support in a positive way. According to Mokaya and Kipyegon (2014), a relationship exists between employee engagement and organizational performance management. Jeve, Oppenheimer, and Konje (2015) found that time passes quickly for employees who enjoy their work. Implementing an employee engagement strategy, allows organizations to benefit from enhanced financial performance and to have increased competitive advantage.

Kumar and Pansari (2016) found that employee engagement has a significant and positive link to organizational performance. Further, the benefits of employee engagement are a positive workplace environment, interpersonal relationships, and general wellbeing (Anitha, 2014). Generally, many benefits accrue to organizations from an effective employee engagement strategy, including increased employee performance and a competitive advantage (Anitha, 2014).

Saxena and Srivastava (2015) found that employee engagement has a strong link to (a) organizational culture, (b) open communication, (c) supervisors' empathy toward employees, (d) recognition, (e) autonomy and self-management, (f) safety measures, and (g) fair compensation and benefits. These findings resulted from a study conducted by Saxena and Srivastava using 1,250 blue-collar and white-collar individuals from 30 
manufacturing companies. Employee engagement scholars reinforced the correlation between employee engagement and the above factors (Permana, Tjakraatmadja, Larso, \& Wicaksono, 2015). Breevaart, Bakker, Hetland, Demerouti, Olsen, and Espevik (2014) supported Saxena and Srivastava's view on a correlation between employee engagement and autonomy and self-management. Breevaart et al. (2014) found that employees who self-manage are likely to engage. Organizations, which use more self-management strategies, seem to have higher engagement levels.

Various scholars identified elements to predict the levels of employee engagement. Many of these elements tended to overlap. Yalabik, Van Rossenberg, Kinnie, and Swart (2015) found that the best predictor of work engagement is the employees' organizational commitment. Psychological meaningfulness at work is a factor in an employee's well-being as it relates to the employee's job satisfaction.

Khan (1990) also supported this concept of the importance of employees having meaningful work to encourage employee engagement. Anitha (2014) found that (a) workplace environment, (b) compensation, (c) team and coworker relationships, and (d) leadership, predicts employee engagement. Geldenhuys et al. (2014) like Khan (1990) found that a positive link exists between psychological meaningfulness, organizational commitment, and engagement. Ahmetoglu, Harding, Akhtar, and Chamorro-Premuzic (2015) noted a different predictor for employee engagement namely, creativity. These employee engagement predictors referred to above may not extend to all organizations or circumstances. Every circumstance does not necessarily require psychological 
meaningfulness or organizational commitment in order to promote employee engagement (Ahmetoglu et al., 2015).

Effective leadership strategies that improve employee engagement, could encourage an engaging workforce that improves the financial performance of organizations (Besieux, Baillien, Verbeke, \& Euwema, 2015). Besieux et al. (2015) made this claim after conducting a study on Belgian banks using a sample of 5,313 participants. Besieux et al. (2015) intended to add to the literature on the topic of leadership and employee engagement and to examine corporate social responsibility (CSR) as a mediator. Leaders committed to CSR usually realize sustainability, which is important as sustainability implies organizational longevity (Glavas, 2016; Chaudhary (2017). Sustainability and longevity usually increase engagement (Glavas, 2016).

Organizational leaders may face challenges when trying to engage employees to improve productivity (Hollis, 2015). Training and development foster employee engagement. When leaders limit training and development or cause training and development to be non-existent, leaders face challenges with employee engagement and employee retention (Anitha, 2014). Chaudhry, Jariko, Mushtaque, Mahesar, and Ghani (2017) supported this notion pointing out that training and development improve employees' performance.

The loss of more than $\$ 300$ billion in productivity in the United States from a disengaged workforce prompted managers to seek to improve employee engagement so that the financial performance of organizations could improve (Mahajan \& Sharma, 2015). The concept of employee engagement is important to scholars and business 
leaders interested in the performance of employees and the performance of the organization (Dagher et al., 2015). Guaspari (2015) contended that many researchers discussed the strong positive relationship between high levels of employee engagement and good organization results.

Higher levels of employee engagement result in increased returns on assets, higher earnings per employee, better organizational performance, higher sales growth, and higher retention (Albdour \& Altarawneh, 2014; Popli \& Rizvi, 2016). According to Albdour and Altarawneh (2014) the basis of this conclusion was a study conducted in Jordan within its banking sector. The study involved all frontline employees and the use of an instrument developed by Saks to measure employee engagement job engagement and organizational engagement.

Nasomboon (2014) indicated that a statistical correlation exists between high levels of employee engagement and improvements in productivity, profitability, and job satisfaction. Nasomboon also noted that the degree of job involvement and trust largely determine the level of organizational effectiveness. Leaders engage employees by ensuring that employees understand the values of the organization, by inspiring staff to achieve the goals of the organization, and by making employees feel valued (Parker, Soomro, \& Hayward, 2015). Engagement is a catalyst for a more productive employee base and can generate value for a company (Griffin, Bryant, \& Koerber, 2015; Oswick, 2015; Nasomboon, 2014). When engagement occurs, leaders notice an increase in productivity and output, as organizations adopt new processes and implement new changes (Nasomboon, 2014). 
Nasomboon conducted a quantitative study in Map Ta Phut, Thailand and using petrochemical companies' managers. The goal of the study was to investigate the relationship among leadership commitment, operational performance, and employee engagement. Nasomboon noted that this study was the first empirical study with these variables, and the study permitted a response to the question, "Does leadership commitment affect organizational performance and engagement?" This finding was consistent with a prior study by Zhang et al. (2014) who demonstrated that leadership style is significantly related to the level of employee engagement.

Shuck and Reio (2014) gave further support to this argument by noting that poor engagement can have a negative impact on organizations and organizational productivity. Shuck and Reio indicated that when employees do not feel engaged, their well-being can decrease, which might result in a decline in productivity and potential negative consequences to an organization. This conclusion resulted from the findings of a study conducted with heath care workers from Canada, the United States and Japan. Using regression analysis, the conclusion was that highly engaged employees had higher psychological well-being and personal accomplishment, whereas employee with low levels of engagement experienced higher emotional exhaustion and depersonalization (Shuck \& Reio, 2014).

Shuck and Reio (2014) noted that because they used self-reports for data collection, generalization could be a potential weakness of the study. This study provided support for the importance of positive emotion at work and aligns with the view of Kahn (1990). The ability to embrace fully one's work roles, to be a part of something 
meaningful, and to engage cognitively, emotionally, and behaviorally has implications for how employees perceive their life. The results conform with Kahn's (1990) perspective in which a psychological benefit emerges from engagement and a psychological cost for disengagement and where work involves the whole person.

Leaders must view employees as one of the highest assets of organizations. Maintaining loyal, productive employees while realizing profits is a challenge for leaders who need to understand the factors that influence and encourage employee engagement (Carter \& Baghurst, 2014). Cattermole, Johnson, and Jackson (2014) noted that employee engagement requires an organizational solution and is not the sole responsibility of the individual. Cattermole et al. noted further that an engaged employee is a productive employee, and the factors that positively influence employee engagement and productivity include (a) competent leaders, (b) broad relevant goals, (c) measurable objectives (d) appropriate resources, and (e) some autonomy. Understanding these factors are key to developing strategies to engage employees.

\section{Measuring Employee Engagement}

Georgiades (2015) found other gaps in the employee engagement literature. Georgiades indicated that leaders had limited understanding of how they should view employee engagement or how to increase employee engagement. Saks and Gruman (2014b) agreed that the gaps existed and added that the validity of prevailing techniques used to measure employee engagement, and how to measure engagement, remained uncertain. 
Byrne (2015) suggested that organizations should consider job performance and job task when measuring employee engagement. Byrne described job performance as the behaviors that employees display when performing their tasks. Byrne considered job task to consist of many activities and how effectively employees carried out the activities, determines the effectiveness of the job task. Earlier employee engagement models, such as Colbert, Mount, Harter, Witt, and Barrick, and Macey and Schneider, focused on individual employee situations within an organization (Cowardin \& Soylap, 2011).

Cowardin and Soylap (2011) discussed a study by Pugh and Dietz (2008) in which Pugh and Dietz aggregated engagement measures to unit and subgroup measures to capture social norms. Costa, Passos, and Bakker (2014) pointed out that any employee engagement measurement must involve the team and not individual members. Two measurements for employee engagement exist in the literature. The first is Schaufeli and Bakker's (2003) Utrecht work engagement scale (Schaufeli, 2015). The second measurement is Soane, Truss, Alfes Shantz, Rees, \& Gatenby's (2012) intellectual, social, affective engagement scale. Neither one of these two methods may be a good choice for measuring all circumstances. Confusion remains about how to best measure employee engagement levels (Saks \& Gruman, 2014a; Burnett \& Lisk, 2019). Disagreement about the definition of employee engagement, together with confusion about how to best to measure employee engagement challenges some leaders who desire to implement a comprehensive employee engagement strategy.

Many employee engagement studies use the Utrecht work engagement scale, or a close modification, described by Schaufeli and Bakker's Utrecht work engagement scale 
manual (2003). This scale works best to measure the health of various components separately and significant employee engagement issues first. It is possible that smaller areas of the Utrecht work engagement scale may contribute to employee engagement problems later if not addressed.

Despite the differences of opinion on the definition of employee engagement, the challenges with measuring employee engagement and the other gaps discussed, Cheema et al. (2015) suggested that after three decades of research on the topic of employee engagement, researchers believe that if employees in an organization engage fully, this would attract better quality persons to the organization.

Soane et al. (2012) built a model for measuring employee engagement: The intellectual, social, affective engagement scale. The purpose of the scale was to define the specific and relevant components of employee engagement, implement the strategy and then measure them (Soane et al., 2012). It may be necessary to combine different indicators from the various employee engagement models for measurement to achieve the best measurement outcome. The intellectual, social, affective engagement scale linked positive associations with task performance, organizational citizenship behavior, and turnover intentions (Soane et al., 2012). Further, Soane et al. found that social engagement can predict employee turnover intentions.

\section{Categories of Employee Engagement}

Adkins (2015) proposed three categories of employee engagement. These are engaged, not engaged, and actively disengaged. Employee engagement occurs when employee individualism synchronizes with their work roles (Kahn, 1990). Kahn (1990) 
posited further that when employees engage at work, the employees express their individuality physically, cognitively, and emotionally. Thompson, Lemmon, and Walter (2015) added that engaged employees are enthusiastic about their work, make fewer mistakes and have a strong commitment to the organization.

Thompson et al. (2015) articulated further that high levels of organizational engagement positively affects sustainability, competitiveness, and the community in general. Thompson et al. reached their conclusions from conducting a study, in which they drew on several previous studies on engaged employees. The goal of the study was to (a) provide a framework for understanding existing research on predictors of employee engagement, (b) expand that framework by including the concept of psychological capital, and (c) provide managers and leaders with a number of case studies that illustrate how to improve employee engagement.

Mann and Harter (2016) pointed out that researchers noted that unengaged employees represented more than 50\% of the 150.6 million U.S. workforce in 2015 (Mann \& Harter, 2016). Unengaged employees have an interest only in the specific tasks assigned and demonstrate limited commitment to the organization. Valentin et al. (2015) noted that organizations are less productive with unengaged employees. Although the effect on productivity is negative, unengaged employees do not present challenges to the organizations by spreading their negativity like disengaged employees do (Chaudhary et al., 2013). Engagement strategies are therefore important to organizations, because while unengaged employees are less destructive than disengaged employees, unengaged employees add little value to the organization since they lack commitment. 
Chaudhary et al. (2013) conducted a study with 126 business executives from the private and public sectors. Private sector participation was from the manufacturing and service industries. The intention was for the authors to examine whether an engaged workforce could be distinguished from a disengaged workforce based on occupational self-efficacy. The findings confirmed the hypothesis that an engaged workforce functioned more productively than a disengaged workforce, as engaged employees had self-efficacy.

Based on the findings of a research study, Joyner (2015) pointed out that $90 \%$ of organizational leaders believed that employee engagement is important to their success. The majority of those leaders however, failed to understand or implement strategies to increase employee engagement (Joyner, 2015). Kumar and Pansari (2015) suggested that only when leaders understand fully the distinction between engagement and disengagement and the merits of having an engaged workforce will efforts to increase engagement really take place.

Job satisfaction. Job satisfaction depends on how an employee feels about his job, work environment, pay, and benefits that affect his performance (Herminingsih, 2017). Job satisfaction is an employee's emotional reaction to occupation based on a range of factors (Pouramini \& Fayyazi, 2015). While employee engagement is the individual's feeling of satisfaction and enthusiasm in work-related task and activities in an organization, a link exists between job satisfaction and employee engagement as job satisfaction may influence employee engagement (Nasomboon, 2014). 
Nimon, Shuck, and Zigarmi (2015) identified various benefits of job satisfaction and organizational performance. Employers determine employees' needs, creating a sense of engagement such as work and life balance, and empowerment to make decisions (Shuck \& Reio, 2014). Pouramini and Fayyazi (2015) found a relationship between: (a) job satisfaction, (b) organizational growth, (c) individual performance, (d) employee productivity and (e)customer satisfaction (Albrecht et al., 2015). Leary et al. (2013) wrote that there is a relationship among effective leadership, employee engagement, and job satisfaction. Therefore, job satisfaction may contribute to an employee's willingness to engage in the organizational tasks and activities, which could result in high productivity (Lysova, Richardson, Khapova, \& Jansen, 2015).

Mishra, Boynton, and Mishra (2014) posited that to promote employee engagement is to provide adequate training and interactive communication. It is essential that leaders encourage activities to encourage job satisfaction if the desire is to have an engaged workforce. Job satisfaction can affect organizational success and is a direct result of employee engagement (Hanaysha \& Tahir, 2016). Job satisfaction can affect organizational success and is a result of employee engagement (Hanaysha \& Tahir, 2016). Understanding how to achieve job satisfaction is a prerequisite for understanding what strategies can engage employees.

Productivity. Disengaged employees erode the bottom line and lower morale. Engaged employees are more productive, more customer-focused, and drive profit and revenue (Heymann, 2015). Companies that have engaged employees tend to experience increased performance (Garg, 2014). Garg (2014) indicated that employees can be at 
work but not engaged, which results in a decline in productivity that potentially causes losses to the organization. Glavas (2016) reported that as of 2016, $87 \%$ of the worldwide workforce was unengaged and in the United States alone, the economy currently loses as much as $\$ 550$ billion annually in productivity because of disengaged workers (Glavas, 2016).

As organizational leaders seek to improve the organization's competitiveness, achieving productivity becomes critical (Griffin et al., 2015), and engagement drives productivity (Anitha, 2014). The business environment needs however, to cater to engagement by ensuring the employees' well-being and emotional connection (Nasomboon, 2014). Emotionally connected employees demonstrate more commitment and engagement (Megha, 2016).

Recent research connected performance, productivity, and engagement (Saks \& Gruman, 2014b). The engagement concept is still controversial and can use additional research to fill the gaps in the literature regarding engagement and productivity (Alagaraja \& Shuck, 2015). Menguc, Auh, Fisher, and Haddad (2013) used the Job Demand-Resource (JD-R) model to explore engagement consequences and antecedents for service employees. The authors found a link between productivity and engagement. The study included an examination of effects, of support, feedback, and autonomy and Menguc et al. (2013) found that positive interactions with leaders produced positive effects on engagement.

Employee engagement has a direct relationship to work satisfaction. If employees are satisfied with the work environment, tasks performed, responsibilities, and the 
management of the organization, employees are more productive (Anitha, 2014).

Employee engagement helps to generate a feel of belongingness with the organization and thus the employee feels 'connected' to the organization (Garg, 2014). Poor job fit and a poor work environment can affect productivity and employee engagement negatively (Garg, 2014). Employees who do not feel engaged, especially if they do not have a good job fit, discourage and distract other employees, and decrease the morale and productivity of the organization (Nimon et al., 2015).

Organizational leaders, who understand the workplace environment and ensure various jobs are less stressful, experience increased productivity (Nimon et al., 2015). When leaders are effective and encourage and motivate employees to do their jobs, productivity and profits increase (Heymann, 2015). Engaged employees are likely to work more enthusiastically and for longer periods of time (Gupta \& Schukla, 2018). Gupta and Schukla (2018) noted in their study of 317 knowledge workers from across India, that personal engagement was a strong predictor of task performance. Garg (2014) suggested that engaged employees produce $15 \%$ more than those unengaged employees, thereby making an engagement program a critical strategic undertaking for organizations.

When comparing organizations in the same industry, Lather and Jain (2015) found that organizations in which high engagement levels existed, experienced higher growth rates in earnings per share than organizations with low engagement. Thompson et al. (2015) conducted a study to examine the influence employee engagement has on organizational performance. The results were that engaged employees produced better quality work than disengaged employees, are more willing to work on assignments 
outside of their job descriptions and tend to remain with the organizations longer (Anitha, 2014). This contributed to higher growth rates in organizations (Thompson et al., 2015).

Retention is critical to organizational effectiveness and productivity (Harris, Li, \& Kirkman, 2014). Researchers for the U.S. Bureau of National Affairs found that U.S. businesses losses were approximately $\$ 11$ billion annually because of employee turnover (Hanzlik, 2015). Guilding, Lamminmaki, and McManus (2014) reported that the cost to replace an employee is higher than the cost to retain an employee. Mutsuddi (2016) conducted a study with a sample size of 31 from varying departments at a hospital in Calcutta to examine the relationship between employee engagement and talent retention. The findings were that employees who engage within the workplace are five times less likely to voluntarily leave the organization (Mutsuddi, 2016).

Employment contracts, especially those that include variable incentive compensation, management's reputation, and the extent of fairness that leaders exercise, contribute toward fostering workplace productivity (Liu \& Zhang, 2015). Liu and Zhang (2015) made this conclusion based on a study conducted by examining four target-based incentive contracts. Putra, Cho, and Liu (2015) indicated that leaders who seek out profitability and productivity must engage their employees and introduce engagement strategies that offer value to their employees.

Challenging and meaningful tasks encourage intrinsically motivated employees to higher levels of performance (Putra et al., 2015). Putra et al. (2015) conducted a study on small restaurants in the United States to examine extrinsic and intrinsic motivation as the antecedents of work engagement. The results of this original work showed that intrinsic 
motivation works best, not only for jobs that require higher levels of cognitive skills, but also for jobs that require lower levels of cognitive skills. This result dispels the notion previously arrived at in research studies in which it was felt that intrinsic motivation worked only with higher cognitive skills (Putra et al., 2015).

Organizational leadership in driving engagement must develop an effective recognition and reward policy (Swartout, Boykins, Dixon, \& Ivanov, 2015). Swartout et al. (2015) suggested that the responsibility of leaders is to reward employees for good performance and recommend solutions to correct deficiencies in behavior, attitude, and work. Some contention exists in the literature as to the relationship between awards and recognition and engagement. Ghosh, Ragini, Gargi, and Srivastava (2016) examined the relationship between employee engagement and awards and recognition. The sample used in the study included 176 private bank employees in India and the results from the regression analysis indicated that recognition and awards significantly influence employee engagement.

Malik, Butt, and Choi (2015) offered a different perspective to the literature when they questioned whether awards and recognition influence all individuals in the same way. Gieter and Hofmans (2015) conducted a study with 179 employees plus supervisorrated task performance data. From the findings Gieter and Hofmans were able to respond to the concerns of Malik et al. (2015). The findings allowed researchers to confirm that employee satisfaction depended on the type of employee, socio-demographic characteristics, and personal work values. Understanding the socio-demographics, type of 
employee and personal work values, enable leaders to develop a successful engagement program that meets the needs of the employees.

Communication between leaders and employees might increase trust within the organization and ultimately increase engagement (Bedarkar \& Pandita, 2014). Adequate and continuing internal communication permits employees to understand what happens in the organization and allows them to commit to achieving the organization's objectives (Bedarkar \& Pandita, 2014). Effective internal communication fosters trust, which encourages employee engagement (Karanges et al. 2015). Business leaders must communicate their organizational goals, mission, and vision from the top to encourage employee engagement (Mishra et al., 2014).

An exploratory study used findings from interviews with public relations executives in the United States to explore the role that internal communication plays in employee engagement (Mishra et al., 2014). The findings were that effective internal communication can provide benefits for both employees and the firm (Mishra et al., 2014). Employees feel more engaged, build trust with their supervisor and the organization. Effective internal communication can enhance engagement (Mishra et al., 2014). What leaders do and how they behave toward employees is critical to fostering employee engagement. Their actions must align closely with the organization's mission and strategy (Cattermole et al., 2014).

Scholars singled out servant leaders as a leadership style whose adherents are able to communicate appropriately. Bakar and McCann (2016) conducted a study to identify the relationship between servant leader communication and organizational citizenship 
behavior. The results indicated that the communication strategies used by servant leaders were positive to the organizational climate and encouraged employees to display organizational citizenship behavior (Bakar \& McCann, 2016).

Wirsching, Mayfield, Mayfield, and Wang (2014) noted that researchers conducted few studies on servant leaders and communication and therefore a gap exists in the literature. Some researchers suggested that effective communication can lead to employee engagement, which leads to increased organizational commitment (Walden, Jung, \& Westerman, 2017). Ruben and Gigliotti (2016) and Bakar and McCann (2016) confirmed gaps in the literature pointing to no empirical support existing to suggest how leaders should use communication to increase employee engagement. Karanges et al. (2015) conducted a linear regression analysis to empirically test the correlation between internal communication and employee engagement. The findings demonstrated that effective communication from leadership encouraged meaningful workplace relationships and contributed to increasing employee engagement (Karanges et al., 2015).

Solaja, Idowu, and James (2016) suggested that leadership styles may influence a leader's ability to communicate effectively and this could affect productivity and employee engagement. Solaja et al. (2016) conducted a study to examine the relationship between leadership style, leadership traits, and productivity as they relate to leadership communication style. The study included 112 academic staff of the university of Lagos, Nigeria, selected through a multi-stage sampling technique. The findings showed a direct relationship between leadership communication style and leadership traits, and both of these had a direct impact on organizational productivity (Solaja et al., 2016). In any 
organization where there is good leadership communication style and personality traits, increased productivity and engagement emerge.

Employee motivation. Motivation is one of the most important elements in influencing human behavior and performance. Leaders continuously demonstrate positive leader-employee relationships to ensure increased employee engagement and productivity by applying employee motivational factors (Zareen, Razzaq, \& Mujtaba, 2014). One of the main factors that contribute to organizational performance is employee job performance. Employees who perform their jobs well will help their organizations meet their strategic goals and objectives (Zareen et al., 2014).

Jose and Mampilly (2014) contended that the catalyst for motivation is a physiological or psychological want that encourages a specific performance to achieve a specific objective. Kahn (1990) also advocated for employee engagement, a physiological and psychological want. According to Jose and Mampilly, motivation is a driving force behind behaviors and leadership behaviors influence employee engagement (Blomme, Kodden, \& Beasley-Suffolk, 2015). Transformational leaders through inspirational motivation behavior according to Prasannakumar (2015), is one element that helps to promote engagement.

Inspirational motivation occurs when leaders inspire followers by setting meaningful and challenging goals and communicating goal attainment enthusiastically. Leaders who inspire, value, develop, and encourage employees may realize improved organizational performance (Samad, Reaburn, Davis, \& Ahmed, 2015). Leadership 
influences organizational outcomes such as job satisfaction, employee commitment and loyalty, and turnover intentions and engagement (Samad et al., 2015).

When leaders provide meaningful work, followers work harder (Menges, Tussing, Wihler, \& Grant, 2017). Kahn (1990) suggested that followers work harder because they feel valued and worthwhile. Highly motivated individuals expend more effort than unmotivated individuals (Lohmann, Houlfort, \& De Allegri, 2016). Similarly, Kahn (1990) posited that engaged employees worked harder and longer than disengaged employees. Engaged employees are motivated employees.

Organizational leaders who exercise effective empowerment strategies among employees and engage in the practice of employee development have increased levels of motivation and engagement among employees (Saks \& Gruman, 2014b). The level of the employee in an organization determines the level of empowerment given to the employee. Empowering employees ensures employee motivation and engagement (Saks \& Gruman, 2014b). Psychological empowerment is an important precursor of employee engagement and productivity. More empowerment leads to more engagement and higher levels of productivity (Jose \& Mampilly, 2014).

Jose and Mampilly (2014) conducted a study in support of this finding. The quantitative study involved an attempt to determine if a relationship exists between employee engagement and psychological empowerment based on primary data collected from 101 employees in three service organizations in central Kerala. The findings were that a significant relationship exists between the two elements, employee engagement and psychological empowerment. 
Employees who work in organizations where the culture embraces their participation in decision-making, tend to have more positive attitudes regarding the organization's growth and success. Organizations that have effective motivational programs and strategies to encourage motivation also tend to have a positive organizational culture (Kuranchie-Mensah \& Amponsah-Tawiah, 2016). A positive organizational culture promotes employee engagement (Anitha, 2014). Warrick (2017) argued that a major factor in the success of an organization is its culture. Organizational culture can significantly influence the performance and effectiveness of a company, the morale, and productivity of its employees, and ability to motivate and engage employees.

Kahn (1990) first proposed work engagement as a motivational concept that offered employees positive energy they could devote to their jobs. Positive energy derived through the right kind of motivation can result in engaged employees and positive organizational performance (Kahn, 1990). Leaders who do not feel motivated may find difficulty motivating their employees (Sarros, Luca, Densten, \& Santora, 2014). Various factors affect employee motivation, including work environment, behavioral influence, and relationships (Sarros et al., 2014). Leaders who value and develop employees may realize improved organizational performance as the employees tend to engage (Sarros et al., 2014). A relationship exists between motivation and employee engagement, and managers must address both motivation and employee engagement simultaneously (Evangeline \& Ragavan, 2016). 


\section{Leadership and Employee Engagement}

Chughtai (2014) pointed out that scholars spent limited time identifying leaderships' role in promoting work engagement. Chughtai noted further that gaps exist in the literature and scholars must investigate the subject further. Regardless of the gaps in the literature, the consensus among some scholars is that employee engagement is key to the success of organizations because increased engagement drives improved productivity and profitability (Griffin et al., 2015; Oswick, 2015). Saks and Gruman (2014a) found that employee engagement is imperative to the survival of organizations; businesses with unengaged employees have a higher failure rate than organizations with engaged workers. Rayton and Yalabik (2014) argued that the quality of the relationship between leaders and employees determine the extent to which employees engage.

Business leaders face the challenge of determining how best to motivate and to encourage engagement among employees (Eneh \& Awara, 2016; Galuska, 2014; Maghraoui \& Zidai, 2016). The success of organizations depends on many factors. One such factor is the leader (Mehmood, Nawab, \& Hamstra, 2016). Leadership style may be the most important factor in determining whether employees engage. Employees act and behave according to the style of the leader. According to Anitha (2014), a strong correlation exists between high levels of employee engagement and effective leadership. Khuong and Yen (2014) found that the higher the levels of employee sociability, ethical leadership, and visionary or transformational leadership, the higher the levels of employee engagement. 
Breevaart et al. (2014) sought to measure the effect of leadership style on employee engagement by examining the impact of transformational leadership on the engagement of 61 military cadets in their work. Breevaart et al. found that the cadets were more engaged on days when the leader demonstrated a transformational leadership style. Schaubroeck, Lam, and Peng (2016) supported these findings and noted that transformational leaders have a positive effect on employee engagement and productivity. Khuong and Yen (2014) in contrast noted that no significant correlation exists with the transactional style of leadership and employee engagement.

Mozammel and Haan (2016) conducted a study in the banking industry in Bangladesh. This quantitative study aimed to determine the connection concerning transformational leadership and engagement among personnel in the banking sector in Bangladesh. Like Singh (2015), Mozammel and Haan found no real correlation between transformational leadership and employee engagement. Mozammel and Hann suggested that culture, geography, and industry could determine how transformational leaders affect employee engagement. The findings of this study showed that in a work environment, applying transformational leadership style is not a guarantee that the employees will fully engage. The results of the current study, however, do not reflect the existing body of literature on transformational leadership and employee engagement (Mozammel \& Haan, 2016).

Anitha (2014) found that employee engagement levels are directly related to an organization's work environment and that leaders determine an organization's culture. A leader has the ability to change the direction of a company (Mehmood et al., 2016). 
Leadership can therefore alter the direction of an organization if they understand the appropriate strategies to engage employees (Ahmed, Phulpoto, Umrani, \& Abbas, 2015).

Organizations rarely succeed in the absence of effective leadership, and organizations need leaders who lead with purpose and motivate their employees (Mehmood et al., 2016). Galuska (2014) found that many organizations lacked effective leaders. Effective leadership comes from adhering to sound leadership practices (Eldor \& Vigoda-Gadot, 2016). Eldor and Vigoda-Gadot (2016) noted further that when leaders acquire the ability to engage employees and realize high performance from employees, both employee performance and organizational performance increase.

Eldor and Vigoda-Gadot (2016) conducted a cross sectional study in Israel in which they presented a framework that positions employee engagement as a potential key mechanism to explain the relationship between employees and their organizations in the contemporary organizational setting. Using an interactive sample of 573 public sector and private sector employees, the findings were that employee engagement is a significant concept for researchers and practitioners because it promotes a variety of ideas about the meaning of the employee-organization relationship in the organizational setting (Eldor \& Vigoda-Gadot, 2016). These findings concur with Kahn's (1990) claim that engagement represents a mutually beneficial employee-organization relationship that sees the employee as a key party.

Organizational leaders must create an environment, in which employees deliver their best performance for the company every day (Eldor \& Harpaz, 2016; Panchanatham \& Jayalakshmi, 2016; Yeh \& Huan, 2017). Anitha (2014) identified seven areas of focus 
that leaders can use to secure employee engagement and productivity to include (a) work environment, (b) leadership, (c) workplace well-being, (d) team and coworker relationships, (e) training and career development, (f) compensation, and (g) organizational policies. Leaders should focus on these areas to motivate their employees to engage (Anitha, 2014). Bhuvanaiah and Raya (2015) suggested that when leadership creates the appropriate work environment and opportunity and guides employees to accomplish personal goals, employees engage.

Kahn (1990) also supported the notion of having an appropriate work environment, opportunities, and appropriate tools if employees are to engage. Kahn posited that employees decide to engage or not depending on whether the work is meaningful. Meaningfulness reflects the level of satisfaction with the activity, the respect and self-worth that the employee experiences on the job (Zhang et al., 2014). Bolarinwa (2015), similar to Kahn and Zhang, identified meaningfulness, safety, and availability of resources as the three psychological conditions leaders needed to align to engage employees.

Differing opinions exist in the literature regarding the impact of leadership on employee engagement. Bolarinwa (2015) noted that this topic requires more scholarly research. The lack of research resulted in a gap in knowledge that serves as an opportunity for researchers to investigate further (Bolarinwa, 2015).

Burch and Guarana (2015) conducted a study with a longitudinal design in Brazil that included employees from a large multinational technology firm. The administration of the questionnaire took place in two phases, and the study included target populations 
of 379 and 292 respectively. Burch and Guarana (2015) investigated the influence of leaders on their followers' engagement and introduced leader-follower relationship quality (LMX) as a predictor of follower engagement. The conclusions, which supported Rayton and Yalabik (2014) were that a relationship exists between leader and follower that could affect both employee outcomes and organizational outcomes (Burch \& Guarana, 2015). The finding provided evidence to support the relative importance of the leader's relationship with followers compared with transformational leader behaviors in predicting follower engagement (Burch \& Guarana, 2015).

The study contributes to the current understanding of how leaders help their followers to engage in their work, on follower engagement levels, and how employee perceptions of leadership affect engagement. The study contributes to the present research, but it has some weaknesses. One such weakness is that it cannot test whether transformational leadership or LMX caused higher levels of follower engagement. The strength of the Burch and Guarana (2015) study is that while the participants were from Brazil, Burch and Guarana reproduced the findings in Europe and the United States. To increase employee engagement, leaders must understand what effective strategies increase engagement (Kumar \& Pansari, 2015). Saks and Gruman (2014b) noted that scholars failed to agree on a single definition of employee engagement, while academics failed to agree on the leadership strategies that increase employee engagement (Carasco-Saul et al., 2015). Regardless of this lack of agreement, Farrell (2016) agrees that business leaders and employee engagement are key drivers for the success of an organization. Engagement cannot exist without leadership (Howell, 2017). In Kahn 
(1990), Kahn supported Farrell (2016) and Howell (2017) when Kahn suggested that leaders need to provide the appropriate environment, psychological conditions, and resources to ensure engagement. Leaders who do not encourage and achieve employee engagement cannot achieve and sustain a competitive advantage (Nair \& Salleh, 2015)

Leadership involves a two-way process between a leader and a follower (Wang, Tsai, \& Tsai, 2014). Leaders must exercise moral behavior and engender trust and respect (Huertas-Valdivia et al., 2018; Khuong \& Dung, 2015). Leaders guide employees through task and role clarification, inspire employees through self-development, and allow employees to make decisions (Wang et al., 2014).

Leadership has varying definitions because there are varying leadership styles (Wang et al., 2014). Mo and Shi (2017) found that leaders' ethical behaviors affected employees' attitudes; which affected employee engagement. Wu (2017) discovered that by engaging in ethical leadership, leaders increased employees' initiatives and in so doing, increased employee engagement. Khuong and Yen (2014) found that ethical leadership, and visionary leadership correlated with higher rates of employee engagement. Khuong and Yen therefore contended that visionary and ethical leadership, such as transformational leadership required more focus regarding employee engagement than the transactional style of leadership.

Agarwal (2014) conducted a quantitative study of 323 managers working in manufacturing and pharmaceutical organizations in western India. Using social exchange theory as a base, Agarwal examined the mediating role of trust in the justice-engagement relationship and the effect of work engagement on employees' innovative work behavior. 
The findings from the Agarwal (2014) study were that justice positively related to work engagement with trust as the mediating element. Engagement significantly influences employees’ innovative work behavior (Agarwal, 2014).

McManus and Mosca (2015) supported and expanded on Agarwal's (2014) view by suggesting that the development of (a) trust, (b) equitable treatment, (c) positive recognition, (d) focus on goal attainment, and (e) the continued development of the knowledge and skill of employees are necessary to increase employee engagement. Trust in particular influences whether employees engage in the workplace (Hough, Green, \& Plumlee, 2015). Trust must be a two-way process whereby a leader trusts an employee and an employee trusts a leader for engagement to exist (Hough et al., 2015). The environment must be trustworthy for employee engagement to increase (Downey, Werff, Thomas, \& Plaut, 2015). Hough et al. (2015) conducted an original study that involved combining the measure of the ethical environment, organizational trust, human resources practices, and employee engagement in a comprehensive model. Hough et al. (2015) found a significant positive relationship between the employees' perception of the ethics of the organization and the trust given by the employee, regarding employee engagement.

Other researchers such as McManus and Mosca (2015) and Khuong and Dung (2015) support the concept of trust being a catalyst for employee engagement. In contrast, Pollitt (2014) noted that trust does not always translate to employee commitment and engagement in the workplace. Hough et al. (2015) argued however, that trust can positively and significantly impact engagement; while mistrust encourages disengagement. Employees who trust their leaders demonstrate higher levels of 
engagement (Downey et al., 2015). Hsieh and Wang (2015) found a correlation between employee trust levels, authentic leadership, and work engagement. Ugwu, Onyishi, and Rodriquez-Sanchez (2014) found that trust in the organization and psychological empowerment are predictors of employee engagement. Leaders must keep their promises to build trust, as the leaders implement strategies to increase employee engagement.

Effective leaders create a working environment that fosters employee engagement, commitment, and satisfaction (Hamid \& D’Silva, 2014). Leaders who encourage worker enthusiasm might positively affect employee engagement and such employees feel engaged and productive (Hamid \& D'Silva, 2014). The basis of these pronouncements resulted from a study of 711 undergraduate Malaysian university students conducted to understand the relationship between leadership attributes and the motivation to lead (Hamid \& D'Silva, 2014).

Hamid and D'Silva (2014) found that leadership training and development gained emotional and cognitive maturity that enabled the students the ability to accept more job types and to engage. This finding is in keeping with Kahn (1990) who suggested that individuals expressed themselves emotionally, cognitively, and physically when engaged, and that employees require appropriate job resources in order to engage. Raj and Srivastava (2017) posited that leadership development programs should cover a broad set of leadership skills and that organizations that offer leadership development programs provide their employees with job resources to increase their engagement, satisfaction, and commitment. Increasing employee engagement and productivity is the continuing 
responsibility of leaders and requires a long-term commitment by leaders and human resources managers (Keeble-Ramsay \& Armitage, 2015).

Leaders must create an environment that encourages employees to participate in the organization's decision-making process (Parker et al., 2015). By increasing employee engagement, employees' organizational commitment increases (Wu, 2017). Parker et al. (2015) found from a study that leaders can increase employees' organizational commitment by creating an environment that promotes employee engagement. Wray (2016) concluded that organizational success occurred when leaders know how to increase employee engagement. Leaders must take a genuine interest in understanding the requirements of employee engagement (Bolarinwa, 2015), and leaders must be supportive of followers. Bolarinwa (2015) suggested three psychological conditions of which leaders must be cognizant, if they have a genuine interest in promoting employee engagement. The conditions include (a) meaningfulness, (b) safety, and (c) availability of resources as the three psychological conditions leaders need to engage employees.

Carasco-Saul et al. (2015) discussed the relationship between leadership and employees and concluded that the relationship was key in supporting organizational effectiveness. Mikkelson, York, and Arritola (2015) and Gollan and Xu (2015) suggested that gaps exist in the research because they could not link the behaviors of leadership and the behaviors of employees. Other researchers emphasized the need for additional research on the relationship between leaders' behaviors and the influence on followers' engagement (Bolarinwa, 2015). Shepperd, Bowes, and Hall (2014) however, conducted a 
study and found that contrary to previous findings by scholars, leadership behaviors influence employee engagement.

Scholars concluded that transformational leadership behaviors facilitate an increase an employees' level of engagement (Blomme et al., 2015; Shepperd et al., 2014). Transformational leaders exhibit certain behaviors, which lead to employee engagement (a) excellent communication, (b) trust and integrity, (c) a meaningful job, (d) effective and supportive direct supervisors, (e) career advancement opportunities, (f) significant contribution to organizational success, $(\mathrm{g})$ pride in the organization, and (h) supportive colleagues (Liu \& Zhang, 2015).

\section{Transition}

Section 1 included the foundation of the study, the background of the problem, the research question, the interview questions, and the literature review supporting leadership and employee engagement. The section indicated that approximately $70 \%$ of employees in the United States do not feel engaged at work (Adkins, 2015). Research findings in 2014 showed that the lack of engagement potentially cost corporations more than $\$ 300$ billion annually in lost productivity (Radda et al., 2015). The main focus of the literature review was on (a) employee engagement theory, (b) alternative theories, (c) employee engagement, and (d) leadership and employee engagement. In Section 2, I will address the focus of the study and include detailed information about the (a) purpose of the study, (b) role of the researcher, (c) research participants, (d) research method and design, (e) population and sampling (f) ethical research, (g) data collection instruments sample, (h) data collection techniques, (i) data organization techniques (j) data analysis, 
and (k) reliability and validity. Section 3 will include data results from the interviews, conclusions from the study, applications to professional practice, implications for social change, and recommendations. 
Section 2: The Project

\section{Purpose Statement}

The purpose of this qualitative single case study was to explore successful strategies that business leaders in the life insurance industry in Florida, use to overcome and mitigate the challenges of disengaged employees and to encourage employee engagement. The population consisted of six leaders who had worked in executive leadership at ABC Corporation in Florida, for a minimum of 5 years. These leaders had successfully implemented strategies to engage employees. The findings could contribute to social change by providing business leaders with possible solutions for improving organizational performance and retention, providing job opportunities within the local community, and contributing to the stability of the local economy.

\section{Role of the Researcher}

The researcher is the primary data collection instrument in a qualitative study (Houghton, Casey, Shaw, \& Murphy, 2013; Yin, 2014). Researchers recruit participants and collect, organize, and interpret data (Yin, 2014). Regardless of the method used for a research study (qualitative, quantitative, or mixed methods), a researcher must gather information for analysis from human subjects (Abildgaard, Saksvik, \& Nielsen, 2016). As the researcher, I conducted all aspects of the research, including developing the interview questions and identifying, recruiting, and interviewing the participants who participated in the data collection through open-ended, semistructured interviews. Openended, semistructured interviews are suitable for qualitative research and allow participants to speak freely within appropriate boundaries (Yin, 2014). 
No preexisting relationships existed between myself and the participants. It is incumbent on a researcher to be able to develop a quick rapport and trust with participants (Yin, 2014). An association existed with some of the senior leaders at the parent company of ABC Corporation, but these individuals did not participate in the study.

Researchers must act responsibly and with integrity. When gathering data from participants for research studies, it is important to ensure the highest ethical standards (National Commission for the Protection of Human Subjects of Biomedical and Behavioral Research, 1979). The protocols set out in the Belmont report provide the basis for working with participants (Bromley, Mikesell, Jones, \& Khodyakov, 2015; U.S. Department of Health and Human Services, 1979). I followed the guidelines that indicate the importance of respect for persons, beneficence, and justice (National Commission for the Protection of Human Subjects of Biomedical and Behavioral Research, 1979). Participants must feel respected and must understand what to expect during and after a study.

As noted in the Belmont report (National Commission for the Protection of Human Subjects of Biomedical and Behavioral Research, 1979), researchers have responsibility for beneficence or the responsibility of not harming participants. Participants who complete consent forms at the outset of the study can gain an understanding of what to expect regarding the purpose of the study, voluntary participation, and confidentiality procedures. Furthermore, according to Bromley et al. (2015), the administration of the procedures in a study must be fair. Beneficence and 
justice are principles of ethical research (National Commission for the Protection of Human Subjects of Biomedical and Behavioral Research, 1979). In this regard, I respected participants' decisions, protected participants from harm, and secured participants' anonymity.

Researchers can successfully mitigate bias by identifying their personal beliefs (Harvey, 2015; Yin, 2014). Failing to understand and mitigate bias can result in negative consequences for data collection, data analysis, and the reliability and validity of the study (Harvey, 2015). I used bracketing as a means of containing any personal experiences and judgment, and my focus was on the information the participants presented and not on presenting my opinion. Yin (2014) pointed out that researchers should be open to different views and opinions to mitigate bias by (a) listening, (b) permitting different views and opinions, and (c) using member checking. This study included the use of member checking. Researchers use member checking to verify the accuracy of their interpretations of the participants' experiences (Elo et al., 2014; Harvey, 2015).

The study included an interview protocol to assist in mitigating any biases in the interview process and to ensure consistency in conducting the interviews (see Appendix B). Qualitative researchers must be cognizant of any biases or potential biases and must mitigate these biases as part of any study (Silverman, 2015). Personal bias may pose a risk with a case study design because of a reliance on interactions with the participants (Silverman, 2015). Researchers need to mitigate personal bias by exposing any bias that they cannot eliminate (Harvey, 2015). I attempted to mitigate bias further by audio 
recording the interviews to assist in obtaining accurate information directly from the participants.

Data collection continued until saturation occurred. Data saturation occurs when no new information or potential themes, codes or patterns emerge in the study (Fusch \& Ness, 2015). I exhausted the number of participants until data saturation occurred.

\section{Participants}

Qualitative research requires participants who have knowledge of the topic and experience in the phenomenon (Gentles, Charles, Ploeg, \& McKibbon, 2015; Yap \& Webber, 2015; Yin, 2014). Researchers should recruit and select participants using specific eligibility criteria (Dasgupta, 2015; Khidir et al., 2016; Yin, 2017). The purpose of this research study was to explore the successful strategies that business leaders use to overcome and mitigate the challenges of disengaged employees and to encourage employee engagement. The knowledge and experiences these leaders shared added value to the study. The participants met the eligibility criteria within the scope of this study.

Participants were from one business entity in Florida, and they were selected by purposeful sampling. The participants were leaders at the senior management level who successfully implemented employee engagement strategies at the organization. The persons selected offered information that helped to answer the overarching research question (Roulston \& Shelton, 2015). Additionally, participants' characteristics aligned with the central research question (Roulston \& Shelton, 2015). This eligibility criterion therefore aligned with the purpose of the research study. 
Walden University's Institutional Review Board (IRB) approved the study and granted permission for me to contact any potential participants. Upon receiving approval, I approached the chief executive officer of the company in person to provide information about the study, including the purpose of the study; to seek permission to pursue the study at $\mathrm{ABC}$ Corporation; to point out the various ways available for use to protect the confidentiality of the corporation and its participants; and to gain access to the appropriate individuals who fit my study's eligibility criteria. Solicitation of the participants occurred through e-mail.

Participants received and signed a consent form to indicate their willingness to participate in the study, with the understanding that they could withdraw at any time during the interview or the study and that their participation was voluntary. The study included the use of the same criteria to select all participants. A researcher uses the consent form to outline the purpose of the study and explain why the research is important for the individual, business, and community (Nel, Stander, \& Latif, 2015). I used the consent form for this purpose.

As suggested by Hennink, Hutter, and Bailey (2015), I informed participants that they need not respond to a question if the response made them uncomfortable in any way. The interviews took place in person, and although there was an hour available for each interview, participants were aware that no time limits existed within the interview. Use of the interview protocol and interview questions ensured consistency.

Developing a working relationship with the participants included open communication, which helps to minimize misinterpretation and bias and can foster a 
spirit of trust (Guillemin, Gillam, Barnard, Stewart, Walker, \& Rosenthal, 2016; Hennink et al., 2015; Yin, 2014). Prior to the actual interviews, I made contact by phone to ensure full disclosure of the purpose of the study, to respond to any concerns that may arise, and to explain the confidentiality procedures. Building trust and ensuring that participants are comfortable in their environment augurs well for the goal of receiving reliable information (Guillemin et al., 2016). Participants should choose the time, place, and date for an interview (Yin, 2014). The participants in this study chose their organization's private conference room for their interviews.

Participants had the opportunity to review and comment on the results and to provide feedback on the interpretation of their interview data through a process to help ensure the validity and reliability of the data; this also allows participants to feel a sense of being a meaningful part of the study. The process described is member checking (Marshall \& Rossman, 2016). The member checking process involved a follow-up faceto-face interview with each participant. This face-to-face interview allowed participants to provide feedback regarding whether the data documented interpreted their responses accurately. The follow-up interviews were no longer than 20 minutes for each participant. Member checking allowed for the validation of the data collected (Marshall \& Rossman, 2016). Researchers often use member checking in their research design to assist in minimizing bias (Elo et al., 2014).

All data will remain confidential and secured in a locked cabinet for destruction after 5 years. As the researcher, I will have sole access to the locked cabinet, and I 
assured the participants that their identities would remain in strict confidence. This assurance adheres to the ethical principles of research (Olsen, Lehto, \& Chan, 2016).

\section{Research Method and Design}

Researchers select a research method that permits them to identify the goals of a study and answer the research questions (Yin, 2014). The principal research methods are qualitative, quantitative, and mixed methods (Yin, 2014). Researchers use the qualitative method to (a) understand human experience, (b) engage participants, (c) observe their behaviors, (d) understand their motivations, (e) observe their practices, (f) understand the employees' personal connection to the organization, and (g) understand a phenomenon (Taylor, Bogdan, \& DeVault, 2015).

Researchers use the qualitative research method to study participants in their environment to gain a better understanding of the factors that contribute to their situation (McCusker \& Gunaydin, 2015; Opsal et al., 2016). Through qualitative research, researchers can understand and interpret individuals' thoughts, experiences, and feelings (Opsal et al., 2016). Qualitative research can include many data collection sources, which facilitate methodological triangulation (Yin, 2013). For this study, I used semistructured interviews with open-ended questions and archival documents and other company documents, e.g., appraisal reports, strategic plans, and other human resource documents, from the company under study. Qualitative researchers use conversation and active listening to gain a better understanding of a phenomenon (McCusker \& Gunaydin, 2015).

The objective of this research was to explore the strategies business leaders use in the life insurance industry in Florida, to engage employees. I used a qualitative research 
method for this study. The use of the qualitative method to study the strategies used to engage employees is supported by Shuck and Reio (2014), who examined employee engagement in different workplaces, and Kahn (1990), who conducted research over 25 years on the topic of employee engagement using a qualitative methodology and a case study design.

Quantitative researchers use statistical data to examine the relationships between different variables (Larson-Hall \& Plonsky, 2015; Warner, 2016) and to accept and reject hypotheses (Yakubovich et al., 2015). Quantitative researchers use (a) random sampling, (b) surveys, (c) experiments, (d) questionnaires, (e) direct observation, or (f) social network analysis to gather their findings (Halcomb \& Peters, 2016). Quantitative researchers carry out experiments, test hypotheses, compare variables and measure the frequency of observations (Raheim et al., 2016; Yakubovich et al., 2015), and many researchers consider quantitative research to be more rigorous than the qualitative method (Larson-Hall \& Plonsky, 2015; Yin, 2014). This study required neither testing hypotheses nor comparing variables. Researchers, including Jose and Mampilly (2014) and Kim et al. (2016), conducted quantitative research on employee engagement. Quantitative research on employee engagement is important when seeking evidence-based outcomes that drive performance (Willgens et al., 2016). Researchers, when determining the research method, must consider the overarching research question (Yin, 2014). To explore strategies for employee engagement, quantitative data was not be necessary, and therefore I did not select the quantitative method. 
Mixed method studies involve a combination of qualitative and quantitative methods, and researchers must have the skills to pursue both quantitative and qualitative research (Lewis, 2015; Morse, 2015a; Yin, 2013). Mixed methods research involves validating results using two methods. These studies are time-consuming, costly, and require larger sample sizes for the quantitative method section than one would use for a qualitative study (Goldman et al., 2015; Morse, (2015a). The time required to complete both a quantitative study and a qualitative study is much longer than the time required to conduct only a qualitative study. Therefore, the mixed method did not meet the requirements for this study.

Qualitative research has four principal research designs: case study, phenomenology, ethnography, and narrative (Petty et al., 2012). I selected the case study design after carrying out an assessment of the other three designs. A case study design allows researchers to investigate the case or cases and to understand how or why a phenomenon occurs (Yin, 2017).

A phenomenological design involves exploring the lived experiences of several participants in multiple organizations using a single data source (Gentles et al., 2015; Marshall \& Rossman, 2016). Phenomenological research involves exploring the generalizations of a phenomenon described by the participants, but the generalizations do not represent a proven case in which the particular phenomenon occurred (Marshall \& Rossman, 2016).A phenomenological design is appropriate to explore the lived experiences of leaders; this study, however, seeks to explore the strategies leaders use to engage employees. A phenomenological approach was therefore not appropriate. 
Ethnographic researchers study cultural groups in their natural environment over a period of time to observe the habits of participants (Eika, Dale, Espnes, \& Hvalvik, 2015; Vogel, 2016). Using this design is costly and time consuming (Thomas, Silverman, \& Nelson, 2015). Ethnography is therefore outside of the scope of this study. The narrative design requires researchers to understand the lives of individuals by interpreting stories of their experiences (Petty et al., 2012); however, interpreting stories of the lives of individuals was not the purpose of this study.

Case study design provides researchers with the opportunity to get close to the participants, who have the conceptual knowledge of the phenomenon under study (Carolan, Forbat, \& Smith, 2016; Marshall \& Rossman, 2016; Yin, 2013). A case study design is a natural approach for conducting business research (Yin, 2014). The flexibility of case studies allows researchers to use multiple data sources to achieve a holistic understanding (Carolan et al., 2016; Yin, 2014). For this reason, case study design has advantages over the phenomenological design, which uses one data source (Yin, 2014).

In a case study, researchers explore issues within the context of an organization and assume reliability in a single case design when concurrence among the criteria exists throughout the data (Vannest \& Ninci, 2015). Reaching concurrence is important for data saturation. To reach data saturation the researcher must have an appropriate sample size and an appropriate sampling technique (Morse, 2015b). Fusch and Ness (2015) however, contended that it is not the sample size, or number of participants, or the quantity of data that determines saturation, but the quality of data determines saturation. Researchers add participants until they reach data saturation (Noohi, Peyrovi, Goghary, \& Kazemi, 2016). 
I reached data saturation using six participants. Purposeful sampling leads to the selection of participants who have extensive knowledge in the area of research (Palinkas et al., 2015). The case study design was therefore suitable for understanding the strategies that business leaders use to engage employees, and I used this design for the study.

\section{Population and Sampling}

The population for this study was six senior business leaders of an insurance company in Florida. These leaders must be able to demonstrate successful experiences with employee engagement in the organization. The leaders selected were the primary decision makers responsible for implementing policy and directing strategy and held senior leadership positions for a minimum of 5 years. The leaders selected had responsibility for different areas across the organization, which allows for diversity in the population, and provides a rich experience. Malterud, Siersma, and Guassora (2016) supported the concept of having a diverse population, with diverse experiences, which Malterud et al. suggested might help to achieve data saturation.

A researcher uses purposeful sampling to recruit participants to engage in the interview process and provide relevant data for a study (Stein et al., 2016). Purposeful sampling involves identifying people who have information specific to a study (Hennink et al., 2015; Palinkas et al., 2015). In purposeful sampling, researchers select participants based on specific criteria (Hennink et al., 2015; Palinkas et al., 2015). The basis for selecting participants should be their ability to provide accurate detailed information about a particular phenomenon, and their ability to respond accurately to the research question to achieve the purpose of the study (Crowe, Inder, \& Porter, 2015; Li \& 
Titsworth, 2015). Purposeful sampling allows those who experienced the phenomenon to discuss the phenomenon with confidence (Elo et al., 2014; Li \& Titsworth, 2015). I used purposeful sampling to select the study participants.

Small sample sizes received support for qualitative exploratory case studies because case study data come from multiple sources, including documents, interviews, direct observations, and participant observations (Yin, 2014). Using small sample sizes in exploratory case studies also received support from Guetterman (2015), who noted that he supported using a small number of individuals to collect information from to generalize the findings to a larger population. Guest et al. (2017) argued similarly in favor of small sample sizes in case studies and emphasized that researchers appreciate the attributes of the case study.

The focus should be on reaching data saturation (Guetterman, 2015; Yin, 2014). Data saturation occurs when additional responses add no new data and no new themes to a study (Fusch \& Ness, 2015; Saxena, 2017). Data saturation is key both to the validity of a study and to the ability to replicate the findings (Guetterman, 2015).

Data collection involved interviewing the six participants face-to-face. Prior to the interviews, the business leaders received information regarding the study, including the study's intended contribution to social change and business. The leaders received eight open-ended questions and were able to ask questions about the study and the process. The participants chose the interview setting. The interviews took place at a time convenient to the participants and were approximately 1 hour. Participants were given more time if 
needed. The interview protocol included asking all participants identical questions to ensure consistency and to assist in determining data saturation.

\section{Ethical Research}

The IRB's responsibility includes ensuring all Walden University research complies with the university's ethical standards as well as U.S. federal regulations. I obtained all relevant approvals from the IRB prior to soliciting participants and prior to collecting data; and all relevant approvals from the $\mathrm{CEO}$ of $\mathrm{ABC}$ Corporation. This process is critical for protecting participants and ensuring researchers operate within ethical standards.

On obtaining the appropriate approvals, prospective participants received an invitation and an informed consent form via e-mail (see Appendix A). The informed consent process allows participants to discuss any concerns prior to agreeing to participate in a study and protects participants from unethical research practices (Blease, Lillienfeld, \& Kelley, 2016; Johnson, 2014; Petrova, Dewing, \& Camilleri, 2016). The consent form provides information on confidentiality associated with participating in the study (Greenwood, 2016). The consent form also includes information on (a) the purpose and nature of the study, (b) the data collection method, and (c) the length of the interviews. I shared with the participants their right, including their right to withdraw if they choose at any time during the study (Aguila, Weidmer, Illingworth, \& Martinez, 2016) by notifying the researcher by e-mail, telephone, or face-to-face communication. Aguila et al. (2016) noted that participants should be able to withdraw without giving a reason and with no consequences expected. Participation was voluntary. Sullivan, Garner, 
and Dubbert (2016) pointed out that the response rate from persons who agree to participate in studies is higher if researchers offer some form of compensation. Participants knew about the voluntary participation prior to agreeing to participate.

Research ethics are important in conducting research (Dongre \& Sankaran, 2016). I conducted this research ethically by following the principles articulated in The Belmont Report (1979) by obtaining the appropriate IRB approval prior to starting the interviews and by adhering to the code of ethics and conduct of the organization. The principles of The Belmont Report (1979) are for persons respect, beneficence, and justice (National Commission for Protection of Human Subjects of Biomedical and Behavioral Research, 1979). Researchers must protect participants from unethical research practices and comply with The Belmont Report (1979), and researchers must treat participants as autonomous individuals (National Commission for Protection of Human Subjects of Biomedical and Behavioral Research, 1979). Each participant who agreed to contribute to the study had the opportunity to review the researcher's interpretation of the responses, before the responses become a final part of the study.

The protection of individuals' identification and the identification of the organization are essential. The identities of both the individuals and the organization must remain confidential (Yin, 2017). To protect the participants and their organization, I coded and disguised their names, by using P1, P2, P3, P4, P5 and P6 for the six participants and referred to the organization using a pseudonym. Allen and Wiles (2016) noted that using pseudonyms to protect the individuals involved in a study projects the importance of the research process to participants. 
I stored signed informed consent forms, transcribed data, and interview recordings on a password-protected flash drive for 5 years, following the completion of the study, before wiping and burning the password-protected flash drive, and shredding any written data. The Walden University IRB approval number is 06-17-19-0529427.

\section{Data Collection Instrument}

As the researcher, I was the primary data collection instrument. The concept of the researcher being the collection instrument received support from Tang, Yang, and Tang (2015), who pointed out that a qualitative researcher is a primary instrument for data collection and analysis. Raheim et al. (2016) and Yin (2017) also supported the concept of the researcher being the primary data collection instrument. The researcher's role in qualitative data collection is important, as a researcher can bring the flexibility and sensitivity needed to the research process and develop relationships to obtain relevant knowledge for the study (Houghton et al., 2013; Koch, Niesz, \& McCarthy, 2014).

Qualitative researchers who are the primary instruments of studies collect data for case studies through six sources. These six sources are (a) documentation, (b) direct observation, (c) archival records, (d) participant-observation, (e) interviews, and (f) physical artifacts (Yin, 2014). Researchers use interviews in qualitative research to collect data (Doody \& Noonan, 2013; Petty et al., 2012; Saxena, 2017). I used eight open-ended interview questions as the primary source of data and second data collection instrument (see Appendix B). Open-ended interview questions may minimize researcher bias (Doody \& Noonan, 2013; Petty et al., 2012). Researchers who conduct 
semistructured interviews can ask follow-up interview questions to obtain interpretations that are more accurate (Petty et al., 2012).

As the researcher, I asked probing questions during the interview to allow participants to share their experiences about strategies used to increase engagement. Other company data sources that supplemented the interviews included human resources documents, strategic plans, annual reports, and performance appraisal documents. These types of supporting documents are also data collection instruments (Cleary, Horsfall, \& Hayter, 2014; Yin, 2014). Using various sources for data promotes a rigorous study and allows for triangulation of the data (Gelderman et al., 2015).

The interview questions aligned with the central research question, and participants will be able to describe their experience of applying strategies to engage employees. The interviews will follow the interview protocol (see Appendix B). Using the interview protocol will help to ensure reliability, consistency, and validity. Researchers use protocols to guide and structure interviews (Petty et al., 2012; Yin, 2014). I received approval from the IRB, and participants signed forms confirming their consent, prior to commencing the interviews.

I used member checking to ensure the validity of the data acquired during the interviews (Simpson \& Quigley, 2016). Årlin, Börjeson, and Östberg (2015) identified member checking as a process used to validate the interpretations, and to check preliminary results to increase validity and credibility. Member checking gives participants the opportunity to examine the data from the interview and to amend as necessary (Elo et al., 2014; Houghton et al., 2013; Yin, 2013). Member checking also 
helps to mitigate personal biases, increases the validity and reliability of a study (Elo et al., 2014; Houghton et al., 2013; Marshall \& Rossman, 2016), and helps to ensure trustworthiness of the research instrument (Marshall \& Rossman, 2016).

Qualitative researchers use multiple sources for triangulating the data, which further increases the reliability and validity of a study (Yin, 2014). The use of multiple sources also received support from Morgan, Pullon, Macdonald, McKinlay, and Gray (2016). Hunt, Chan, and Mehta (2011) presented a number of steps to conduct successful interviews. I followed these steps. The steps are (a) think critically and reflectively on prior interview experience; (b) prepare prudently for the interview; (c) be mindful of the power dynamics within the interview; (d) be diligent by being attentive to the language and verbal cues; and (e) evaluate the progress of the entire process on an ongoing basis.

\section{Data Collection Technique}

This study seeks to determine the successful strategies that business leaders use to engage employees. The participants included six business leaders who work at ABC Corporation, selected through purposeful sampling. Interviews may be structured, unstructured, or semistructured (Koch et al., 2014). I conducted face-to-face, semistructured, interviews for each participant. The interviews occurred at a time and in a place that is comfortable, convenient, and mutually acceptable.

Initial face-to-face contact with participants is important in building trust. Doody and Noonan (2013) indicated that researchers establish confidentiality by understanding when to solicit more information, respecting participants' time, and allowing participants to speak freely, which builds trust and confidence. The interview questions were open- 
ended to secure the views and opinions from the participants. One advantage of face-toface interviews is to provide an understanding of a whole phenomenon (Saxena, 2017). One disadvantage of face-to-face interviews in qualitative research is that it could take a long time to transcribe the recorded interviews (Harvey, 2015; Saxena, 2017).

I used archival documents and other company records as support data, which facilitated triangulation. Using archival data provides access to company engagement information that is not available in public records (Doody \& Noonan, 2013). The disadvantage is that researchers must take care with archival and company information to ensure it is accurate, complete, and not outdated (Doody \& Noonan, 2013).

Each open-ended interview took approximately 1 hour, although participants were able to speak for longer. Interviews have advantages when researchers seek to understand the experiences of participants. Face-to-face interviews also allow an assessment of body language and tone of voice (Doody \& Noonan, 2013). Field notes supported making comments on body language and tone (Yin, 2014), and allowed the ability to determine how I should probe.

Yin (2014) indicated that the interviewing process potentially allows for bias, which presents a potential disadvantage for the use of this technique. Other disadvantages include receiving inaccurate information, especially from participants who may be reluctant to share their true feelings (Doody \& Noonan, 2013). Researchers, therefore, must first establish trust, ask probing questions, and use other sources to triangulate the data (Doody \& Noonan, 2013). The study did not include a pilot study. Pilot studies are trial runs the researcher uses to conduct a pretest of the research instrument (Van 
Teijlingen \& Hundley, 2015). Instead, I followed the interview protocol without exception.

I recorded each interview with my Livescribe Smartpen digital recording device and used my smart phone as a backup. Using a digital recording device allows researchers the ability to observe nonverbal expressions that could be useful in interpreting the results or in seeking further clarification during member checking. This process complies with methods recommended by Yin (2014). Before the project commenced and before the interviews started, participants knew that their names and the name of the corporation would remain unknown.

The study used an interview protocol. A researcher uses the interview protocol to build rapport to provide an investigative interview of the chosen participants (CastilloMontoya, 2016). The day before each interview, all participants received an e-mail reminding them to prepare for a semistructured interview, that will last 30 minutes to an hour. I requested a response to the e-mail acknowledging receipt of the information and confirmation that the participant would participate.

Prior to starting each interview, and to presenting the project again to each participant, each participant gave approval for the use of an audio recorder. I asked only one question at a time, ensured that the participants' responses were exhaustive before proceeding to the next question and avoided expressing any emotions during the interview to avoid bias. Taking notes and checking the audio recorder from time to time to ensure that it was working are part of the interview process. The interview process also included transcribing the recorded information to a Word document. 
Member checking involves participants reviewing, agreeing, or correcting if necessary, the interpretation of the data and the way the responses addressed the research question (Marshall \& Rossman, 2016). Member checking encourages the accuracy and relevance of participants' responses, as well as the reliability and validity of the data (Marshall \& Rossman, 2016). Member checking is important for the data collection technique, as it permits the transferability and credibility of the interview data (Carter, Bryant-Lukosius, DiCenso, Blythe, \& Neville, 2014; Morse, 2015a). I used NVivo 12 to identify and analyze the significant themes, to code the data and to understand and connect themes from the transcribed data, thereby contributing to a more effective data analysis process.

\section{Data Organization Technique}

Data organization includes (a) data checking, (b) journalizing, (c) transcribing interview responses into a Word document, and (d) entering data into the qualitative software NVivo 12. NVivo is data analysis software used by qualitative researchers to analyze qualitative research by managing data, revealing themes, querying ideas, graphically modeling ideas and concepts, and reporting the data (Woods, Paulus, Atkins, \& Macklin, 2015). Transcriptions of the data collected from the interview must match what participants said in their interview. I took notes at each interview. Taking notes can assist with data analysis and enriches the interview details (Leech, Collins, \& Onwuegbuzie, 2014).

For anonymity, each participant had a label P1, P2, P3, P4, P5, and P6 and the company, ABC Corporation. I stored the transcribed data by code, date, and time for each 
interview, and use the information from the audio recording to transcribe the data into a Word document and stored it on a password-protected USB flash drive before uploading the data to NVivo 12 for further storage, to code and identify the various themes. The transcripts contained no sensitive information. All documentation including company information and instruments relating to the study will remain in a locked fire-proof filing cabinet for a period of 5 years before destruction, in accordance with Walden IRB guidelines.

\section{Data Analysis}

Researchers examine multiple sources of data when they employ a case study design (Johnson, 2015; Petty et al., 2012; Yin, 2014). The data comprise the basis of the analysis from which the findings of the study will develop in a final report. Data analysis involves working through data to discover common themes and patterns that answer the research question (Johnson, 2015; Petty et al., 2012; Yin, 2011).

Triangulation and member checking are key elements of the data analysis process to ensure reliability and validity (Yin, 2017). The study includes methodological triangulation, which allowed the use of at least two data collection procedures, interviews and company documents, and to examine the topic from different perspectives. According to Fusch and Ness (2015) researchers who triangulate data examine a topic from different perspectives. Methodological triangulation involves the use of multiple methods of data collection including interviews and observations (Modell, 2015). I achieved methodological triangulation through interviewing six participants, taking field 
notes, reviewing archival and company data, and by examining the interview notes to ensure validity during the data analysis.

Data coding is an important part of data analysis in qualitative research (Johnson, 2015; Potestio et al., 2015; Yin, 2013). I compared, contrasted, and analyzed the responses to the interview questions. The goal of researchers is to find common themes from the experiences of participants (Petty et al., 2012). Yin (2013) noted that data analysis consists of (a) examining, (b) categorizing, and (c) tabulating, to deal with the research question of a study. The study included the data analysis process proposed by Yin (2011) and supported by Marshall and Rossman (2016). Yin (2011) described five steps in the process: (a) compile, (b) disassemble, (c) reassemble, (d) interpret, and (e) conclude.

After collecting the data, I performed analysis to identify themes and patterns that respond to the research question, which follows: What strategies do business leaders use to engage employees? The actual categories that emerged depended on the data obtained. The study included importing the transcripts into NVivo 12 from a Word document before compiling the data. NVivo 12 is a qualitative analytic tool that researchers use to code themes, collect ideas, and make comparisons between words and phrases from interviews (Thomas et al., 2015). The software provides a single point of entry for all data (Woods et al., 2015). In addition, I used the software to store all data pertaining to the study. Compiling means organizing the data (Yin, 2011). After compiling the data, I disassembled the data and begin to code. In this process, as suggested by Yin (2011), I identified and assigned descriptive words to the data and then grouped the data to allow 
the themes to emerge. NVivo 12 has an auto-coding feature, which is useful for identifying similarities and inconsistencies in data and themes (Woods et al., 2015) The study used this auto-coding feature.

Having dissembled the data, the next step according to Yin (2011) is reassembling. Reassembling involved examining the data in various ways to allow themes to emerge (Yin, 2011). I then analyzed and interpreted the data (Yin, 2011). The last step in the data analysis process is concluding, which required documenting the themes in sequence (Yin, 2011) and in accordance with the conceptual framework. The interview questions that support the data that responded to the research question appear in Appendix B. To promote triangulation, the study involved reviewing certain company documents and archival materials. I therefore analyzed the interview responses, and company reports and archival data on (a) employee job satisfaction, (b) motivation, (c) absenteeism, (d) turnover, and (e) and productivity and engagement. The conceptual framework for this study is Kahn's (1990) theory of employee engagement. For completeness, there should be some congruence or link between the conceptual framework, the literature review, and the research question. This was achieved by examining and correlating themes (Teruel, Navarro, González, López-Jaquero, \& Montero, 2016). Data analysis focuses on the research question. Kahn (1990) proposed that the working environment affects how employees respond to their work. When conditions are optimal, employees respond positively. Kahn's engagement theory aligns with this study. 


\section{Reliability and Validity}

In qualitative research, reliability and validity are important factors when designing studies, analyzing the results, and determining the quality of the studies (Kornbluh, 2015). Researchers establish reliability and validity by addressing Lincoln and Guba's (1985) accepted criteria of dependability, credibility, transferability, and

confirmability. Reliability and validity relate to dependability, credibility, transferability, and confirmability (Noble \& Smith, 2015). A relationship exists between reliability, validity, and trustworthiness (Koch et al., 2014), and Noble and Smith (2015) and Morse (2015a) pointed to the fact that researchers use varying methods to ensure the reliability and validity of research. Researchers must address such elements in qualitative research (Houghton et al., 2013; O’Reilly \& Parker, 2013; Yin, 2013). Conducting a comprehensive examination of data helps to ensure the trustworthiness and relevance of the findings, conclusions, and recommendations (Houghton et al., 2013; Noble \& Smith, 2015; Yin, 2014).

\section{Reliability}

Ensuring reliability can be challenging because of the various methodologies used in both quantitative and qualitative research. Whether researchers conduct qualitative or quantitative research, reliability implies consistency (Elo et al., 2014; Houghton et al., 2013) Consistency refers to the concept that another researcher could use the same procedure to reproduce the study, and obtain similar results (Marshall \& Rossman, 2016). Yazan (2015) indicated that reliability in research means being able to replicate the themes and results of other people in different circumstances. Reliability deals with 
replicability and consistency, as well as the trustworthiness, credibility, and dependability of a research study (Houghton et al., 2013).

Ensuring dependability requires qualitative researchers to justify all aspects of a study, including the purpose, design, and method (Morse, 2015a). Researchers must clearly articulate the various research processes in their studies and all elements of enquiry (Houghton et al., 2013; Yin, 2013). Noble and Smith (2015) noted that providing a transparent and clear description of the research process leads to consistency and neutrality. Research reliability also depends on whether and to what extent a study is free from error (Marshall \& Rossman, 2016; Noble \& Smith, 2015).

A study must be trustworthy. The four elements of trustworthiness are credibility, transferability, dependability, and confirmability (Houghton et al., 2013; O'Reilly \& Parker, 2013). To ensure trustworthiness, I made notes of any decisions and the corresponding sequence of these decisions and maintained a record of all analytical information and the methodological approach and procedures used to arrive at the data. Participants knew of the requirements of the study and noted that compensation was not available. Participants knew that the information they shared would remain in strict confidence. Such knowledge helps with the trustworthiness of the study (Houghton et al., 2013; Petty et al., 2012; Yin, 2014).

Feedback from participants contributes to reliability, validity, and credibility. (Houghton et al., 2013; Yin, 2013). Yin (2015) encouraged qualitative researchers to use member checking over transcript review whenever practical. I used member checking. Member checking also helps to ensure data saturation and allows researchers and 
participants to build trust and develop a rapport (Harvey, 2015). Fusch and Ness (2015) described member checking as a quality control method that qualitative researchers use to validate data retrieved from interviews. Member checking is the preferred data validation method for qualitative interviewers (Morse, 2015a). Morse (2015a) suggested three steps in the member checking process to ensure reliability: (a) perform the initial interview, (b) interpret the data from the participant, and (c) share the interpretation with the participant for validation. I followed the process articulated by Morse to ensure an understanding of the precise meanings of the responses and to make any changes necessary that would clarify the responses.

Triangulating data using multiple sources also contributes to reliability (Carter et al., 2014; Houghton et al., 2013; Yin, 2013). Confirmability and dependability, which are two elements of trustworthiness, result from ensuring data obtained from multiple, independent sources are accurate, as supported by Kornbluh (2015), who suggested that accurate data is important in qualitative research. Elo et al. (2014) noted that readers determine dependability by evaluating the consistency and transparency of the data. I ensured confirmability and dependability by documenting all changes and triangulating the sources leading to consistent themes (Carter et al., 2014; Elo et al., 2014; Houghton et al., 2013). Further, using (a) the interview protocol, (b) recording the interviews, and (c) replicating the data collection process, facilitated dependability (Elo et al.,2014).

\section{Validity}

Dwork et al. (2015) noted that qualitative researchers could increase the quality of their study by ensuring validity. Validity requires (a) accuracy of reporting, also called 
the descriptive element, (b) interpreting the views, thoughts, and experiences of participants, also referred to as the descriptive element, (c) the application and explanation of the theoretical framework, also called theoretical validity (Elo et al., 2014). Leung (2015) indicated that (a) the appropriateness of the design and method selected, (b) the sample size, (c) data collection and (d) the results, determine validity of the study. Noble and Smith (2015) discussed two aspects of validity: internal and external. Noble and Smith indicated further that internal validity refers to credibility, and external validity refers to transferability.

Researchers use credibility to determine if any association exists between the originating data sources and the researcher's interpretation (Simpson \& Quigley, 2016). Credibility relates to the methodological procedure used to establish a significant level of consistency between participants' responses and a researcher's interpretations (Houghton et al., 2013; Marshall \& Rossman, 2016; Petty et al., 2012). Nyhan (2015) pointed out that researchers consider credibility as the measure of trust readers have in the data findings of a study. To achieve credibility, Morse (2015a) suggested the use of member checking while Yin (2013) suggested that researchers record the participant interviews and maintain copies of such recordings. I followed these procedures.

Elo et al. (2014) noted that believability and value of data within a study ensure credibility of the study. Qualitative researchers need to incorporate different strategies to ensure validity if they expect their research to be robust (Houghton et al., 2013; Marshall \& Rossman, 2016; Yin, 2014). I ensured the credibility of the study by selecting the 
appropriate participants through purposeful sampling. Participants must have had success in using engagement strategies.

I used the appropriate data collection methodology through the open-ended interview questions and ensured the participants' responses were open, complete, and truthful by allowing participants sufficient time to respond as they wish, which contributed to data saturation. Yin (2014) suggested using clear and concise language to improve validity. I followed this suggestion when conducting interviews. Ensuring the elimination of any potential bias is another step that can strengthen credibility (Houghton et al., 2013; Marshall \& Rossman, 2016; Yin, 2014).

I clarified my background as a past auditor of the parent company, reviewed the data from different perspectives, and used multiple sources of data to effect triangulation of the data (Marshall \& Rossman, 2016) and to ensure data saturation. Yin (2014) suggested that methodological triangulation increases the validity in case studies. I used methodological triangulation. Data saturation occurs when no new data or themes emerge (Fusch \& Ness,2015), which reflects credibility in the study (O’Reilly \& Parker, 2013). The participants were able to clarify the interpretation of their responses, as necessary. This process is member checking (Houghton et al., 2013; Marshall \& Rossman, 2016). Member checking, methodological triangulation and data saturation assist researchers to increase the validity of the case study (Marshall \& Rossman, 2016; Yin, 2014).

Future researchers will determine the external validity or transferability of this study, as transferability is important to qualitative researchers (Elo et al., 2014). To a significant extent, other researchers and those who read this study will determine the 
extent of transferability as they think fit as noted by Marshall and Rossman (2016), Noble and Smith (2015), and O'Reilly and Parker (2013). To increase transferability, I chose the participants carefully to ensure their relevance to the context of the study and findings and will document clearly and concisely the description of the sample for the study, in accordance with Houghton et al. (2013) and Petty et al. (2012).

Thick descriptions contribute to transferability by making it easier for other researchers to replicate the study by transferring the findings to their studies and by demonstrating a clear relationship between the research topics under study (Prion \& Adamson, 2014; Yin, 2014). Marshall and Rossman (2016), noted that by providing a detailed description of the research context, researchers can achieve transferability. This study includes thick descriptions, an interview protocol, and an audit trail, which as noted by Trainor and Graue (2014) facilitate transferability.

Qualitative researchers also consider confirmability as a part of the validation process (Houghton et al., 2013). According to Simpson and Quigley (2016) confirmability relates to the objectivity and correctness of the information. The study includes documentation of all processes, procedures, and decisions to reduce bias in interpreting the results of the analysis used in this study, and to ensure confirmability. Simpson and Quigley suggested that the process for establishing confirmability and dependability are similar. Researchers ensure confirmability by using the findings resulting from the data from the research and not from the bias of the researcher (Munn, Porritt, Lockwood, Aromataris, \& Pearson, 2014). I used also member checking in this study to ensure confirmability. Successful confirmability indicates that a researcher 
understands the activity from the participants' perspective and the meaning that the researcher attributes to the activity or phenomenon under study (Elo et al., 2014; Houghton et al., 2013; Petty et al., 2012).

\section{Transition and Summary}

The purpose of this single case study is to determine strategies business leaders use to engage employees. In Section 2, I repeated the purpose statement, and discussed my role as the researcher. Further discussions included the participants, research method and design, population and sampling, ethical research, data collection instruments and techniques, data organization techniques, data analysis techniques, reliability, and validity. Data collection consisted of face-to-face interviews with business leaders, and a review of company documentation. The interview questions align with the research question, and member checking and triangulating data through multiple data sources, purposeful sampling, and thick descriptions add to trustworthiness of the research process. Section 3 includes an overview of the study, a presentation of the findings, applications to professional practice, implications for social change, recommendations for action, recommendations for further research, reflections, and a summary and conclusions. 
Section 3: Application to Professional Practice and Implications for Change Introduction

The purpose of this qualitative single case study was to explore strategies to overcome and mitigate the challenges of employee disengagement and to encourage engagement. I used Kahn's (1990) personal engagement theory as the conceptual framework. The findings revealed the successful strategies developed and implemented by leaders at an insurance company in Florida. These strategies, which contributed to an increasingly engaged workforce, were (a) leader-employee relationship in the working environment; (b) effective internal communication and feedback; (c) compensation, awards, benefits, and incentives; and (d) professional training and development to improve employee engagement. Section 3 includes the presentation of the findings, application to professional practice, implications for social change, recommendations for action and further research, personal reflections, and the conclusion of the study.

\section{Presentation of Findings}

The overarching question of this research study was: What successful strategies do business leaders use to overcome or mitigate the challenges of disengaged employees and to encourage employee engagement? I conducted face-to-face semistructured, openended interviews with six business leaders who had experience implementing successful strategies to engage employees. Each interview started with participants reviewing and signing consent forms. I informed the participants of their right to withdraw from the study and reminded them that participation was voluntary. The IRB approved my semistructured open-ended interview questions before the interview process began. 
Participants used a private conference room at the ABC Corporation for the interviews. Using the interview protocol (see Appendix B) allowed each participant to respond to the same questions (Appendix A) in the same order. The interviews lasted approximately 45 minutes, and I achieved data saturation after the fifth interview.

After transcribing and interpreting the data, I used member checking so that participants could validate the data. Participants were coded P1 through P6 to ensure confidentiality. After I transcribed and interpreted all data, participants were able to validate the interpretations of the data through member checking. Member checking consisted of a face-to-face discussion with each participant that lasted approximately 20 minutes. Member checking involved providing participants with interpretations of each of their responses to the interview questions to confirm the accuracy of those interpretations.

The data collection structure used for this study was methodological triangulation. Triangulation involves collecting and reviewing multiple data sources to obtain a more vigorous understanding of a phenomenon (Modell, 2015). In addition to interviewing the participants, I also reviewed the organization's documents, memoranda, flyers, and board minutes relating to human resources, strategic plans, and archival information to corroborate the data.

Yin (2017) specified the following five-step process for data analysis: (a) compile, (b) disassemble, (c) reassemble, (d) interpret, and (e) conclude. I compiled the data received from the interview transcripts, employee handbook, strategic plans, performance reviews, executive committee meeting minutes, human resource committee 
meeting minutes, and extracts of directors' meeting minutes that were relevant to the study. I imported all information into NVivo 12 to analyze the findings. Next, I disassembled the data based on the information received from each participant and reassembled the data by bringing together similar information. For the interpretation process, I used word search, queries, and coding to identify major themes, and I documented the conclusions following interpretation. Four main themes facilitated the response to the overarching research question.

\section{Theme 1: Leader-Employee Relationship}

All six leaders expressed the perspective that the leader-employee relationship is critical in encouraging employee engagement. P1 pointed out that the company was small and leaders encouraged employees to behave like family by socializing and generally supporting each other. The suggestion of being like family also included being respectful, trusting, and friendly. P2 stated, "If leaders were approachable, honest, and trustworthy and treated employees well, the employees develop trust and work hard to contribute to the organization." P2 also noted, "Developing a good relationship with employees puts them at ease, and they get the job done more efficiently and effectively. Employees go beyond the call of duty when necessary." P4 agreed that leaders must listen to their employees, communicate positive messages about their value to the organization, and generally encourage employees.

P3 supported this view by stating, "Although the leader is, within the organizational context, the final authority, when leaders involve employees in decisionmaking, they feel valued, work harder and become engaged." P4 indicated that leaders 
who permit employee involvement in decision making tend to increase employee engagement more than leaders who make all decisions and who practice a top-down approach to management. P5 stated, "I believe that leaders who involve employees in the decision making of their departments or organizations encourage employee engagement." According to P6, employee engagement is essential to the success of an organization. When employees contribute to decision making, their levels of commitment to their organizations' success are higher. This improved commitment is the result of increased employee engagement.

P2 and P4 noted that leaders' perceived honesty is vital to employee commitment and engagement. P2 commented, "Being involved in the decision making encourages employees to believe that there are no hidden agendas by the company. It engenders trust." P4 supported this notion by pointing out that, "if employees are not involved in decision-making, distrust develops, and with distrust comes disengagement. Disengagement results in negative consequences for the organization." A strong correlation exists between involving employees in the decision-making process and employee engagement (Cesario \& Chambel, 2017). Kuruppuge and Gregar (2017) also supported the view that involving employees in decision making results in increased employee engagement.

P2, P3, P4. and P6 felt that, in the current environment, employees are not satisfied with being just another number in an organization. Leaders need to ensure that employees feel a sense of belonging to the organization. Such a connection results in employees feeling engaged and having a sense of purpose. 
P1, P2, P3, and P6 indicated that increasing employees' involvement is crucial because it increases employee engagement, which encourages job satisfaction. P4 stated that there was a circle to consider. Increased employee involvement leads to increased engagement, which leads to increased job satisfaction, which further improves employee engagement. Similarly, decreased involvement leads to decreased employee engagement, which leads to job dissatisfaction, which leads to further decreases in employee engagement. P5 commented, "I find that I can encourage job satisfaction by encouraging employee engagement.” All participants noticed an increase in job satisfaction, organizational involvement, and employee engagement since they started involving employees in decision making. Evidence of this improved relationship emerged in the employee job satisfaction survey, which employees complete annually. The results of this survey were available in the minutes of the human resources committee and reported to the board of directors.

The company's policy and employee handbook showed the leader-employee relationship to be critical to organizational effectiveness. From the minutes, I found that the leader-employee relationship earned a score of three out of five in 2017 , before the implementation of the employee engagement program. At the end of 2018, the score increased to four out of five, which demonstrated that the employee engagement strategies had started to work. By June 2019, the score increased to 4.25. The board minutes noted the increase. Several initiatives appeared in company reports outside of the company's strategic plan, with a goal of ensuring excellent leader-employee 
relationships. All participants considered the leader-employee relationship to be the most influential strategy in employee engagement.

Leaders must be responsible for ensuring the culture in the work environment is positive. Gamero-Burón and Lassibille (2018) supported the notion that leadership can have a positive or negative effect on employees at work, depending on their efforts. Leaders can influence employee engagement. The work culture at ABC Corporation is a positive and collaborative work environment. The work environment is safe, comfortable, and friendly. Employees are respectful. Work schedules are flexible, and the culture encourages a sense of teamwork. As noted in the literature, engagement linked with organizational alignment develops from promoting a positive organizational culture (Alagaraja \& Shuck, 2015).

P2 commented, "Leaders need to have the right people in the right jobs to support a positive environment." The conceptual framework supported this; Kahn (1990) posited that ensuring the organization has the right people in the right jobs also helps leaders create optimal work environments and conditions. P4 added that positive interactions result in employee engagement. In Kahn's theory, cognitively engaged team members share a common purpose (Shuck, Zigarmi, \& Owen, 2015). Employees become good team members when connected to leaders who ensure positive interactions. Therefore, when employees feel involved at work, they tend to take ownership of their work. Kahn (1990) asserted that task characteristics, role characteristics, and work interactions have an influence on meaningfulness at work, and meaningfulness at work can lead to employee engagement. 


\section{Relationship to literature and conceptual framework. Existing research}

corresponds with the discoveries in Theme 1 on the importance of the leader-employee relationship to the organization. Özduran and Tanova (2017) noted that leaders need to be effective communicators and support the achievement of employees. Leaders should develop an effective employee-leader relationship to improve employee performance (Hayden, Fourné, Koene, Werkman, \& Ansari, 2017). Reed, Goolsby, and Johnston (2016) suggested that managers who listen to employees and provide constructive feedback increase employee confidence and productivity. Lightle, Castellano, Baker, and Sweeney (2015) found that employees who perceive that they receive support from their leader feel inclined to increase their emotional commitment and engagement.

Yang and Treadway (2018) confirmed that a lack of interaction results in negative work behaviors among employees. Job alignment, or hiring the right people in the right place, is an important part of ensuring employee engagement (Alagaraja \& Shuck, 2015). The participants all felt that it was important to align teams. All six study participants commented on the importance of hiring the right people for the job and the organizational culture. The participants suggested that a workforce would engage more if leaders recruited the right people for the right job and if there were an emphasis on the organizational culture.

In Kahn's theory, cognitively engaged team members share a common purpose (Shuck et al., 2015). Employees become good team members when they connect to leaders who ensure positive interactions. Therefore, when employees feel involved at work, they tend to take ownership of their work. Kahn (1990) indicated that task 
characteristics, role characteristics, and work interactions have an influence on meaningfulness at work. Meaningfulness at work can lead to employee engagement.

Theme 1 findings also correlated with Kahn's (1990) theory of psychological meaningfulness. Kahn posited that psychological meaningfulness occurs when employees feel valuable, useful, and meaningful. Kahn noted that employees experience psychological meaningfulness when their leaders appreciate their work. A supportive interpersonal connection with a leader supports the leader-employee relationship. Kahn confirmed that psychological meaningfulness affects employee engagement. Kahn's theory corresponded with Theme 1 of the leader-employee relationship regarding increasing employee engagement and profitability.

\section{Theme 2: Effective Internal Communication and Feedback}

All the participants agreed that employee engagement would not occur unless there was consistent and effective internal communication. P1 pointed out that communication had been a major problem at the company. Before the leaders developed and implemented a communication strategy, rumors and innuendoes were regular, which created an uncertain environment with unproductive and disengaged employees. The communication strategy, among other things, included a monthly newsletter, weekly department face-to-face meetings, e-mail use, and Skype for branches outside the United States.

P2 commented that the communication strategy included a newsletter, quarterly staff meetings with the entire office, and mandatory weekly department and small group meetings. These interactions helped employees to commit and engage. P3 spoke about 
the success of the daily video stream shown throughout the 22 jurisdictions in which the group operated. This form of communication encouraged individuals, regardless of location, to feel a sense of belonging.

P4 suggested that the employee engagement strategy could not work without the effective communication strategy implemented by company leaders. Yap, AbdulRahman, and Chen (2017) described effective communication as the distribution and understanding of information between leaders and employees. P5 stated that communication was essential to the quality of the relationship between leader and employee, but communication had to be open and honest to be effective. P5 felt that the level of communication between leader and employee at the company achieved the desired level of openness and honesty, which contributed to increased dedication and commitment by employees. Analysis of the results of the annual internal satisfaction survey supported this fact. The company's strategic plan and analysis of the progress of implementing the communication strategy and its impact on employee engagement showed that the internal satisfaction rating increased by $35 \%$ the first year following implementation and by $50 \%$ the second year. Comments in the board minutes indicated that employees appeared to feel far more satisfied following the implementation of the communications strategy by their leaders.

P6 noted that the communication strategy was effective as it allowed employees to understand what was happening in the company, participate in decisions, and give and receive feedback. Employees felt that their leaders valued their opinions when the leaders communicated with them frequently. P1, P2, P3, and P4 indicated that how leaders 
communicated with employees determined whether engagement was positive or negative. Ineffective communication caused employees to disconnect and become disengaged.

P6 stated that "face-to-face communication allowed for observation of body language and eye contact, which are important for interpreting whether the employee understands and agrees with the presentation. E-mails and videoconferencing supplemented the face-to-face communication." P3 said that the weekly meetings provided a forum to discuss all elements of the company's operations. These meetings encouraged employees to feel a sense of belonging to the organization and a sense of trust in their leaders. P5 added,

Part of the communication strategy included placing a suggestion box in each department. Following each meeting and whenever employees felt the need to give or receive feedback, they used this box to make contact. Employees also approached their leaders to give and provide feedback verbally on matters, which could improve the operations.

P5 also noted that introducing formal performance appraisals led to feedback on employees' performance. Kim and Holzer (2016) indicated that performance appraisals encourage trust between a leader and an employee. Saratun (2016) also supported this concept. P3 indicated that effective communication facilitated the relationship-building process. The human resource section of the strategic plan and the human resources board minutes mentioned the need to facilitate relationship-building through the communication strategy. 
Relationship to literature and conceptual framework. According to Yap et al. (2017), communication allows for improved collaboration among teams and increased efficiency in operations. Employees tend to engage when they understand their role (Tucker, 2017). Internal communication correlates with employee engagement (Kang \& Sung, 2017). Saxena and Srivastava (2015) found an association between open communication and employee engagement. P2 noted that employees feel valued when they can approach their leaders and receive and give feedback. P2 stated, "This increases employee engagement and benefits the organization."

Theme 2, communications and employee feedback, supported the conceptual framework of this study, which was Kahn's employee engagement theory. Kahn (1990) reported that psychological meaningfulness, psychological safety, and psychological availability are conditions that affect employee performance and employee engagement. When leaders provide employees with feedback on their performance, employees are able to address areas requiring improvement, and the employees' contributions and feelings of meaningfulness improve.

\section{Theme 3: Compensation, Awards, Benefits, and Incentives}

All participants noted that leaders who offer attractive awards and incentives motivate employees to remain engaged and to work hard. They all indicated that business leaders are responsible for delivering awards and incentives to employees that facilitate the enhancement of the employees' quality of life in the workplace. P1 stated that the company had an adequate and attractive award system, good incentives, and a 
competitive benefits package. The benefits package included base pay; annual cash bonuses; and annual restricted stock, life and health insurance, and pensions.

P1 also stated, "These awards, as the organization refers to them, are based on the performance of the organization and the individual performance." P2 pointed out that individuals can earn up to two times their annual salary from a cash bonus. I reviewed the employee handbook as part of the study, which included some policies relating to the organization and undertook a comprehensive review of the rules of the restricted stock and annual bonus. P2 stated, "Since the implementation of these awards and incentives, employees appeared more committed and worked long hours to get the job done." The annual employee survey included a question about awards, incentive pay, and other benefits. The score for this question increased steadily following the implementation of the cash bonus and other types of awards.

P2 and P3 voiced strong opinions that awards, incentives, and other benefits were the primary catalysts for employee engagement, especially in their organization. All participants spoke of the spotlight awards and flextime system as being key to the success of the awards, incentives, and other benefits strategy. P4 said, "Persons received spotlight awards for actions that went beyond the call of duty or if the employee developed ideas to improve efficiency or save money for his department." P4 also said, "There is no limit on the number of spotlight awards each person can receive. These awards were cash awards of \$500 each." P4 and P2 noted that employees responded to cash, which served as a motivational strategy to increase employee engagement. 
P5 and P6 both indicated that the flextime system was more important to the engagement strategy than the spotlight awards were. They noted that employees could abuse the spotlight system and it could become costly. P5 stated, "Individuals especially those who had young children, appreciated flexible working hours." Flexible working hours allowed individuals to look after their personal affairs while still maintaining the organization's desired number of working hours. P1 and P3 commented that they were aware that, since introducing the flextime system, prospective candidates for various positions with the organization mentioned the importance of this benefit. The summary sheets of the interviews conducted by the human resources department corroborated this suggestion. The retention rate also increased, as confirmed by the HR statistical logs. Employees appreciate leaders who permit their employees to enjoy a flexible working schedule. This flexible schedule permitted individuals to work occasionally from home. Employees tend to be loyal and committed (Antony, 2018; Kaliannan \& Adjovu, 2015). Leaders who offer attractive compensation, incentives, and other benefits encourage a high-performance organization (Chapman, Sisk, Schatten, \& Miles, 2018). P5 identified competitive compensation as a significant part of a competitive benefits package: "Employees who receive such compensation and benefits packages remain engaged with the organization.” Chapman et al. (2018) supported this view.

P3 pointed out that the company pays a competitive compensation in the 90th percentile of the market for most positions, to ensure the employees' well-being and engagement. The human resources strategy document corroborated this statement. The company also has a wellness program, and $87 \%$ of employees participate in the program. 
The organization's website indicated its wellness program positively affected the employees' work performance by increasing productivity by 35\% from December 2017 to December 2018 and employee engagement also increased during this period.

P5 stated, "Unwell employees tend to be absent from work. High levels of absenteeism reduce productivity and can cause employee disengagement.” P1 commented that "to perform at their best, employees must be healthy both physically and psychologically." P2 commented that "engagement depends on employees being physically and psychologically healthy." P4 commented,

Leaders need to be aware of the physical and psychological health of employees. If the physical and psychological health were affected negatively in any way, then the employees could not perform their best at work. The work environment would not engage. P5 agreed that the employees' psychological and physical health are critical for employee engagement.

Relationship to literature and conceptual framework. Employee performance increases when employees receive incentives and awards, such as an increase in salary and company bonuses (Reader, Mearns, Lopes, \& Kuha, 2017). Compensation, incentives, and awards encourage staff to work harder and more productively (Almond \& Gray, 2017). Awards to individuals can improve employee engagement (Whittington, 2015). Leaders need to focus on psychological well-being and work performance to increase employee engagement (Shuck, Zigarmi, \& Owen, 2015). Viitala, Tanskanen, and Säntti (2015) also supported this view and suggested that the well-being of employees influences performance, profitability, and engagement. 
Kahn's (1990) engagement theory relates to the findings on awards, incentives, and other benefits. Kahn asserted that employees express their work performance physically, cognitively, and emotionally. Engagement theory relates to psychological meaningfulness, safety, and availability as catalysts for employee engagement. Employees experience meaningfulness at work when they are happy, are committed to performing the assigned task, and find their work valuable and worthwhile. Engaged employees focus on the goals and objectives of the organization. Theme 3 aligns with Kahn's engagement theory, which indicates that employees are psychologically or intrinsically motivated, which increases employee engagement. Leaders can increase employee engagement by offering meaningful work with competitive compensation, awards, incentives, and other benefits, which allows employees to feel valued. Kahn noted that the perceived value of work awards affects the extent to which workers are ready to engage.

\section{Theme 4: Professional Training and Development}

Leaders can positively affect employees' perception of value within the organization through psychological meaningfulness. Training and development facilitate this process (Basit \& Arshad, 2016). P1, P2, P3, and P4 indicated that professional development, training opportunities, and other programs could positively affect employee engagement. P5 and P6 commented that leaders need to ensure the necessary resources are available and support the achievement of personal goals and ambitions if the objective is to motivate employees to engage. Similarly, Fletcher (2016) commented that 
leaders target personal, professional, and organizational development to promote engagement among members of the organization.

P3 stated, "Leaders should provide employees periodically with the opportunity to train in areas that are strategic to the company throughout their tenure at $\mathrm{ABC}$ corporation.” P3 also stated, "New employees receive a comprehensive orientation and training about all areas of the company before commencing work." P1and P2 noted that employees exposed to training and development tend to exhibit confidence in their work. They believed that this confidence leads to improved worker performance and engagement. All six participants indicated that employees must always have access to the relevant training and development resources. P6 commented, "I ensure that my employees have all of the resources they need to function effectively."

Relationship to literature and conceptual framework. The availability of resources for growth and development determines whether employees engage or disengage (Kahn, 1990). P5 indicated that when appropriate resources are available, employees become engaged. P1 stated, "Employees feel that the organization is strong when training and development opportunities are available and align with employees' personal goals.” Some researchers support this view of training, development, personal goals, and an organization's strength being aligned and being essential for employee engagement. Employees will work hard and commit their time if they know that the leaders are willing to invest in employees' development. Programs to increase employees' knowledge and competence are likely to improve engagement and work performance within the organizations (Eldor \& Harpaz, 2016; Presbitero, 2017). 


\section{Applications to Professional Practice}

The specific business problem for this study was that some business leaders lack strategies to overcome and mitigate the challenges of employee disengagement and to encourage employee engagement. The results of this study reveal the specific strategies that leaders at $\mathrm{ABC}$ Corporation in Florida used successfully to achieve employee engagement. The findings are relevant to business practice. They include specific strategies that leaders can use to achieve a positive working environment that allows the organization to be prosperous.

The strategies recommended are as follows: (a) develop a leader-employee relationship in the working environment; (b) provide effective internal communication and feedback; (c) provide compensation, awards, benefits, and incentives; (d) provide professional training and development to improve employee engagement. The findings also supported the literature. Positive leader-employee interaction promotes a positive work culture (Alagaraja \& Shuck, 2015). Leaders might apply these findings to strengthen relationships between employees and leadership within an organization by enhancing performance and developing a competitive advantage. The data from my research supported and added to the existing body of knowledge related to employee engagement.

Leaders might apply the findings of this study to ensure employee engagement by providing a competitive compensation and benefits package together with awards and incentives for employees. Employees who believe that their organization's compensation and benefits structure, awards, and incentives are not competitive become disgruntled. 
This occurrence affects employee performance and engagement negatively (Chapman et al., 2018). Raina and Kalse (2018) noted that compensation and benefits drive employee engagement. Leaders noted that highly dissatisfied individuals are also highly disengaged (Raina \& Kalse, 2018).

Employees who believe that their leaders have a strategy for their professional development are likely to be engaged. The feedback provided to employees from a performance management system allows employees to achieve their professional goals while maintaining engagement. Leaders can use performance management to assess and reward employees as appropriate and determine employees' professional training and development needs, which would result in improving employee engagement (Bakker \& Albrecht, 2018). Leaders may use the findings of this study to improve business practices by developing human resource guidelines and best practices to improve employee engagement.

Employees who believe that their leaders do not recognize their work could become disengaged. Ford et al. (2015) noted that disengaged employees lack energy and do not fully participate in their role at work. When employees feel the leaders recognize their work, the employees may become engaged (Gilbert \& Kelloway, 2018; Pegulescu, 2018). When employees believe that their leader recognizes their achievement, levels of employee engagement increase (Mohammed \& Alem, 2018).

In summary, the results of this study include the following suggestions for leaders to improve business practice: (a) offer attractive compensation, benefits, awards, and incentives, including wellness programs and flexible work hours; (b) trust employees to 
do their jobs; (c) have employees participate in the decision making; (d) provide employees with meaningful work; (e) conduct performance management reviews and provide feedback; and (f) recognize employees' achievements. Other recommendations include (a) introducing a performance management system that would encourage employees to attend professional development and training programs, (b) promoting transparency in written and face-to-face communications, (c) showing concern for employees' personal lives, (d) demonstrating honesty and trust in the organization to encourage employee engagement, and (e) ensuring employees have access to all necessary resources for the job. The findings of this study can guide leaders who have difficulty creating an environment where employees remain engaged and committed.

\section{Implications for Social Change}

Engaged employees are skilled, proactive, devoted, and enthusiastic and generally go beyond the expectations of the job (Lavy \& Littman-Ovadia, 2017). Engaged employees contribute to the productivity and profitability of the organization (Kumar \& Pansari, 2015). The study findings could contribute to social change by providing leaders with strategies to increase employee engagement, which can improve employee retention and create employment opportunities for families in communities. When organizations operate profitably, leaders can reinvest profits and offer sustained employment to the workforce, which may contribute to increased purchasing power and the economic wellbeing of communities. 


\section{Recommendations for Action}

Business leaders need to determine whether the strategies articulated in the findings of this study are appropriate for their business types. If the strategies outlined are appropriate, the leaders should consider implementing some of the strategies. If leaders find that none of the specific strategies highlighted in this study are relevant to their operations, the leaders should develop and implement an appropriate engagement strategy. This approach could improve the financial performance of the business. Data from the financial highlights of $\mathrm{ABC}$ corporation's financial report to the board indicated an increase of $53.4 \%$ in profitability from $\$ 103$ million to $\$ 158.1$ million after employee engagement implementation. Premium revenue improved by $41.3 \%$ from $\$ 745.6$ million to $\$ 1,054$ billion, and the employee satisfaction and customer satisfaction indices both improved from $3 \%$ to exceed $4 \%$ after the implementation of employee engagement.

Leaders understand that implementing successful employee engagement strategies can result in a positive culture for engaged employees. Engaged employees are happy and committed. They have high employee retention, are productive, and have satisfied customers. Participants in this study will receive a summary of the study's findings via email and an electronic copy of the completed study if they are interested. Additionally, I will have the study findings published in the ProQuest/UMI dissertation database. I will also seek to present the results of the research at seminars, conferences, and other related professional events and relevant forums. 


\section{Recommendations for Further Research}

The purpose of this qualitative single case study was to explore successful strategies that business leaders use to overcome or mitigate the challenges of disengaged employees and to encourage employee engagement. Study findings were limited to a single company in a single geographical area. A multiple case study may provide a deeper understanding of the concept. Future researchers should focus on employee engagement strategies in other geographic regions and other companies in the same industry. Additionally, the study included leaders only. Future researchers should interview subordinates to understand what strategies they think are effective. Employees' perception may be different from the perception of leaders and could add additional value to this subject.

Quantitative scholars should examine the relationship between employee engagement and other variables, such as leadership styles, employees' compensation, and developmental programs. Examining the relationship between variables might provide leaders with new knowledge to mitigate the challenges of employee disengagement and to encourage engagement, which might improve the performance of the organization. Therefore, I recommend that future researchers consider conducting a mixed methodology study, which would allow for statistical explanations supported by qualitative observations of employee engagement strategies.

\section{Reflections}

The Doctor of Business Administration journey was challenging. The program required a level of time management that I did not initially anticipate. As a full-time 
employee and a father of two young children, the process and requirements were arduous. On reflection, however, it is a process designed to encourage students to complete without feeling overwhelmed. I now understand the importance of following protocol fully. The challenges of the program helped me to become more disciplined and patient.

Participants welcomed me enthusiastically and participated seemingly without reservation. The study allowed me to hone my research skills and to gather and analyze data on strategies relating to employee engagement. I plan to apply these skills in my organization. As the researcher, the credibility and the validity of the research was a priority. Recognizing my personal biases was central to ensuring the credibility of the data. I followed all protocols established to maintain validity and acquired a profound understanding of employee engagement strategies that leaders use to increase employee engagement.

\section{Conclusion}

The purpose of this qualitative single case study was to explore successful strategies that business leaders use to overcome or mitigate the challenges of disengaged employees and to encourage employee engagement. Participant responses from face-toface semistructured interviews were from executive leaders who had experience implementing successful employee engagement strategies in their workplaces. In addition to the interviews, I reviewed various company documents and archival information to supplement the data collected and to validate data source themes.

An analysis of the responses, guided by Kahn's personal engagement theory as a conceptual framework, resulted in four themes: (a) develop a leader-employee 
relationship in the working environment; (b) leaders should provide effective internal communication and feedback; (c) provide compensation, awards, benefits, and incentives; (d) provide professional training and development to improve employee engagement. The literature and conceptual framework supported the study findings. Leaders who implement the strategies should realize improved employee engagement. 


\section{References}

Abildgaard, J., Saksvik, P., \& Nielsen, K. (2016). How to measure the intervention process? An assessment of qualitative and quantitative approaches to data collection in the process evaluation of organizational interventions. Frontiers in Psychology, 7(1380), 1-10. doi:10.3389/fpsyg.2016.01380

Adedayo, A. (2016). Citations in introduction and literature review sections should not count for quality. Performance Measurement and Metrics, 16, 303-306. doi:10.1108/PMM-01-2015-0001

Adkins, A. (2015) Majority of U.S. employees not engaged despite gains in 2014. Gallup, 1 (1), 1-3. Retrieved from eeandra.com

Adkins, A. (2016). Employee engagement in U.S. stagnant in 2015. Retrieved from http://www.gallup.com/poll/188144/employee-engagement-stagnant-2015.aspx

Agarwal, U. A. (2014). Linking justice, trust, and innovative work behavior to work engagement. Personnel Review, 43, 41-73. doi:10.1108/PR02-2012-0019

Aguila, E., Weidmer, B. A., Illingworth, A. R., \& Martinez, H. (2016). Culturally competent informed-consent process to evaluate a social policy for older persons with low literacy: The Mexican case. SAGE Open, 6(3), 1-11. doi: $10.1177 / 21582446016665886$

Ahmed, U., Phulpoto, W., Umrani, W. A., \& Abbas, S. I. (2015). Diving deep in employee training to understand employee engagement. Business and Economics Journal, 7, 1-4. doi:10.4172/2151-6219.1000199 
Ahmetoglu, G., Harding, X., Akhtar, R., \& Chamorro-Premuzic, T. (2015). Predictors of creative achievement: Assessing the impact of entrepreneurial potential, perfectionism, and employee engagement. Creativity Research Journal, 27, 198205. doi:10.1080/10400419.2015.1030293

Alagaraja, M., \& Githens, R. P. (2016). Capacity and capability building for national HRD: A multi-level conceptual framework. Human Resource Development Review, 15, 77-100. doi:10.1177/1534484315623908

Alagaraja, M., \& Shuck, B. (2015). Exploring organizational alignment-employee engagement linkages and impact on individual performance: A conceptual model. Human Resource Development Review, 14, 17-37. doi:10.1177/1534484314549455

Albdour, A. A., \& Altarawneh, I. I. (2014). Employee engagement and organizational commitment: Evidence from Jordan. International Journal of Business, 19, 192 212. Retrieved from http://www.craig.csufresno.edu/ijb/

Albrecht, S. L., Bakker, A. B., Gruman, J. A., Macey, W. H., \& Saks, A. M. (2015). Employee engagement, human resource management practices and competitive advantage: An integrated approach. Journal of Organizational Effectiveness: People and Performance, 2, 7-35. doi:10.1108/joepp-08-2014-0042

Allen, R., \& Wiles, J. (2016). A rose by any other name: Participants choosing research pseudonyms. Qualitative Research in Psychology, 13, 149-165. doi:10.1080/14780887.2015.1133746 
Almond, P., \& Gray, G. C. (2017). Frontline safety: Understanding the workplace as a site of regulatory engagement. Law \& Policy, 39, 5-26. doi:10.1111/lapo.12070

Anand, G. (2017). Corporate excellence through governance and employee engagement. Journal of Commerce \& Management Thought, 8, 554-562. doi:10.5958/0976478X.2017.00033.7

Anitha, J. (2014). Determinants of employee engagement and their impact on employee performance. International Journal of Productivity and Performance Management, 63, 308-323. doi:10.1108/IJPPM-01-2013-0008

Annansingh, F., \& Howell, K. (2016). Using phenomenological constructivism (PC) to discuss a mixed method approach in information systems research. Electronic Journal of Business Research Methods, 14, 39-49. Retrieved from http://www.ejbrm.com

Antony, M. R. (2018). Paradigm shift in employee engagement: A critical analysis on the drivers of employee engagement. International Journal of Information, Business and Management, 10, 32-46. Retrieved from https://ijibm.elitehall.com

Årlin, C., Börjeson, L., \& Östberg, W. (2015). Participatory checking and the temporality of landscapes: Increasing trust and relevance in qualitative research. In C. Isendahl \& D. Stump (Eds.), The Oxford handbook of historical ecology and applied archaeology (pp. 345-365). doi:10.1093/oxfordhb/9780199672691.013.19

Bakar, H., \& McCann, R. (2016). The mediating effect of leader-member dyadic communication style agreement on the relationship between servant leadership 
and group-level organizational citizenship behavior. Management Communication Quarterly,30, 32-58. doi:10.1177/0893318915601162

Bakker, A., \& Albrecht, S. (2018). Work engagement: Current trends. Career Development International, 23, 4-11. doi:10.1108/CDI-11-2017-0207

Bakker, A., \& Demerouti, E. (2017). Job demands-resources theory: Taking stock and looking forward. Journal of Occupational Health Psychology, 22, 273-285. doi:10.1037/ocp0000056

Barnham, C. (2015). Quantitative and qualitative research. International Journal of Market Research, 57, 837-854. doi:10.2501/IJMR-2015-070

Barrick, M. R., Thurgood, G. R., Smith, T. A., \& Courtright, S. H. (2015). Collective organizational engagement: Linking motivational antecedents, strategic implementation, and firm performance. Academy of Management Journal, 58, 111-135. doi:10.5465/amj.2013.0227

Barron, K. E., \& Hulleman, C. S. (2015). Expectancy-value-cost model of motivation. In (N. J. Smelser \& P. B. Baltes (Eds.), International encyclopedia of the social \& behavioral sciences (pp. 261-271). doi:10.1016/b978-0-08-097086-8.26099-6

Basit, A. A., \& Arshad, R. (2016). The role of needs-supplies fit and job satisfaction in predicting employee engagement. UKM Journal of Management, 47, 1-17. Retrieved from http://ejournal.ukm.my/pengurusan

Bass, B. M. (1985). Leadership and performance. New York, NY: Free Press. 
Bedarkar, M., \& Pandita, D. (2014). A study on the drivers of employee engagement impacting employee performance. Procedia - Social and Behavioral Sciences, 133, 106-115. doi:10.1016/j.sbspro.2014.04.174

Besieux, T., Baillien, E., Verbeke, A., \& Euwema, M. (2015). What goes around comes around: The mediation of corporate social responsibility in the relationship between transformational leadership and engagement. Economic and Industrial Democracy, 39(2), 249-271. doi:10.1177/0143831X15614914

Bettis, R., Gambardella, A., Helfat, C., \& Mitchell, W. (2014). Quantitative empirical analysis in strategic management. Strategic Management Journal, 35, 949-953. doi:10.1002/smj.2278

Bhuvanaiah, T., \& Raya, R. (2015). Mechanism of improved performance: Intrinsic motivation and employee engagement. SCMS Journal of Indian Management, 12(4), 92-97. Retrieved from www.scmsgroup.org

Blease, C. R., Lillienfeld, S. O., \& Kelley, J. M. (2016). Evidence-based practice and psychological treatments: The imperatives of informed consent. Frontiers Psychology, 7, 1170-1174. doi:10.3389/fpsyg.2016.01170

Blomme, R. J., Kodden, B., \& Beasley-Suffolk, A. (2015). Leadership theories and the concept of work engagement: Creating a conceptual framework for management implications and research. Journal of Management \& Organization, 21, 125-144. doi:10.1017/jmo.2014.71 
Bolarinwa, O. A. (2015). Principles and methods of validity and reliability testing of questionnaires used in social and health science researches. Nigerian Postgraduate Medical Journal, 22(4), 195-201. doi:10.4103/1117-1936.173959

Breevaart, K., Bakker, A., Hetland, J., Demerouti, E., Olsen, O. K., \& Espevik, R. (2014). Daily transactional and transformational leadership and daily employee engagement. Journal of Occupational and Organizational Psychology, 87, 138157. doi:10.1111/joop.12041

Bromley, E., Mikesell, L., Jones, F., \& Khodyakov, D. (2015). Framing health matters. From subject to participant: Ethics and the evolving role of community in health research. American Journal of Public Health, 105, 900-908. doi:10.2105/AJPH.2014.302403

Burch, T., \& Guarana, C. (2015). The comparative influences of transformational leadership and leader-member exchange on follower engagement. Journal of Leadership Studies, 8(3), 6-12. doi:10.1002/jls.21334

Burnett, J. R., \& Lisk, T. C. (2019). The future of employee engagement: Real-time monitoring and digital tools for engaging a workforce. International Studies of Management \& Organization, 49, 108-119. doi:10.1080/00208825.2019.1565097 Burns, J. M. (1978). Leadership. New York, NY: Harper \& Row. Byrne, Z. (2015). Understanding what employee engagement is and is not: Implications for theory, research, and practice. New York, NY: Routledge. 
Carasco-Saul, M., Kim, W., \& Kim, T. (2015). Leadership and employee engagement: Proposing research agendas through a review of literature. Human Resource Development Review, 14, 38-63. doi:10.1177/1534484314560406

Carolan, C., Forbat, L., \& Smith, A. (2016). Developing the DESCARTE model: The design of case study research in health care. Qualitative Health Research, 26, 626-639. doi:10.1177/1049732315602488

Carter, D., \& Baghurst, T. (2014). The influence of servant leadership on restaurant employee engagement. Journal of Business Ethics, 124, 453-464. doi:10.1007/s10551-013-1882-0

Carter, N., Bryant-Lukosius, D., DiCenso, A., Blythe, J., \& Neville, A., J. (2014). The use of triangulation in qualitative research. Oncology Nursing Forum, 41, 545547. doi:10.1188/14.ONF.545.547

Carter, W. R., Nesbit, P. L., Badham, R. J., Parker, S. K., \& Sung, L. K. (2016). The effects of employee engagement and self-efficacy on job performance: A longitudinal field study. International Journal of Human Resource Management, 29, (17), 1-20. doi:10.1080/09585192.2016.1244096

Castillo-Montoya, M. (2016). Preparing for interview research: The interview protocol refinement framework. The Qualitative Report, 21, 811-830. Retrieved from http://www.nsuworks.nova.edu/tqr

Cattermole, G., Johnson, J., \& Jackson, D. (2014). Employee engagement creates a brighter economic future at Jupiter Hotels. Strategic HR Review, 13(2), 81-85. doi:10.1108/SHR-11-2013-0110 
Cesario, F., \& Chambel, M. J. (2017). Linking organizational commitment and work engagement to employee performance. Knowledge and Process Management, 24, 152-158. doi:10.1002/kpm.1542

Chapman, E. F., Sisk, F. A., Schatten, J., \& Miles, E. W. (2018). Human resource development and human resource management levers for sustained competitive advantage: Combining isomorphism and differentiation. Journal of Management and Organization, 24, 533-550. doi:10.1017/jmo.2016.37

Chaudhary, R. (2017). Corporate social responsibility and employee engagement: Can CSR help in redressing the engagement gap? Social Responsibility Journal, 13, 323-338. doi:10.1108/SRJ-07-2016-0115

Chaudhary, R., Rangnekar, S., \& Barua, M. (2013). Engaged verses disengaged: The role of occupational self-efficacy. Asian Academy of Management Journal, 18, 91108. Retrieved from http://web.usm.my/aamj/

Chaudhry, N. I., Jariko, M. A., Mushtaque, T., Mahesar, H. A., \& Ghani, Z. (2017). Impact of working environment and training \& development on organization performance through mediating role of employee engagement and job satisfaction. European Journal of Training and Development Studies, 4(2), 33-48. Retrieved from http://www.eajournals.org

Cheema, S., Akram, A., \& Javed, F. (2015). Employee engagement and visionary leadership: Impact on customer and employee satisfaction. Journal of Business Studies Quarterly, 7(2), 139-148. Retrieved from http://www.jbsq.org 
Chughtai, A. (2014). Can ethical leadership enhance employees' work engagement? Business and Management Review, 4(3), 14-15. Retrieved from http://www.bmr.businessjournalz.org

Cleary, M., Horsfall, J., \& Hayter, M. (2014). Data collection and sampling in qualitative research: Does size matter? Journal of Advanced Nursing, 70, 473-475. doi:10.1111/jan.12163

Costa, P., Passos, A., \& Bakker, A. (2014). Team work engagement: A model of emergence. Journal of Occupational and Organizational Psychology, 87, 414436. doi: org/10.1111/joop.12057

Cowardin, N., \& Soylap, N. (2011). Improving organizational workflow with social network analysis. Consulting Psychology Journal: Practice and Research, 4, 272283. doi:10.1037/aO026754

Crowe, M., Inder, M., \& Porter, R. (2015). Conducting qualitative research in mental health: Thematic and content analyses. Australian \& New Zealand Journal of Psychiatry, 49, 616-623. doi:10.1177/0004867415582053

Dagher, G., Chapa, O., \& Junaid, N. (2015). The historical evolution of employee engagement and self-efficacy constructs. Journal of Management History, 21, 232-256. doi:10.1108/JMH-05-2014-0116

Dasgupta, M. (2015). Exploring the relevance of case study research. Vision: The Journal of Business Perspective, 19, 147-160. doi:10.1177/0972262915575661

De Clercq, D., Bouckenooghe, D., Raja, U., \& Matsyborska, G. (2014). Servant leadership and work engagement: The contingency effects of leader-follower 
social capital. Human Resource Development Quarterly, 25, 183-212. doi:10.1002/hrdq.21185

Dongre, A. R., \& Sankaran, R. (2016). Ethical issues in qualitative research: Challenges and options. International Journal of Medical Science and Public Health, 5, 1187-1194. doi:10.5455/ijmsph.2016.19102015179

Doody, O., \& Noonan, M. (2013). Preparing and conducting interviews to collect data. Nurse Researcher, 20(5), 28-32. doi:10.7748/nr2013.05.20.5.28.e327

Downey, S., Werff, L., Thomas, K., \& Plaut, V. (2015). The role of diversity practices and inclusion in promoting trust and employee engagement. Journal of Social Psychology, 45, 35-44. doi:10.1111/jasp.12273.

Dwork, C., Feldman, V., Hardt, M., Pitassi, T., Reingold, O., \& Roth, A. (2015). The reusable holdout: Preserving validity in adaptive data analysis. Science, 349, 636638. doi:10.1126/science.aaa9375

Eika, M., Dale, B., Espnes, G. A., \& Hvalvik, S. (2015). Nursing staff interactions during the older residents' transition into long-term care facility in a nursing home in rural Norway: An ethnographic study. BMC Health Services Research, 15, 1-12. doi:10.1186/s12913-015-0818-z

Eldor, L., \& Harpaz, I. (2016). A process model of employee engagement: The learning climate and its relationship with extra-role performance behaviors. Journal of Organizational Behavior, 37, 213-235. doi:10.1002/job.2037 
Eldor, L., \& Vigoda-Gadot, E. (2016). The nature of employee engagement: Rethinking the employee-organization relationship. International Journal of Human Resource Management, 28, 526-552. doi:10.1080/09585192.2016.1180312

Elo, S., Kaariainen, M., Kanste, O., Polkki, T., Utriainen, K., \& Kyngas, H. (2014). Qualitative content analysis: A focus on trustworthiness. SAGE Open, 1-10. doi: $10.1177 / 2158244014522633$

Eneh, S. I., \& Awara, N. F. (2016). Strategic human resource management practices and organizational growth: A theoretical perspective. Global Journal of Social Sciences, 15, 27-37. doi.10.4314/qiss.v15i1.3

Ernst, D. (2014). Expectancy theory outcomes and student evaluations of teaching. Educational Research and Evaluation, 20, 536-556. doi:10.1080/13803611.2014.997138

Evangeline, E. T., \& Ragavan, V. G. (2016). Organizational culture and motivation as instigators for employee engagement. Indian Journal of Science and Technology, 9(2), 1-4. doi:10.17485/ijst/2016/v9i2/86340

Farrell, M. (2016). Leadership mistakes. Journal of Library Administration, 53, 439-440. doi:10/1080.01930826.2013.882198

Ferinia, R., Yuniarsi, T., \& Disman, H. (2016). Relationship between selected factors of motivation, employee engagement and employee performance among nurses at Adventist Hospital. International Journal of Basic and Applied Sciences, 5, 177. doi:10.14419/ijbas.v5i3.5948 
Filipova, M. K. (2015). Relationship between corporate culture and competitive power of the companies in the tourism industry. Tourism \& Management Studies, 11, 98103. Retrieved from http://www.dialnet.unirioja.ed

Fletcher, L. (2016). How can personal development plans effect employee engagement? The roles of meaningfulness and perceived line manager relations. International Journal of Human Resource Management, 30, 7 , doi:10.1080/09585192.2016.1184177

Ford, D., Myrden, S. E., \& Jones, T. D. (2015). Understanding “disengagement from knowledge sharing": Engagement theory versus adaptive cost theory. Journal of Knowledge Management, 19, 476-496. doi:10.1108/JKM-11-2014-0469

Fusch, P., \& Ness, L. (2015). Are we there yet? Data saturation in qualitative research. Qualitative Report, 20, 1408-1416. Retrieved from http://tqr.nova.edu/ Galuska, L. A. (2014). Education as a springboard for transformational leadership development: Listening to the voices of nurses. Journal of Continuing Education in Nursing, 45, 67-76. doi:10.3928/00220124-20140124-21

Gamero-Burón, C., \& Lassibille, G. (2018). Work engagement among school directors and its impact on teachers' behavior at work. Journal of Developing Areas, 52(2), 27-39. doi:10.1353/jda.2018.0020

Garg, P. (2014). Impact of employee engagement on a sector. International Journal of Management Research and Reviews, 4, 62-72. Retrieved from http://ijmrr.com/ 
Geldenhuys, M., Laba, K., \& Venter, C. M. (2014). Meaningful work, work engagement and organisational commitment. SA Journal of Industrial Psychology, 40, 1-10. doi:10.4102/sajip.v40i1.1098

Gelderman, C., Semeijn, J., \& Bruijn, A. (2015). Dynamics of service definitions: An explorative case study of the purchasing process of professional ICT-services. Journal of Purchasing and Supply Management, 21, 1-8. doi:10.1016/j.pursup.2015.04.004

Gentles, S. J., Charles, C., Ploeg, J., \& McKibbon, K. (2015). Sampling in qualitative research: Insights from an overview of the methods literature. Qualitative Report, 20, 1772-1789. Retrieved from http://nsuworks.nova.edu/tqr/

George, G., \& Joseph, B. (2014). A study on employees' engagement level in travel organizations with reference to Karnataka. Indian Journal of Commerce and Management Studies, 5, 8-15. Retrieved from http://scholarshub.net

Georgiades, S. (2015). Communication process to achieve employee engagement. Employee Engagement in Media Management, 3, 39-59. doi:10.1007/978-3- 319$16217-1 \_3$

Ghosh, P., Ragini, A., Gargi, C., \& Srivastava, D. (2016). Rewards and recognition to engage private bank employees: Exploring the "obligation dimension." Management Research Review, 39, 1738-1751. doi:10.1108/MRR-09-2015-0219

Gieter, S., \& Hofmans, J. (2015). How reward satisfaction affects employees' turnover intentions and performance: an individual differences approach. Human Resource Management Journal, 25, 200-216. doi:10.1111/1748-8583.12072 
Gilbert, S. L., \& Kelloway, E. K. (2018). Leadership, recognition and well-being: A moderated mediational model. Canadian Journal of Administrative Sciences/Revue Canadienne des Sciences de l'Administration, 35, 34-41. doi:10.1002/cjas. 1477

Gilliam, D. A., \& Rayburn, S. W. (2016). Propensity for reciprocity among frontline employees. Journal of Services Marketing, 30, 290-301. doi:10.1108/JSM-052015-0194

Glavas, A. (2016). Corporate social responsibility and employee engagement: Enabling employees to employ more of their whole selves at work. Frontiers in Psychology, 7, 1-10. doi:10.3389/fpsyg.2016.00796

Goldman, R. E., Parker, D. R., Brown, J., Walker, J., Eaton, C. B., \& Borkan, J. M. (2015). Recommendations for a mixed methods approach to evaluating the patient-centered medical home. Annals of Family Medicine, 13, 168-175. doi:10.1370/afm. 1765

Gollan, P. J., \& Xu, Y. (2015). Re-engagement with the employee participation debate: Beyond the case of contested and captured terrain. Work, Employment, and Society, 29, 1-13. doi:10.1177/0950017014522722

Greenwood, M. (2016). Approving or improving research ethics in management journals. Journal of Business Ethics, 137, 507-520. doi:10.1007/s10551-015-2564-X

Griffin, J. J., Bryant, A., \& Koerber, C. P. (2015). Corporate responsibility and employee relations: From external pressure to action. Group \& Organization Management, 40, 378-404. doi:10.1177/1059601114560168 
Guaspari, J. (2015). Why employee engagement isn't working. Strategic HR Review, 14, 214-219. doi:10.1108/SHR-09-2015-0070

Guest, G., Namey, E. E., \& Mitchell, M. L. (2017). Collecting qualitative data: A field manual for applied research. doi:10.4135/9781506374680

Guetterman, T. C. (2015). Descriptions of sampling practices within five approaches to qualitative research in education and the health sciences. Forum: Qualitative Social Research, 16(2), 1-23. Retrieved from http://www.qualitativeresearch.net/index.php/fqs

Guilding, C., Lamminmaki, D., \& McManus, L. (2014). Staff turnover costs: In search of accountability. International Journal of Hospitality Management, 36, 231-243. doi:10.1016/j.jhm.2013.10.001

Guillemin, M., Gillam, L., Barnard, E., Stewart, P., Walker, H., \& Rosenthal, R. (2016). "Doing trust": How researchers conceptualize and enact trust in their research practice. Journal of Empirical Research on Human Research Ethics, 11, 370381. doi: $10.1177 / 1556264616668975$

Gupta, M., \& Schukla, K. (2018). An empirical clarification on the assessment of engagement at work. Advances in Developing Human Resources, 20, 44-57. doi:10.1177/1523422317741692

Gupta, N., \& Sharma, V. (2016). Exploring employee engagement: A way to better business performance. Global Business Review, 17, 45-63. doi:10.1177/0972150916631082 
Haddock-Millar, J., Sanyal, C., \& Muller-Camen, M. (2015). Green human resource management: A comparative qualitative case study of a United States multinational corporation. International Journal of Human Resource Management, 27, 192-211. doi:10.1080/09585192.2015.1052087

Halcomb, E., \& Peters, K. (2016). Research would not be possible without participants: Maintaining appropriate relationships with participants requires a degree of reflexivity from the researcher. Nurse Researcher, 24, 6-7. doi:10.7748/nr.24.1.6.s2

Hamid, J. A., \& D'Silva, J. L. (2014). The effect of leadership attributes and motivation to lead on preferred job characteristics (job attributes): Case study of undergraduates in Malaysian universities. International Journal of Business and Management, 9, 230-238. doi:10.5539/ijbm.v9n12p230

Hamon, R., \& Bull, K. (2016). "What do you have to offer me?”: A relationship building activity for demonstrating social exchange theory. Family Science Review, 21, 2640. doi:10.26536/fsr.2016.21.01.03

Hanaysha, J. (2016). Testing the effects of employee engagement, work environment, and organizational learning on organizational commitment. Procedia, Social and Behavioral Sciences, 229, 289-297. doi:10.1016/j.sbspro.2106.07.139

Handayani, S., Anggraeni, A. I., Andriyansah, Suharnomo, \& Rahardja, E. (2017). Analysis of antecedent and consequence of employee engagement in small and medium-sized enterprises in Central Java, Indonesia. European Research Studies 
Journal, 20(3A), 500-510. Retrieved from

http://www.researchgate.net/publications/319101633

Hanzlik, V. (2015). Video is a sound employee engagement investment. Workforce Solutions Review, 5, 33-34. Retrieved from http://www.futurapublishing.com/

Harrell-Cook, G., Levitt, K., \& Grimm, J. (2017). From engagement to commitment: A new perspective on the employee attitude-firm performance relationship. International Journal of Leadership Journal, 9, 3-29. Retrieved from http://tesu.edu

Harris, T., Li, N., \& Kirkman, B. (2014). Leader-member exchange (LMX) in context: How LMX differentiation and LMX relational separation attenuate LMX's influence on OCB and turnover intention. Leadership Quarterly, 25, 314-328. doi:10.1016/j.leaqua.2013.09.001

Harvey, L. (2015). Beyond member checking: A dialogic approach to the research interview. International Journal of Research \& Method in Education, 38, 23-38. doi:10.1080/1743727X.2014.914487

Hayden, M. L., Fourné, S. P., Koene, B. A., Werkman, R., \& Ansari, S. (2017). Rethinking top-down and bottom-up roles of top and middle managers in organizational change: Implications for employee support. Journal of Management Studies, 54, 961-985. doi.10.1111/joms.12258

Hazelton, S. (2014). Positive emotions boost employee engagement. Human Resource Management International Digest, 22, 34-37. doi:10.1108/HRMDID-01-20140013 
Hennink, M. M., Hutter, I., \& Bailey, A. (2015). Qualitative research methods. Thousand Oaks, CA: Sage.

Herda, D. N., \& Lavelle, J. J. (2015). How client identification and client commitment uniquely influence auditor objectivity. Current Issues in Auditing. 9, 36-41. doi:10.2308/ciia-51279

Herminingsih, A. (2017). The influence of the organizational justice and trust to the leaders on employee engagement with job satisfaction as intervening variable. Archives of Business Research, 5(2), 56-69. doi:10.14738/abr.52.2602

Heymann, M. (2015). Spotlight on service: Integrating workforce management with employee engagement to optimize customer satisfaction and profitability. Global Business \& Organizational Excellence,34, 6-12. doi:10.1002/joe.21621

Hoare, Z., \& Hoe, J. (2013). Understanding quantitative research: Part 2. Nursing Standard, 27(18), 48-55. doi:10.7748/ns2013.01.27.18.48.c9488

Hollis, L. P. (2015). Bully university? The cost of workplace bullying and employee disengagement in American higher education. SAGE Open, 5(2), 1-11. doi:10.1177/2158244015589997

Hough, C., Green, K., \& Plumlee, G. (2015). Impact of ethics environment and organizational trust on employee engagement. Journal of Legal, Ethical and Regulatory Issues, 18(3), 45-60. Retrieved from http:// www.alliedacademies.org Houghton, C., Casey, D., Shaw, D., \& Murphy, K. (2013). Rigour in qualitative case study research. Nurse Researcher, 20, 12-17. Retrieved from http://nurseresearcher.rcnpublishing.co.uk 
Howell, A. (2017). Engagement starts at the top: The role of a leaders' personally on employee engagement. Strategic HR Review, 16(3). doi:10.1108/SHR-03-20170017

Hsieh, C. C., \& Wang, D. S. (2015). Does supervisor-perceived authentic leadership influence employee work engagement through employee-perceived authentic leadership and employee trust? International Journal of Human Resource Management, 26, 2329-2348. doi:10.1080/09585192.2015.1025234

Huang, Y., Lee, J., McFadden, A., Murphy, L. A., Robertson, M. M., Cheung, J. H., \& Zohar, D. (2016). Beyond safety outcomes: An investigation of the impact of safety climate on job satisfaction, employee engagement and turnover using social exchange theory as the theoretical framework. Applied Ergonomics, 55, 248-257. doi:10.1016/j.apergo.2015.10.007

Huertas-Valdivia, I., Llorens-Montes, J., \& Ruiz-Moreno, A. (2018). Achieving engagement among hospitality employees: A serial mediation model. International Journal of Contemporary Hospitality Management, 30, 217-241. doi:10.1108/IJCHM-09-2016-0538

Hunt, M. R., Chan, L. S., \& Mehta, A. (2011). Transitioning from clinical to qualitative research interviewing. International Journal of Qualitative Methods, 10, 191-201. Retrieved from http://journals.sagepub.com/home/ijq

Ibrahim, M., \& Falasi, S. (2014). Employee loyalty and engagement in UAE public sector. Employee Relations, 36, 562-582. doi:10.1108/ER-07-2013-0098 
Imran, H., Arif, I., Cheema, S., \& Azeem, M. (2014). Relationship between job satisfaction, job performance, attitude towards work and organizational commitment. Entrepreneurship and Innovation Management Journal, 2, 135-144 Retrieved from http://absronline.org/

Jeve, Y. B., Oppenheimer, C., \& Konje, J. (2015). Employee engagement within the NHS: A cross-sectional study. International Journal of Health Policy and Management, 4, 85-90. doi:10.15171/ijhpm.2015.1

Jha, B., \& Kumar, A. (2016). Employee engagement: A strategic tool to enhance performance. Journal for Contemporary Research in Management, 3, 21-29. Retrieved from www.psgim.ac.in/journals/index.php/jcrm

Johnson, B. (2014). Ethical issues in shadowing research. Qualitative Research in Organizations and Management, 9, 21-40. doi:10.1108/QROM-09-2012-1099

Johnson, P. (2015). Evaluating qualitative research: Past, present and future. Qualitative Research in Organizations and Management: An International Journal, 10, 320324. doi:10.1108/QROM-07-2015-1303

Jose, G., \& Mampilly, S. R. (2014). Psychological empowerment as a predictor of employee engagement: An empirical attestation. Global Business Review, 15, 93104. doi:10.1177/0972150913515589

Joyner, F. (2015). Bridging the knowing/doing gap to create high engagement work cultures. Journal of Applied Business Research, 31, 1131-1148. Retrieved from http://www.cluteinstitute.com/ 
Kahn, W. A. (1990). Psychological conditions of personal engagement and disengagement at work. Academy of Management Journal, 33, 692-725. doi:10.2307/256287

Kaliannan, M., \& Adjovu, S. (2015). Effective employee engagement and organizational success: A case study. Procedia- Social and Behavioral Sciences, 172(27). doi:10.1016/j.sbspro.2015.01.350

Kang, M., \& Sung, M. (2017). How symmetrical employee communication leads to employee engagement and positive employee communication behaviors. Journal of Communication Management, 21, 82-102. doi:10.1108/JCOM-04-2016-0026

Karanges, E., Johnston, K., Beatson, A., \& Lings, I. (2015). The influence of internal communication on employee engagement: A pilot study. Public Relations Review, 4, 129-131. doi:10.1016/j.pubrev.2014.12.003

Karumuri, V. (2016). Employee engagement: Hotel industry. SCMS Journal of Indian Management, 1, 120-128. Retrieved from http://www.scmsgroup.org

Kassa, A., \& Raju, S. (2015). Investigating the relationship between corporate entrepreneurship and employee engagement. Journal of Entrepreneurship in Emerging Economies, 7, 148-167. doi:10.1108/JEEE-12-2014-0046

Keating, L., \& Heslin, P. (2015). The potential role of mindsets in unleashing employee engagement. Human Resource Management Review, 25, 329-341. doi:10.1016/j.hrmr.2015.01.008 
Keeble-Ramsay, D. R., \& Armitage, A. (2015). HRD challenges faced in the post-global financial crisis period: Insights from the UK. European Journal of Training and Development, 39, 86-103. doi:10.1108/ejtd-04-2014-0033

Khidir, A., Asad, H., Abdelrahim, H., Elnashar, M., Killawi, A., Hammoud, M., . . . Fetters, M. D. (2016). Patient responses to research recruitment and follow-up surveys: Findings from a diverse multicultural health care setting in Qatar. BMC Medical Research Methodology, 16, 1-14. doi:10.1186/s12874-016-0109-3

Khuong, M., \& Dung, D. (2015). The effect of ethical leadership and organizational justice on employee engagement: The mediating role of employee trust. International Journal of Trade, Economics and Finance, 6, 235-240. doi:10.7763/IJTEF.2015.V6.475

Khuong, M. N., \& Yen, N. H. (2014). The effects of leadership styles and sociability trait emotional intelligence on employee engagement. A study in Binh Duong City, Vietnam. International Journal of Current Research and Academic Review, 2, 121-136. Retrieved from http://www.ijcrar.com/

Kim, T., \& Holzer, M. (2016). Public employees and performance appraisal: A study of antecedents to employees' perception of the process. Review of Public Personnel Administration, 36, 31-56. doi:10.1177/0734371X14549673

Kim, W., Khan, G. F., Wood, J., \& Mahmood, M. T. (2016). Employee engagement for sustainable organizations: Keyword analysis using social network analysis and burst detection approach. Sustainability, 8, 1-11. doi:10.3390/su8070631 
Knafl, K., Leeman, J., Havill, N., Crandell, J., \& Sandelowski, M. (2015). Delimiting family in syntheses of research on childhood chronic conditions and family life. Family Process, 54, 173-184. doi:10.1111/famp.12101

Koch, L., Niesz, T., \& McCarthy, H. (2014). Understanding and reporting qualitative research: An analytical reviews and recommendations for submitting authors. Rehabilitation Counseling Bulletin, 57, 131-143. doi:10.1177/0034355213502549

Kornbluh, M. (2015). Combatting challenges to establishing trustworthiness in qualitative research. Qualitative Research in Psychology, 12, 397-414. doi:10.1080/14780887.2015.1021941

Kumar, V., \& Pansari, A. (2015). Measuring the benefits of employee engagement. MIT Sloan Management Review, 56, 65-72. Retrieved from http://mitsmr.com/

Kumar, V., \& Pansari, A. (2016). Competitive advantage through engagement. Journal of Marketing Research, 53, 497-514. doi:10.1509/jmr.15.0044

Kuranchie-Mensah, E. B., \& Amponsah-Tawiah, K. (2016). Employee motivation and work performance: A comparative study of mining companies in Ghana. Journal of Industrial Engineering and Management, 9, 255-309. doi:10.3926/jiem.1530

Kuruppuge, R. H., \& Gregar, A. (2017). Family involvement, employee engagement and employee performance in enterprising family firms. Acta Universitatis Agriculturae et Silviculturae Mendelianae Brunensis, 65, 1695-1707. doi:10.11118/actaun201765051695 
Larson-Hall, J., \& Plonsky, L. (2015). Reporting and interpreting quantitative research findings: What gets reported and recommended for the field. Language Learning, 65, 127-159. doi:10.1111/lang.12115

Lather, A., \& Jain, V. (2015). Ten C's leadership practices impacting employee engagement: A study of hotel and tourism industry. XIMB Journal of Management, 12, 59-74. Retrieved from www.ximb.ac.in/ximb_journal/

Lavy, S., \& Littman-Ovadia, H. (2017). My better self: using strengths at work and work productivity, organizational citizenship behavior, and satisfaction. Journal of Career Development, 44(2), 95-109. doi:10.1177/0894845316634056

Leary, T. G., Green, R., Denson, K., Schoenfeld, G., Henley, T., \& Langford, H. (2013). The relationship among dysfunctional leadership dispositions, employee engagement, job satisfaction, and burnout. Psychologist-Manager Journal, 16, 112-130. doi:10.1037/h0094961

Lee, J., \& Ok, C. (2015). Drivers of work engagement: An examination of core selfevaluations and psychological climate among hotel employees. International Journal of Hospitality Management, 44, 84-98. doi:10.1016/j.ijhm.2014.10.008

Lee, Y., Kim, S., \& Kim, S. (2014). The impact of internal branding on employee engagement and outcome variables in the hotel industry. Asia Pacific Journal of Tourism Research, 19, 1359-1380. doi:10.1080/10941665.2013.863790

Leech, N. L., Collins, K. M., \& Onwuegbuzie, A. J. (2014). Collecting qualitative data for social network analysis and data mining. Encyclopedia of Social Network Analysis and Mining, 1, 124-133.doi:10.1007/978-1-4614-6170-8_395 
Leung, L. (2015). Validity, reliability, and generalizability in qualitative research. Journal of Family Medicine and Primary Care, 4, 324-327. doi:10.4103/22494863.161306

Lewis, S. (2015). Qualitative inquiry and research design: Choosing among five approaches. Health Promotion Practices, 16, 473-475. doi: $10.1177 / 1524839915580941$

Li, L., \& Titsworth, S. (2015). Student misbehaviors in online classrooms: Scale development and validation. American Journal of Distance Education, 29, 41-55. doi:10.1080/08923647.2015.994360

Liden, R., Wayne, S., Liao, C., \& Meuser, J. (2014). Servant leadership and serving culture: Influence on individual and unit performance. Academy of Management Journal, 56, 1434-1452. doi:10.5465/amj.2013.0034

Lightle, S. S., Castellano, J., Baker, B., \& Sweeney, R. J. (2015). The role of corporate boards in employee engagement. IUP Journal of Corporate Governance, 14(4), 7-10. Retrieved from https://www.iupindia.in/Corporate_Governance.asp

Lincoln, Y. S., \& Guba, E. G. (1985). Naturalistic inquiry. London, England: Sage.

Liu, X., \& Zhang, Y. (2015). Effects of target timing and contract frame on individual performance. European Accounting Review, 24, 329-345. doi:10.1080/09638180.2014.942337

Lohmann, J., Houlfort, N., \& De Allegri, M. (2016). Crowding out or no crowding out? A self-determination theory approach to health worker motivation in 
performance-based financing. Social Science \& Medicine, 169, 1-8.

doi:10.1016/j.socscimed.2016.09.006

Lu, L., \& Anderson-Cook, C. M. (2015). Improving reliability understanding through estimation and prediction with usage information. Quality Engineering, 27, 304316. doi:10.1080/08982112.2014.990033

Lysova, E. I., Richardson, J., Khapova, S. N., \& Jansen, P. G. (2015). Change-supportive employee behavior: A career identity explanation. Career Development International, 20, 35-62. doi:10.1108/CDI-03-2014-0042

Maghraoui, R., \& Zidai, J. (2016). Effects of employee ownership on the performance of French companies SBF120: Empirical validation. Journal of Accounting, Finance and Auditing Studies, 2, 195-217. Retrieved from http://jafas.org/

Mahajan, S., \& Sharma, R. (2015). Impact of effective leadership on employee engagement. International Journal of Education and Management Studies, 5, 288-291. Retrieved from http://www.iahrw.com

Malik, M. A. R., Butt, A. N., \& Choi, J. N. (2015). Rewards and employee creative performance: Moderating effects of creative self-efficacy, reward importance, and locus of control. Journal of Organizational Behavior, 36, 59-64. doi:10.1002/job,1943

Malterud, K., Siersma, V. D., \& Guassora, A. D. (2016). Sample size in qualitative interview studies: Guided by information power. Qualitative Health Research, 26, 1753-1760. doi:10.1177/1049732315617444 
Mann, A., \& Harter, J. (2016). The worldwide employee engagement crisis. Retrieved from http://www.gallup.com

Marshall, C., \& Rossman, G. (2016). Designing qualitative research (6th ed.). Thousand Oaks, CA: Sage.

Matza, L. S., Boye, K. S., Stewart, K. D., Curtis, B. H., Reaney, M., \& Landrian, A. S. (2015). A qualitative examination of the content validity of the EQ-5D-5L in patients with type 2 diabetes. Health \& Quality of Life Outcomes, 13, 1-10. doi:10.1186/s12955-015-0373-7

McCleskey, J. (2014). Situational, transformational, and transactional leadership and leadership development. Journal of Business Studies Quarterly, 5, 117-130. Retrieved from http://jbsq.org/

McCusker, K., \& Gunaydin, S. (2015). Research using qualitative, quantitative or mixed methods and choice based on the research. Perfusion, 30, 537-542. doi:10.1177/0267659114559116

McManus, J., \& Mosca, H. (2015). Strategies to build trust and improve employee engagement. International Journal of Management and Information Systems, 19, 37-42. Retrieved from www.cluteinstitute.com

Megha, S. (2016). A brief review of employee engagement: Definition, antecedents and approaches. International Journal of Research in Commerce \& Management, 7, 79-88. Retrieved from http://www.ijrcm.org.in 
Mehmood, Q., Nawab, S., \& Hamstra, M. (2016). Does authentic leadership predict employee work engagement and in-role performance? Journal of Personnel Psychology, 15, 139-142. doi:10.1027/1866-5888/a000164

Menges, J. I., Tussing, D. V., Wihler, A., \& Grant, A. M. (2017). When job performance is all relative: How family motivation energizes effort and compensates for intrinsic motivation. Academy of Management Journal, 60, 695-719. doi:10.5465/amj.2014.0898

Menguc, B., Auh, S., Fisher, M., \& Haddad, A. (2013). To be engaged or not to be engaged: The antecedents and consequences of service employee engagement. Journal of Business Research, 66, 2163-2170. doi:10.1016/j.jbusres.2012.01.007

Mikkelson, A. C., York, J. A., \& Arritola, J. (2015). Communication competence, leadership behaviors, and employee outcomes in supervisor-employee relationships. Business and Professional Communication Quarterly, 78, 336-354. doi: $10.1177 / 2329490615588542$

Mishra, K., Boynton, L., \& Mishra, A. (2014). Driving employee engagement: The expanded role of internal communications. International Journal of Business Communication, 51, 183-202. doi:10.1177/2329488414525399

Mo, S., \& Shi, J. (2017). Linking ethical leadership to employees' organizational concern. Journal of Business Ethics, 141, 151-162. doi:10.1007/s10551-0152734-X 
Modell, S. (2015). Theoretical triangulation and pluralism in accounting research: A critical realist critique. Accounting, Auditing \& Accountability Journal, 28. doi:10.1108/AAAJ-10-2014-1841

Mohammed, A., \& Alem, M. (2018). Students' intention to join the hotel industry in Malaysia: The role of physical working conditions, pay and benefits, and promotion opportunities. Journal of Business \& Retail Management Research, 12, 240-245. doi:10.24052/jbrmr/v12is04/art-24

Mokaya, S. O., \& Kipyegon, M. J. (2014). Determinants of employee engagement in the Banking industry in Kenya; case of cooperative bank. Journal of Human Resource Management and Labor Studies, 2, 187-200. doi:10.15640/jhrmls

Moreland, J. (2013). Improving job fit can improve employee engagement and productivity. Employment Relations Today, 40, 57-62. doi:10.1002/ert.21400

Morgan, S. J., Pullon, S. R., Macdonald, L. M., McKinlay, E. M., \& Gray, B. V. (2016). Case study observational research: A framework for conducting case study research where observation data are the focus. Qualitative Health Research, 27, 1060-1068. doi:10.1177/1049732316649160

Morse, J. M. (2015a). Critical analysis of strategies for determining rigor in qualitative inquiry. Qualitative Health Research, 25, 1212-1222.

doi:10.1177/1049732315588501

Morse, J. M. (2015b). "Data were saturated..." Qualitative Health Research, 25, 587-588. doi:10.1177/1049732315576699 
Mozammel, S., \& Haan, P. (2016). Transformational leadership and employee engagement in the banking sector in Bangladesh. Journal of Developing Areas, 50, 43-55. doi:10.1353/jda.2016.0127

Munn, Z., Porritt, K., Lockwood, C., Aromataris, E., \& Pearson, A. (2014). Establishing confidence in the output of qualitative research synthesis: The ConQual approach. BMC Medical Research Methodology, 14, 15-33. doi:10.1186/147-2288-14-108

Mutsuddi, I. (2016). Employee retention and engagement practices in the healthcare sector. A study on Medica Super-Specialty Hospital, Kolkata, Delhi Business Review, 17, 65-78. Retrieved from http://www.delhibusinessreview.org/

Nair, M. S., \& Salleh, R. (2015). Linking performance appraisal justice, trust, and employee engagement: A conceptual framework. Procedia - Social and Behavioral Sciences, 211, 1155-1162. doi:10.1016/j.sbspro.2015.11.154

Nasomboon, B. (2014). The relationship among leadership commitment organizational performance and employee engagement. International Business Research, 7, 7790. doi:10.5539/ibr.v7n9p77

National Commission for Protection of Human Subjects of Biomedical and Behavioral Research. (1979). The Belmont Report: Ethical principles and guidelines for the protection of human subjects of research. Washington, DC: Department of Health and Human Services.

Nazir, O., \& Islam, J. U. (2017). Enhancing organizational commitment and employee performance through employee engagement: An empirical check. South Asian Journal of Business Studies, 6, 98-114. doi:10.1108/SAJBS-04-2016-0036. 
Nel, T., Stander, M. W., \& Latif, J. (2015). Investigating positive leadership, psychological empowerment, work engagement and satisfaction with life in a chemical industry. SA Journal of Industrial Psychology, 41, 1-13. doi:10.4102/sajip.v4i1.1243

Nieberding, A. (2014). Employee engagement and other bonding forces in organizations. Consulting Psychology Journal: Practice and Research, 66, 320-323. doi:10.1037/cpb0000022

Nimon, K., Shuck, B., \& Zigarmi, D. (2015). Construct overlap between employee engagement and job satisfaction: A function of semantic equivalence? Journal of Happiness Studies, 17, 1149-1171. doi:10.1007/s10902-015-9636-6

Nimri, M., Bdair, A., \& Bitar, H. (2015). Applying the expectancy theory to explain the motivation of public sector employees in Jordan. Middle East Journal of Business, 10, 70-83. Retrieved from http://www.mejb.com

Noble, H., \& Smith, J. (2015). Issues of validity and reliability in qualitative research. Evidence Based Nursing, 18, 34-35. doi:10.1136/eb-2015-102054

Noohi, E., Peyrovi, H., Goghary, Z. I., \& Kazemi, M. (2016). Perception of social support among family caregivers of vegetative patients: A qualitative study. Consciousness and Cognition, 41, 150-158. doi:10.1016/j.concog.2016.02.015

Nyhan, B. (2015). Increasing the credibility of political science research: A proposal for journal reforms. Political Science \& Politics, 48, 78-83. doi: $10.1017 / \mathrm{s} 1049096515000463$ 
Olsen, D. P., Lehto, R. H., \& Chan, R. R. (2016). Ethical case study of the researcherparticipant relationship in end-of-life research. Western Journal of Nursing Research, 38, 1-16. doi:10.1177/0193945916639590

Opsal, T., Wolgemuth, J., Cross, J., Kaanta, T., Dickmann, E., Colomer, S., \& ErdilMoody, Z. (2016). “There are no known benefits ...": Considering the risk/benefit ratio of qualitative research. Qualitative Health Research, 26, 1137 1150. doi:10.1177/1049732315580109

O’Reilly, M., \& Parker, N. (2013). Unsatisfactory saturation: A critical exploration of the notion of saturated sample sizes in qualitative research. Qualitative Research Journal, 13, 190-197. doi:10.1177/ 1468794112446106

Oswick, C. (2015). Guest editorial. Human Resource Development Review, 14, 8-16. doi: $10.1177 / 1534484314558743$

Özduran, A., \& Tanova, C. (2017). Manager mindsets and employee organizational citizenship behaviors. International Journal of Contemporary Hospitality Management, 29, 589-606. doi:10.1108/IJCHM-03-2016-0141

Palinkas, L. A., Horwitz, S. M., Green, C. A., Wisdom, J. P., Duan, N., \& Hoagwood, K. (2015). Purposeful sampling for qualitative data collection and analysis in mixed method implementation research. Administration and Policy in Mental Health and Mental Health Services Research, 42, 533-544. doi:10.1007/s10488-013-0528-y

Panchanatham, N., \& Jayalakshmi, V. (2016). A study on employee safety and workplace hazards in relation to performance of jewelry manufacturing industries. Journal of 
Contemporary Research in Management, 11, 1-9. Retrieved from http://www.psgim.ac.in/

Parker, D. A., Soomro, A., \& Hayward, C. P. (2015). Responsible conduct and documentation of research: A standard operating procedure template that can be customized. Ontario, Canada: McMaster University.

Pegulescu, A. (2018). Is appraisal a controversial human resource management tool or a motivating working path? Economics, Management and Financial Markets, 13, 224-233. Retrieved from https://addletonacademicpublishers.com leconomicsmanagement-and-financial-markets

Permana, I., Tjakraatmadja, J. H., Larso, D., \& Wicaksono, A. (2015). Exploring potential drivers of employee engagement, enablement, and empowerment: A quest toward developing a framework for building sustainable employee excellence for manufacturing environment in Indonesia. Mediterranean Journal of Social Sciences, 6, 577-587. doi:10.5901/mjss.2015.v6n2s1p577

Petrova, E., Dewing, J., \& Camilleri, M. (2016). Confidentiality in participatory research: Challenges from one study. Nursing Ethics, 23, 442-454. doi:10.1177/0969733014564909

Petty, N. J., Thomson, O. P., \& Stew, G. (2012). Ready for a paradigm shift? Part 1: Introducing the philosophy of qualitative research. Manual Therapy, 17, 267-274. doi:10.1016/j.math.2012.03.006 
Pollitt, D. (2014). Micron trust is like strawberry pie: Targeting employees' appetite for commitment. Human Resource Management International Digest, 22, 26-28. doi:10.1108/HRMID-10-2014-0139

Popli, S., \& Rizvi, I. A. (2015). Exploring the relationship between service orientation, employee engagement and perceived leadership style: A study of managers in the private service sector organizations in India. Journal of Services Marketing, 29, 59-70. doi:10.1108/jsm-06-2013-0151

Popli, S., \& Rizvi, I. A. (2016). Drivers of employee engagement: The role of leadership style. Global Business Review,17, 965-979. doi:10.1177/0972150916645701

Potestio, M. L., Boyd, J. M., Bagshaw, S. M., Heyland, D., Oxland, P., Doig, C. J., \& Stelfox, H. T. (2015). Engaging the public to identify opportunities to improve critical care: A qualitative analysis of an open community forum. Plos ONE, 10, 1-11. doi:10.1371/journal.pone.0143088

Pouramini, Z., \& Fayyazi, M. (2015). The relationship between positive organizational behavior with job satisfaction, organizational citizenship behavior, and employee engagement. International Business Research, 8(9), 57. doi:10.5539/ibr.v8n9p57

Prasannakumar, J. P. (2015). Cost of employee turnover: A study based on critical level of employees of five-star hotels in Bangalore. Chanakya International Journal of Business Research, 1, 79-88. doi:10.15410/cijbr/2015/v1i1/61409

Presbitero, A. (2017). How do changes in human resource management practices influence employee engagement? A longitudinal study in a hotel chain in the 
Philippines. Journal of Human Resources in Hospitality \& Tourism, 16, 56-70. doi:10.1080/15332845.2016.1202061

Prion, S., \& Adamson, K. (2014). Making sense of methods and measurement: Rigor in qualitative research. Clinical Simulation in Nursing, 10, 107-108. doi:10.1016/j.ecns.2013.05.003

Purvis, R. L., Zagenczyk, T. J., \& McCray, G. E. (2015). What's in it for me? Using expectancy theory and climate to explain stakeholder participation, its direction and intensity. International Journal of Project Management, 33, 3-14. doi:10.1016/j.ijproman.2014.03.003

Putra, E. D., Cho, S., \& Liu, J. (2015). Extrinsic and intrinsic motivation on work engagement in the hospitality industry: Test of motivation crowding theory. Tourism and Hospitality Research, 15, 1-14. doi:10.1177/1467358415613393

Radda, A. A., Majidadi, M. A., \& Akanno, S. N. (2015). Employee engagement: The new model of leadership. Indian Journal of Management Science, 5, 17-26. Retrieved from http://www.scholarshub.net/ijms.html

Raheim, M., Magnussen, L. H., Sekse, R. J. T., Lunde, Å., Jacobsen, T., \& Blystad, A. (2016). Researcher-researched relationship in qualitative research: Shifts in positions and researcher vulnerability. International Journal of Qualitative Studies on Health and Well-being, 11, 996. doi:10.3402/qhw.v11.30996

Raina, B., \& Kalse, A. (2018). A study of human resource practices on employee work engagement in hospitality industry. BVIMSR's Journal of Management Research, 10, 194-206. Retrieved from http://www.bvimsr.com/bjmr.php 
Raj, R., \& Srivastava, K. L. (2017). Transformational leadership and innovativeness: The mediating role of organizational learning. Journal of Management Research, 17, 201-219. Retrieved from http://www.sapub.com

Rayton, B. A., \& Yalabik, Z. Y. (2014). Work engagement, psychological contract breach, and job satisfaction. International Journal of Human Resource Management, 25, 2382-2400. doi:10.1080/09585192.2013.876440

Reader, T. W., Mearns, K., Lopes, C., \& Kuha, J. (2017). Organizational support for the workforce and employee safety citizenship behaviors: A social exchange relationship. Human Relations, 70, 362-385. Retrieved from http://www.journals.sagepub.com

Reed, K., Goolsby, J. R., \& Johnston, M. K. (2016). Listening in and out: Listening to customers and employees to strengthen an integrated market-oriented system. Journal of Business Research, 69, 3591-3599. doi:10.1016/j.jbusres.2016.01.002

Rothmann, S., \& Baumann, C. (2014). Employee engagement: The effects of workhome/home-work interaction and psychological conditions. South African Journal of Economic and Management Sciences, 17, 515-530. Retrieved from http://www.sajems.org

Roulston, K., \& Shelton, S. A. (2015). Reconceptualizing bias in teaching qualitative research methods. Qualitative Inquiry, 21, 332-342.

doi: $10.1177 / 1077800414563803$ 
Ruben, B., \& Gigliotti, R. (2016). Leadership as social influence: An expanded view of leadership communication theory and practice. Journal of Leadership and Organizational Studies, 23, 467-479. doi:10.1177/1548051816641876

Sajjadi, A. (2014). New emerging leadership theories and styles. Technical Journal of Engineering and Applied Sciences Journal, 4(3), 180-188. Retrieved from http://tjeas.com/

Saks, A. M., \& Gruman, J. A. (2014a). Getting newcomers engaged: The role of socialization tactics. Journal of Managerial Psychology, 26, 383-402. doi:10.1108/02683941111139001

Saks, A. M., \& Gruman, J. A. (2014b). What do we really know about employee engagement. Human Resource Development Quarterly, 25, 155-182. doi:10.1002/hrdq. 21187

Samad, A., Reaburn, P., Davis, H., \& Ahmed, E. (2015). Towards and understanding of the effect of leadership on employee wellbeing and organizational outcomes in Australian universities. Journal of Developing Areas, 49, 441-448. doi:10.1353/jda.2015.0121

Saratun, M. (2016). Performance management to enhance employee engagement for corporate sustainability. Asia-Pacific Journal of Business Administration, 8, 84102. doi:10.1108/APJBA-07-2015-0064

Sarros, J. C., Luca, E., Densten, I., \& Santora, J. C. (2014). Leaders and their use of motivating language. Leadership \& Organization Development Journal, 35, 226240. doi:10.1108/LODJ-06-2012-0073 
Saxena, R. (2017). Muddling through the passage of qualitative research: Experiences of a novice researcher. Vision, 21, 314-322. doi:10.1177/0972262917721423

Saxena, V., \& Srivastava, R. K. (2015). Impact of employee engagement on employee performance-case of manufacturing sectors. International Journal of Management Research and Business Strategy, 4, 141-171. Retrieved from http://www.ijmrbs.com/

Schaubroeck, J. M., Lam, S. S. K., \& Peng, A. C. (2016). Can peers' ethical and transformational leadership improve coworkers' service quality? A latent growth analysis. Organizational Behavior and Human Resource Decision Process, 133, 45-58. doi:10.1016/j.obhdp.2016.02.002

Schaufeli, W. B. (2015). Engaging leadership in the job demands-resource model. Career Development International, 20, 446-463. doi:10.1108/CDI-02-2015-0025

Schoenung, B., \& Dikova, D. (2016). Reflections on organizational team diversity research. Equality, Diversity \& Inclusion, 35, 221-231. doi:10.1108/EDI-11-20150095

Shepperd, M., Bowes, D., \& Hall, T. (2014). Researcher bias: The use of machine learning in software defect prediction. IEEE Transactions on Software Engineering, 40, 603-616. doi:10.1109/TSE.2014.2322358

Shuck, B., \& Reio, T. G. (2014). Employee engagement and well-being a moderation model and implications for practice. Journal of Leadership \& Organizational Studies, 21, 43-58. doi:10.1177/1548051813494240 
Shuck, M. B., Zigarmi, D., \& Owen, J. (2015). Psychological needs, engagement, and work intentions: A Bayesian multi-measurement mediation approach and implications for HRD. European Journal of Training and Development, 39, 2-21. doi:10.1108/EJTD-08-2014-0061

Silverman, D. (2015). Interpreting qualitative data (5th ed.). Thousand Oaks, CA: Sage.

Simpson, A., \& Quigley, C. F. (2016). Member checking process with adolescent students: Not just reading a transcript. Qualitative Report, 21, 377-392. Retrieved from http://www.nsuworks.nova.edu/tqr

Singh, K. (2015). Leadership style and employee productivity: A case study of Indian banking operations. Journal of Knowledge Globalization, 8, Number 2.

Singh, R. (2016). The impact of intrinsic and extrinsic motivators on employee engagement in information organizations. Journal of Education for Library and Information Science, 57, 197-206. doi:10.12783/issn.2328-2967/57/2/11

Slack, R. E., Corlett, S., \& Morris, R. (2015). Exploring employee engagement with (corporate) social responsibility: A social exchange perspective on organizational participation. Journal of Business Ethics, 127, 537-548. doi:10.1007/s10551-0142057-3

Soane, E., Truss, C., Alfes, K., Shantz, A., Rees, C., \& Gatenby, M. (2012). Development and application of a new measure of employee engagement: The ISA engagement scale. Human Resource Development International, 15, 529-547.

doi:10.1080/13678868.2012.726542 
Solaja, O., Idowu, F., \& James, A. (2016). Exploring the relationship between leadership communication style, personality trait, and organizational productivity. Serbian Journal of Management, 11, 99-117. doi:10.5937/sjm11-8480

Stein, R. C., Dunn, J. A., Bartlett, J. M., Campbell, A. F., Marshall, A., Hall, P., . . Makris, A. (2016). Methods: Recruitment and study of personalized care in the treatment of women with early breast cancer. Health Technology Assessment, 20(10), 1-236. doi:10.3310/hta20100

Storm, D., Sears, K., \& Kelly, K. (2014). Work engagement: The roles of organizational justice and leadership style in predicting engagement among employees. Journal of Leadership and Organizational Studies, 21, 71-82. doi: $10.1177 / 1548051813485437$

Sullivan, S. C., Garner, K. K., \& Dubbert, P. (2016). Recruitment for an advance care planning study: Lessons learned. Journal of the American Geriatrics Society, 64, 666-667. doi:10.1111/jgs.13984

Swartout, S., Boykins, S., Dixon, M., \& Ivanov, S. (2015). Low morale in organizations: A symptom of deadly management diseases? International Journal of Organizational Innovation, 8, 17-24. Retrieved from ijoi-online.org

Tang, G., Yang, J., \& Tang, S. (2015). Qualitative analysis of a quadratic integrate-and fire neuron model with state-dependent feedback control. Discrete Dynamics in Nature \& Society, 2015, 1-12. doi:10.1155/2015/836402

Taylor, S. J., Bogdan, R., \& DeVault, M. (2015). Introduction to qualitative research methods: A guidebook and resource. Hoboken, NJ: Wiley. 
Teruel, M. A., Navarro, E., González, P., López-Jaquero, V., \& Montero, F. (2016). Applying thematic analysis to define an awareness interpretation for collaborative computer games. Information and Software Technology, 74, 17-44. doi:10.1016/j.infsof.2016.01.009

Tetnowski, J. (2015). Qualitative case study research design. Perspectives on Fluency and Fluency Disorders, 25, 39-45. doi:10.1044/ffd25.1.39

Thomas, J., Silverman, S., \& Nelson, J. (2015). Research methods in physical activity (7th ed.). Champaign, IL: Human Kinetics.

Thompson, K., Lemmon, G., \& Walter, T. (2015). Employee engagement and positive psychological capital. Organizational Dynamics, 44, 185-195. doi:10.1016/j.orgdyn.2015.05.004

Trainor, A. A., \& Graue, E. (2014). Evaluating rigor in qualitative methodology and research dissemination. Remedial and Special Education, 35, 267-274. doi:10.1177/0741932514528100

Tucker, E. (2017). Engaging employees: Three critical roles for managers. Strategic HR Review, 16, 107-111. doi:10.1108/SHR-03-2017-0018

Turner, S., \& Endres, A. (2017). Strategies for enhancing small-business owners'success rates. International Journal of Applied Management and Technology, 16, 34-49. doi:10.5590/IJAMT.2017.16.1.03

Ugwu, F. B., Onyishi, I. E., \& Rodriquez-Sanchez, A. M. (2014). Linking organizational trust with employee engagement: The role of psychological empowerment. Personnel Review, 43, 377-400. doi:10.1108/PR-11-2012-0198 
U.S. Bureau of Labor Statistics. (2016). Monthly labor review. Retrieved from https://www.bls.gov/opub/mlr/2016/home.htm

U.S. Department of Health and Human Services. (1979). The Belmont report. Retrieved from http://www.hhs.gov/ohrp/regulations-and-policy/belmont-report/index.html

U.S. Merit Systems Protection Board. (2015). Managing for engagement:

Communication connection and courage. Retrieved from http://www.mspb.gov

Valentin, M., Valentin, C., \& Nafukho, F. (2015). The engagement continuum model using corporate social responsibility as an intervention for sustained employee engagement: Research leading practice. European Journal of Training and Development, 39, 182-202. doi:10.1108/EJTD-01-2014-0007

Van De Voorde, K., Van Veldhoven, M., \& Veld, M. (2016). Connecting empowerment focused HRM and labour productivity to work engagement: The mediating role of job demands and resources. Human Resource Management Journal, 26, 192-210. doi:10.1111/1748-8583.12099

Vannest, K. J., \& Ninci, J. (2015). Evaluating intervention effects in single-case research designs. Journal of Counseling \& Development, 93, 403-411. doi:10.1002/jcad.12092

Van Teijlingen, E., \& Hundley, V. (2015). Pilot studies in family planning and reproductive health care. Journal of Family Planning and Reproductive HealthCare, 31, 219-221. doi:10.1783/1471189054483735 
Viitala, R., Tanskanen, J., \& Säntti, R. (2015). The connection between organizational climate and well-being at work. International Journal of Organizational Analysis, 23, 606-620. doi:10.1108/IJOA-10-2013-0716

Vogel, E. (2016). Ongoing endings: Migration, love, and ethnography. Journal of Contemporary Ethnography, 45, 673-691. doi:10.1177/0891241616654542

Vroom, V. (1964). Work and motivation. San Francisco, CA: Jossey-Bass.

Walden, J., Jung, E., \& Westerman, C. (2017). Employee communication, job engagement, and organizational commitment: A study of members of the millennial generation. Journal of Public Relations Research, 29, 73-89. doi:10.1080/1062726X.2017.1329737

Wang, C. J., Tsai, H. T., \& Tsai, M. T. (2014). Linking transformational leadership and employee creativity in the hospitality industry: The influences of creative role identity, creative self-efficacy, and job complexity. Tourism Management, 40, 7989. doi:10.1016/j.tourman.2013.05.008

Warner, L. R. (2016). Invited reflection contested interpretations and methodological choices in quantitative research. Psychology of Women Quarterly, 40, 342-346. doi:10.1177/0361684316655453

Warrick, D. D. (2017). What leaders need to know about organizational culture. Business Horizons, 60, 395-404. doi:10.1016/j.bushor.2017.01.011

Whittington, K. D. (2015). Does motivation predict persistence and academic success? Open Journal of Nursing, 5, 10-12. doi:10.4236/ojn.2015.51002 
Willgens, A. M., Cooper, R., Jadotte, D., Lilyea, B., Langtiw, C., \& Obenchain-Leeson, A. (2016). How to enhance qualitative research appraisal: Development of the methodical congruence instrument. Qualitative Report, 21, 2380-2395. Retrieved from http://www.nsuworks.novs.edu/tqr

Wirsching, S., Mayfield, J., Mayfield, M., \& Wang, W. (2014). Motivating language as a mediator between servant leadership and employee outcomes. Management Research Review, 38, 1234-1250. doi:10.1108/MRR-01-2014-0009

Woods, M., Paulus, T., Atkins, D. P., \& Macklin, R. (2015). The discourse of QDAS: Reporting practices of ATLAS.ti and NVivo users with implications for best practices. International Journal of Social Research Methodology, 19, 1-13. doi:10.1080/13645579.2015.1102454

Wray, C. C. (2016). Staying in the know: Tools you can use to keep up with your subject area. Collection Management, 41, 182-186. doi:10.1080/01462679.2016.1196628

Wu, Y-C. (2017). Mechanisms linking ethical leadership to ethical sales behavior. Psychological Reports, 120, 537-560. doi:10.1177/0033294117693594

Xanthopoulou, D., Bakker, A. B., \& Fischbach, A. (2015). Work engagement among employees facing emotional demands. Journal of Personnel Psychology, 12, 7484. doi:10.1027/1866-5888/a000085

Yakubovich, D., Berlin, S., Kahanovitch, U., Rubinstein, M., Farhy-Tselnicker, I., Styr, B., \& Dascal, N. (2015). A quantitative model of the girk1/2 channel reveals that its basal and evoked activities are controlled by unequal stoichiometry of G $\alpha$ and

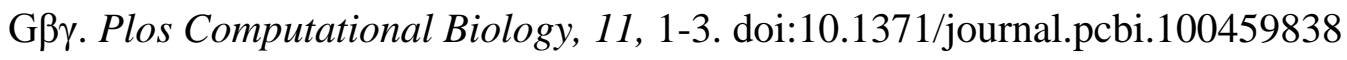


Yalabik, Z. Y., Popaitoon, P., Chowne, J. A., \& Rayton, B. A. (2013). Work engagement as a mediator between employee attitudes and outcomes. International Journal of Human Resource Management, 24, 2799-2823. doi:10.1080/09585192.2013.763844

Yalabik, Z. Y., Van Rossenberg, Y., Kinnie, N., \& Swart, J. (2015). Engaged and committed? The relationship between work engagement and commitment in professional service firms. International Journal of Human Resource Management, 26, 1602-1621. doi:10.1080/09585192.2014.953972

Yang, J., \& Treadway, D. C. (2018). A social influence interpretation of workplace ostracism and counterproductive work behavior. Journal of Business Ethics, 148, 879-891. doi:10.1007/s10551-015-2912-x

Yap, J. B. H., Abdul-Rahman, H., \& Chen, W. (2017). Collaborative model: Managing design changes with reusable project experiences through project learning and effective communication. International Journal of Project Management, 35, 1253-1271. doi:10.1016/j.ijproman.2017.04.010

Yap, Q. S., \& Webber, J. K. (2015). Developing corporate culture in a training department: A qualitative case study of internal and outsourced staff. Review of Business \& Finance Studies, 6, 43-56. Retrieved from http://www.theibfr.com/rbfcs.htm

Yazan, B. (2015). Three approaches to case study methods in education: Yin, Merriam, and Stake. Qualitative Report, 20, 134-152. Retrieved from http://nsuworks.nova.edu/tqr 
Yeh, S. S., \& Huan, T. C. (2017). Assessing the impact of work environment factors on employee creative performance of fine-dining restaurants. Tourism Management, 58, 119-131. doi:10.1016/j.tourman.2016.10.006

Yin, R. K. (2011). Qualitative research from start to finish (3rd ed.). Thousand Oaks, CA: Sage.

Yin, R. K. (2013). Case study research: Design and methods (4th ed.). Thousand Oaks, CA: Sage.

Yin, R. K. (2014). Case study research: Design and methods (5th ed.). Thousand Oaks, CA: Sage.

Yin, R. K. (2017). Case study research and applications: Design and methods (6th ed.). Thousand Oaks, CA: Sage.

Zareen, M., Razzaq, K., \& Mujtaba, B. G. (2014). Impact of transactional, transformational, and laissez-faire leadership styles on motivation: A quantitative study of banking employees in Pakistan. Public Organization Review, 15, 531549. doi:10.1007/s11115-014-0287-6

Zhang, T., Avery, G. C., Bergsteiner, H., \& More, E. (2014). The relationship between leadership paradigms and employee engagement. Journal of Global Responsibility, 5, 4-21. doi:10.1108/JGR-02-2014-0006

Zhu, Y., \& Akhtar, S. (2014). How transformational leadership influences follower 148 helping behavior: The role of trust and prosocial motivation. Journal of Organizational Behavior, 35, 373-392. doi:10.1002/job.1884 


\section{Appendix A: Interview Questions}

\section{Interview Questions}

The interview questions for the participants will be as follows:

1. How do you define employee engagement?

2. What role do you play in engaging your employees?

3. What strategies do you use to engage employees within your corporation?

4. What strategies work best to engage your employees?

5. What was your employees' response to those strategies?

6. What benefits do you think can be derived from successful employee engagement strategies?

7. How do you gauge the success of employee engagement strategies at your organization?

8. What information can you share that was not already covered? 


\section{Appendix B: Interview Protocol}

\section{Interview Protocol}

The interview protocol will consist of the following steps:

1. Introductory statements, setting the stage for the interviews, comfortable environment over a meal;

2. Semistructured interview questioning; watch for non-verbal cues, paraphrase as required, ask more probing questions;

3. Wrap up interview, thanking participants for participating

4. Schedule member checking meeting, participants to verify themes noted during the interview;

5. Corrections to themes if noted by the participants; and

6. Recording of reflexive notes. 